\title{
Highly Insulating Windows Volume Purchase Program Final Report
}

Prepared for:

Emerging Technologies Program

Building Technologies Office Office of Energy Efficiency and Renewable Energy

U.S. Department of Energy

\section{Prepared by:}

Pacific Northwest National Laboratory and Energetics, Incorporated 


\title{
DISCLAIMER
}

This report was prepared as an account of work sponsored by an agency of the United States Government. Neither the United States Government nor any agency thereof, nor Battelle Memorial Institute, nor any of their employees, makes any warranty, express or implied, or assumes any legal liability or responsibility for the accuracy, completeness, or usefulness of any information, apparatus, product, or process disclosed, or represents that its use would not inf ringe privately owned rights. Reference herein to any specific commercial product, process, or service by trade name, trademark, manufacturer, or otherwise does not necessarily constitute or imply its endorsement, recommendation, or favoring by the United States Government or any agency thereof, or Battelle Memorial Institute. The views and opinions of authors expressed herein do not necessarily state or reflect those of the United States Government or any agency thereof.

\author{
PACIFIC NORTHWEST NATIONAL LABORATORY \\ operated by \\ BATTELLE \\ for the \\ UNITED STATES DEPARTMENT OF ENERGY \\ under Contract DE-AC05-76RL01830
}

Printed in the United States of America
Available to DOE and DOE contractors from the
Office of Scientific and Technical Information
P.O. Box 62, Oak Ridge, TN 37831-0062;
ph: (865) 576-8401
fax: $(865) 576-5728$
email: reports@adonis.osti.gov
Available to the public from the National Technical Information Service
5301 Shawnee Rd., Alexandria, VA 22312
ph: (800) 553-NTIS (6847)
email: orders@ntis.gov <http://www.ntis.gov/about/form.aspx>
Online ordering: http://www.ntis.gov

This document was printed on recycled paper. 
PNNL-22183

DOE/EE-0884

\section{Highly Insulating Windows Volume Purchase Program Final Report}

GB Parker

TS Mapes

WJ Zalis

February 2013

Prepared for

Emerging Technologies Program

Building Technologies Office

Office of Energy Efficiency and Renewable Energy

U.S. Department of Energy

Prepared by

Pacific Northwest National Laboratory

and Energetics, Incorporated 



\begin{abstract}
A market transformation program for highly insulating windows (U-factor no greater than 0.22 ) and low-E (low emissivity) storm windows was undertaken by the U.S. Department of Energy Building Technology (DOE/BT) program in Fiscal Year 2009 to accelerate the adoption and reduce the costs of these windows in the residential and commercial buildings sectors. Highly insulating windows and low-E storm windows were already commercially available in the United States in 2009 but annual surveys by the National Association of Home Builders (NAHB) showed that highly insulating windows accounted for less than 2 percent of the total volume of windows being sold in the United States.

This report documents the development, execution outcomes and lessons learned of the Highly Insulating Windows Volume Purchase (WVP) Program carried out over a three-year period from 2009 through 2012. The primary goals of the program were met: 1) reduce the incremental cost of highly insulating windows compared to ENERGY STAR windows; and 2) raise the public and potential buyers' awareness of highly insulating windows and their benefits. A key outcome of the program is that the 2013 ENERGY STAR Most Efficient criteria for primary residential windows were adopted from the technical specifications set forth in the WVP program.
\end{abstract}





\section{Executive Summary}

A market transformation program for highly insulating windows (those with a whole window heat transfer coefficient or U-factor no greater than 0.22) and low-E (low emissivity) storm windows was undertaken by the U.S. Department of Energy Building Technology (DOE/BT) program in Fiscal Year (FY) 2009 to accelerate the adoption and reduce the costs of these windows in the residential and commercial buildings sectors.

The program aligns with today's DOE strategy of 'market priming' to 1) pull new products, practices and services into market faster at scale and 2) provide technical support to ENERGY STAR for new higher-tier products. ${ }^{1}$ This strategy and supporting activities are highly leveraged by partnerships with the fenestration/window industry, government laboratories, universities, utilities, and consumer groups, as well as other relevant DOE programs. DOE research and development (R\&D) is coupled with voluntary and mandatory deployment efforts at national, regional, and local levels. ${ }^{2}$

The program was conducted from mid-FY 2009 through December 2012 and accomplished both of its primary goals:

1. Reduce the average incremental cost of highly insulating windows for customers compared to ENERGY STAR windows with a target of $\sim \$ 4 / \mathrm{ft}^{2}$.

2. Raise consumer/purchaser/builder awareness of the value and availability of highly insulating windows and low-E storm windows.

Table ES.1 shows a historical average cost differential between ENERGY STAR windows and highly insulating windows. Today's cost differential (cost premium) was reduced by $\sim 55$ percent from 2008 , prior to the start of the Windows Volume Purchase (WVP) program with an average differential of $\sim \$ 3.70 / \mathrm{ft}^{2}$. Also, during this time period, the DOE's R\&D program invested in production-engineering improvements in the window industry. These data therefore show Program Goal \#1 was met.

Table ES.1. Historic Incremental Cost Premium for a Highly Insulating Window over an ENERGY STAR Window ${ }^{3}$

FY

2008

2010

2012

2020
U-0.20-0.22 Window Cost Premium over ENERGY STAR $\$$ /square foot

$\$ 6.78-\$ 10.00$ (before WVP Program)

$\$ 5.83-\$ 7.23$

$\$ 1.59-\$ 5.83$

$\$ 1.58-\$ 3.33$ (projected)

The program attracted over 60 vendors of highly insulating windows and low-E storm windows who had a desire to participate in the program. Some of these vendors were launching new products with the

\footnotetext{
${ }^{1}$ http://apps1.eere.energy.gov/buildings/publications/pdfs/corporate/myp11.pdf

2 Note that the terms 'vendor,' 'bidder,' 'participant,' 'manufacturer,' 'supplier,' 'company,' and 'contractor' are used interchangeably throughout this document. All terms refer to the entity that is selling window products to the buyers through the Windows Volume Purchase (WVP) Program.

3 "Windows Update: High Efficiency Windows \& Windows Attachments.” U.S. DOE All-Hands Meeting, January 10, 2013.
} 
program, some had a long history of selling highly insulating window products, and some were well-known national-brand manufacturers.

Sales through the program period were 40,479 windows, with a value of greater than $\$ 9.7$ million. The monthly totals for numbers of windows sold as reported by the vendors for the entire program period are shown in Figure ES.1. Although the overall sales through the program were modest, the market penetration of highly insulating windows increased substantially. This could be attributable to the extensive education and outreach undertaken by the program combined with the significant media coverage increasing awareness of the availability and benefits of highly insulating windows.

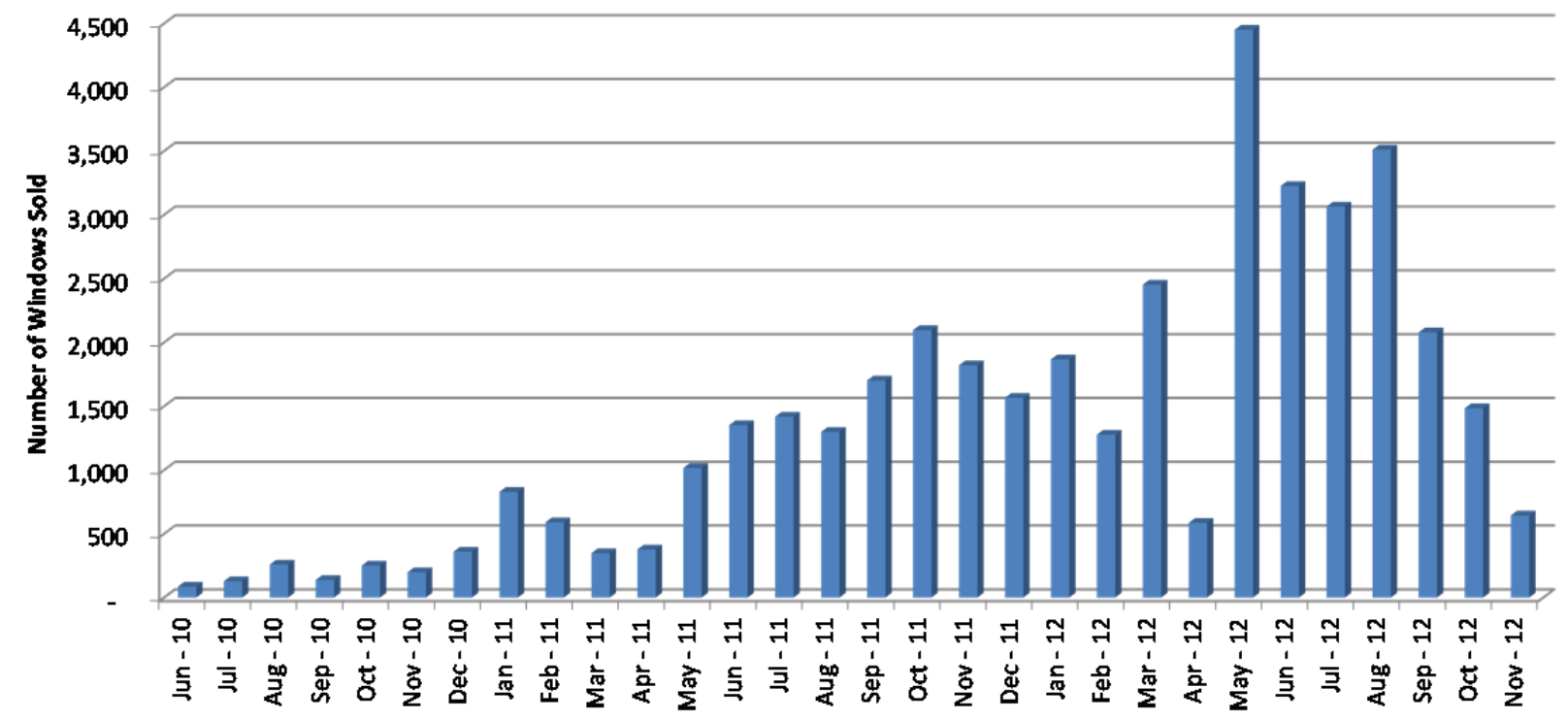

Figure ES.1. Sales of Windows by Month during the Program Period

Based on data from the National Association of Home Builders for the United States and Northeast region of the country (New England and E. North Central) as shown in Figure ES.2, the sales of R-5 windows (triple-pane windows) increased in this cold-climate region of the country from $\sim 6$ percent in 2009 to 13 percent in New England and 15.5 percent in E. North Central in 2011, which is an increase of more than 100 percent in market penetration. For the United States as a whole the increase is from 9.1 to 9.9 percent or a modest 10 percent increase. This increase is even more significant considering that newhousing market starts decreased by $\sim 50$ percent during this same time period. 


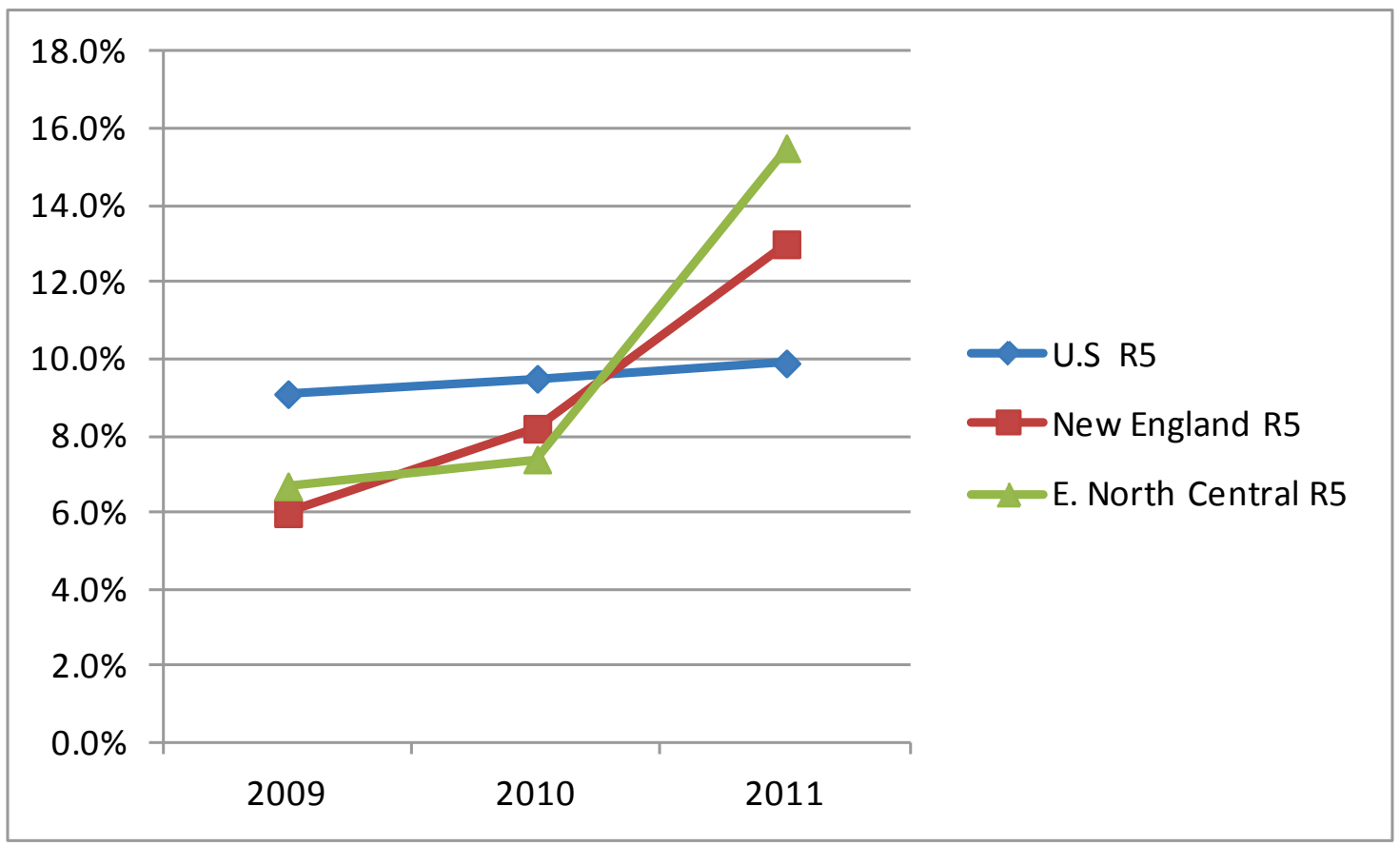

Figure ES.2. Sales of R-5 Windows as a Percentage of all Windows in the Residential Sector

Lastly, the U.S. Environmental Protection Agency (EPA) ENERGY STAR program announced that an EPA Most Efficient program for window technology would be launched in January 2013. ${ }^{1}$ The ENERGY STAR Most Efficient 2013 designation recognizes the most efficient products among those that qualify for the ENERGY STAR. The final criteria were established by ENERGY STAR in November 2012 for residential window products. The EPA criteria were in alignment with the WVP program specifications of a U-factor no greater than 0.20, a Performance Grade of 15 , certification, and listing in the National Fenestration Ratings Council (NFRC) Certified Products Directory. ${ }^{2}$

Consumer/purchaser/builder awareness of ENERGY STAR is well documented ${ }^{3}$ and therefore the establishment of the Most Efficient program for primary residential windows with specifications adopted from the WVP program will serve to continue to increase awareness of these window products. Therefore Program Goal \#2 was met.

The overall strategy by DOE for successfully transforming the market for highly insulating windows - of which this program (market priming) is integral for success - can be represented as shown in Figure ES.3.

\footnotetext{
1 http://www.windowanddoor.com/news-item/government/industry-provides-feedback-new-energy-star-criteria

2 http://www.energystar.gov/ia/partners/downloads/EPA_Memo_ENERGY_STAR_Most_Efficient_2013.pdf?6ad0-a614

3 http://www.energystar.gov/ia/partners/publications/pubdocs/National\%20Awareness\%20of\%20ENERGY\%20STAR\%202011.pdf
} 


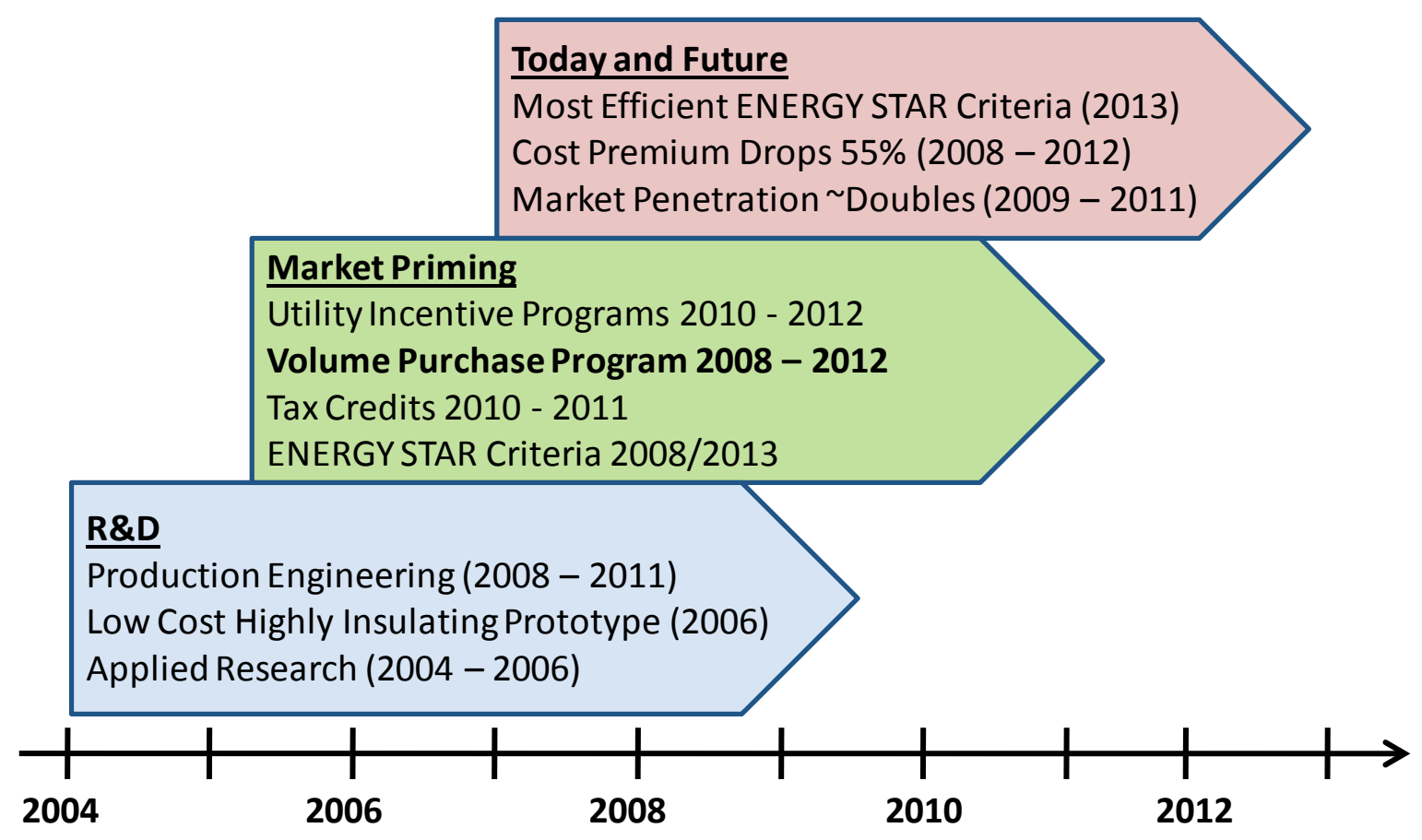

Figure ES.3. DOE Process for Transforming the Market for Highly Insulating Windows 


\section{Acknowledgments}

The authors wish to thank all the members of the Windows Volume Purchase Program core team who were instrumental in developing the program, promoting highly insulating windows and educating the public and buyers on the benefits of these windows. The team included Jason Bogovich, Myra Sinnott, Hoi Yee Lam, Eric Jones and Fred Wagner of Energetics, Incorporated; Nils Peterman and Neal Humphrey of the Alliance to Save Energy; Christian Kohler and Steve Selkowitz, Lawrence Berkeley National Laboratory; and Sheryl Cardenas, Eric Garcia, Annie Haas, Christine Kelly, Susan Loper, Shan Osborn, Dan Skorski, and Jamie Spangle of the Pacific Northwest National Laboratory.

Special recognition goes to the U.S. Department of Energy Building Technologies Program Manager P. Marc LaFrance for his vision, technical contributions, assistance working with the window industry, and long-term support for this project. 



\section{Acronyms and Abbreviations}

AAMA

$\mathrm{AL}$

ASE

CEE

$\mathrm{CR}$

DCED

DOE

EPA

EWC

FY

IGU

LBNL

MEEA

NAFS

NAHB

NEEA

NFRC

PNNL

$\mathrm{R}$-value

R\&D

RFP

SIR

U-factor

UI

WDMA

WVP
American Architectural Manufacturers Association

air leakage

Alliance to Save Energy

Consortium for Energy Efficiency

condensation resistance

Department of Community and Economic Development (Pennsylvania)

U.S. Department of Energy

Environmental Protection Agency

Efficient Windows Collaborative

fiscal year

insulated glass unit

Lawrence Berkeley National Laboratory

Midwest Energy Efficiency Alliance

North American Fenestration Standard

National Association of Home Builders

Northwest Energy Efficiency Alliance

National Fenestration Ratings Council

Pacific Northwest National Laboratory

measure of thermal resistance

research and development

Request for Proposal

savings-to-investment ratio

heat transfer coefficient as a measure of heat loss

united inches

Window and Door Manufacturers Association

Windows Volume Purchase 



\section{Contents}

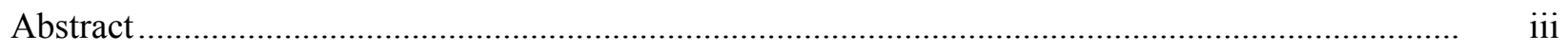

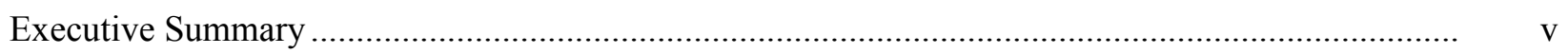

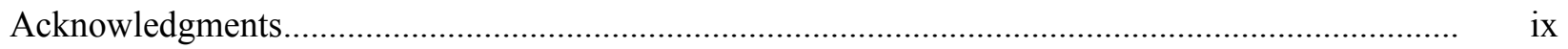

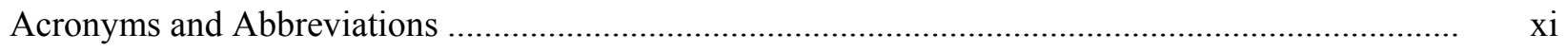

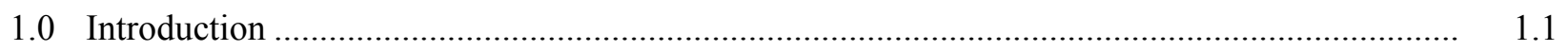

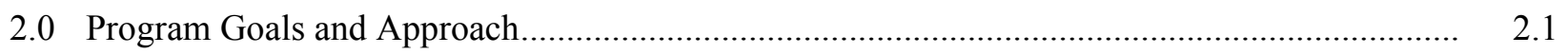

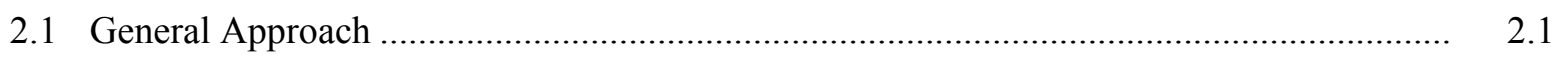

3.0 Program Partners and Stakeholders .........................................................................

3.1 Principal Partners: Windows Volume Purchase Core Team .............................................. 3.1

3.2 Other Key Partners ............................................................................................... 3.1

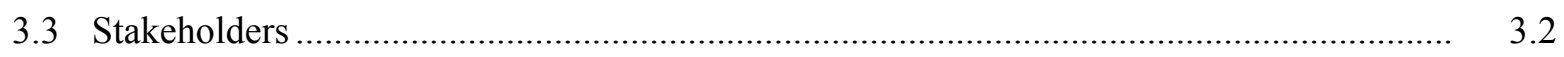

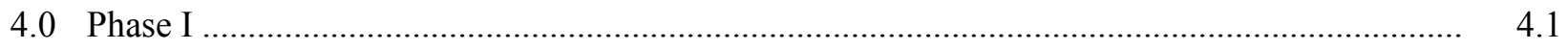

4.1 Development of the Overall Approach ..................................................................... 4.1

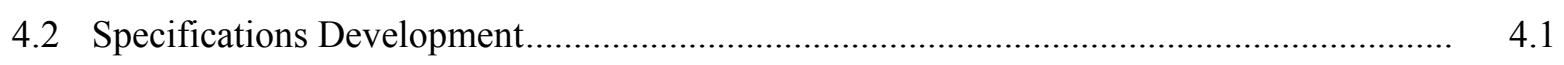

4.2.1 Thermal Performance: U-Factor …................................................................ 4.2

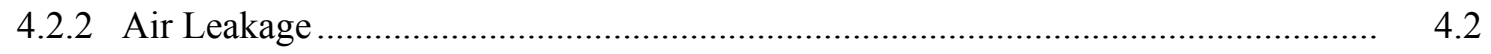

4.2.3 Minimum Order (Purchase Quantity).............................................................. 4.2

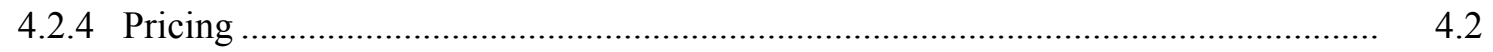

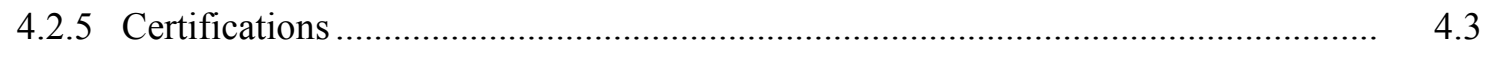

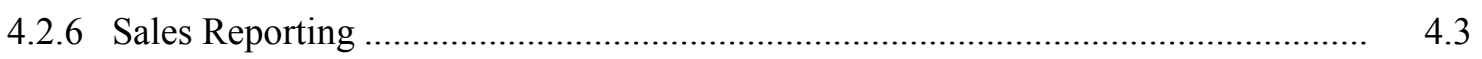

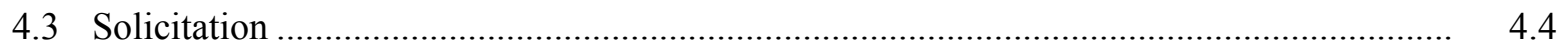

4.4 Verification of Products and Prices ............................................................................. 4.4

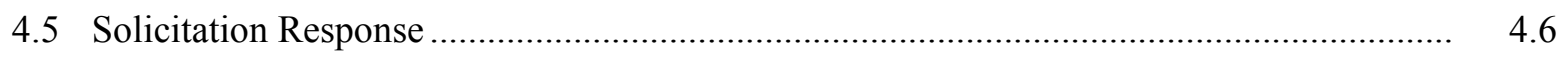

4.6 WVP Program Vendor Website ................................................................................ 4.7

4.6.1 Open Bid Request Form ........................................................................... 4.7

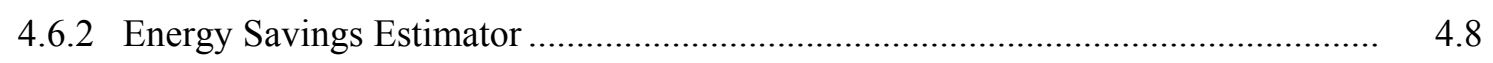

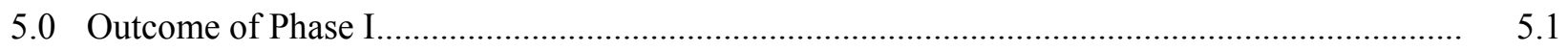

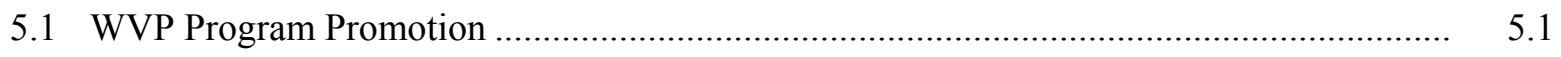

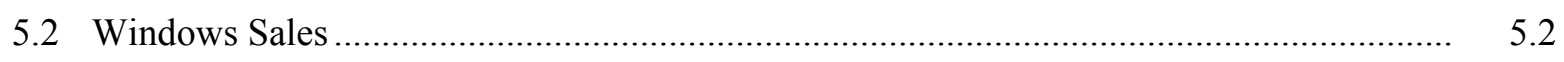

5.3 Windows Products Pricing and Purchasing................................................................ 5.2

5.4 Impact of the Nationwide Tax Credit for Windows ....................................................... 5.3

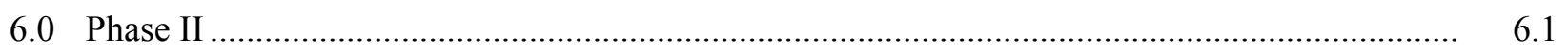

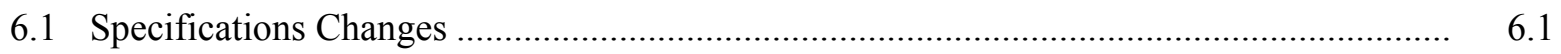

6.1 .1 Condensation Resistance ............................................................................. 6.1

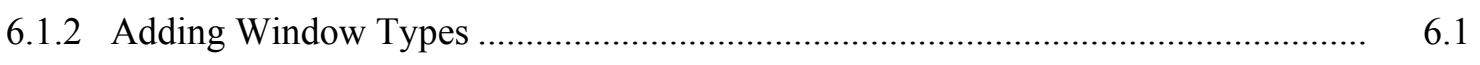

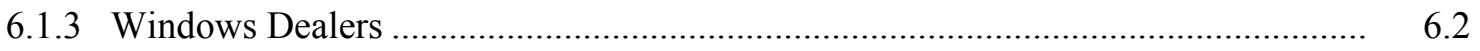




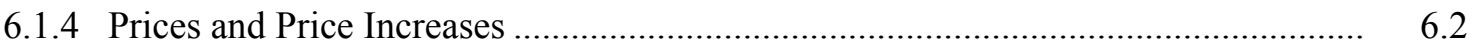

6.1.5 Bid Quantities....................................................................................... $\quad 6.2$

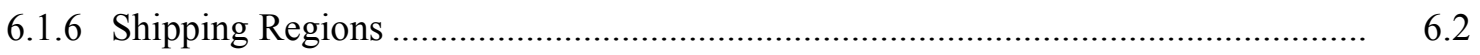

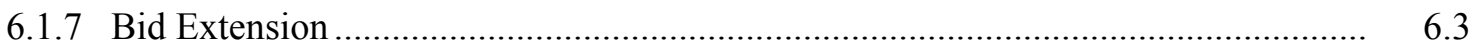

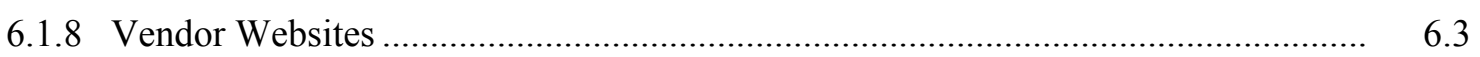

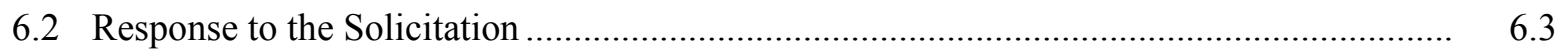

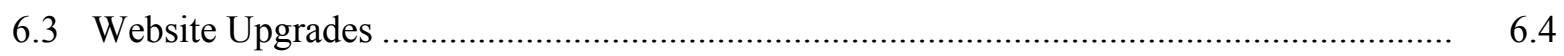

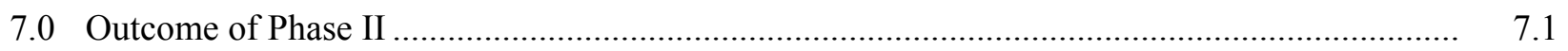

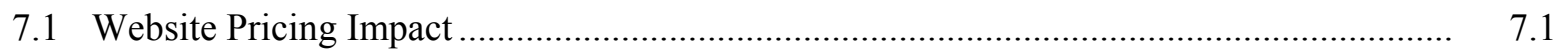

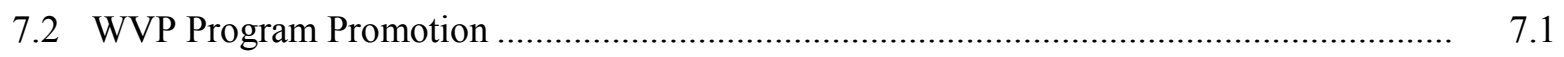

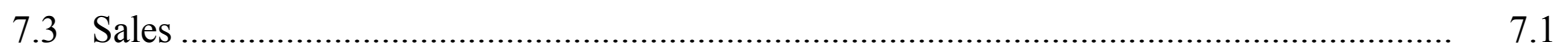

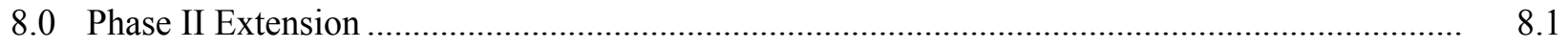

8.1 Phase II Extension Sales \& Total Program Sales .............................................................. 8.2

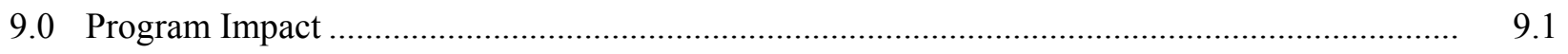

9.1 Incremental Cost Reduction ............................................................................. 9.1

9.2 Increased Nationwide Market Penetration ..................................................................... 9.1

9.3 ENERGY STAR Most Efficient …................................................................................ 9.2

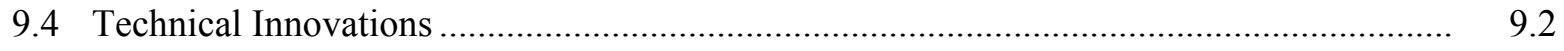

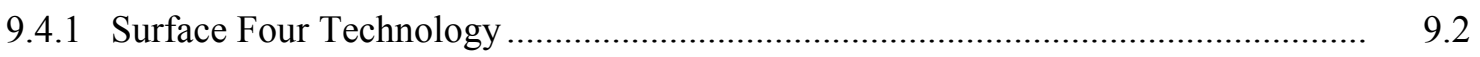

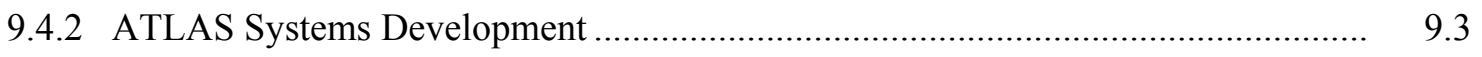

9.4.3 TRACO R-5 Commercial Windows .................................................................... 9.3

9.5 Specifications, Certifications and Incentives ............................................................. 9.3

9.5.1 State of Pennsylvania Weatherization Priority List............................................. 9.3

9.5.2 Updated Storm Window Certification................................................................. 9.4

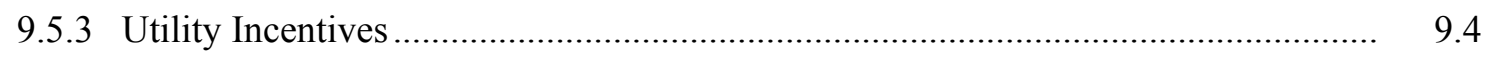

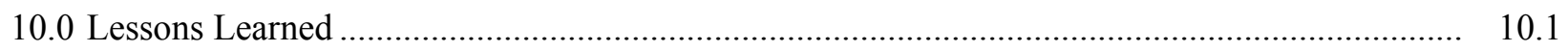

Appendix A - Education and Outreach Summary for Windows Volume Purchase Program ............ A. A

Appendix B - Phase I Specifications ..................................................................................... B. 1

Appendix C - Cover Letter: Request for Proposal (RFP) No: 121400, December 19, 2009 ............. C. C.1

Appendix D - Sample Agreement ........................................................................................ D. 1

Appendix E - Sample Sales Reporting Document ................................................................... E. E.

Appendix F - Phase II Solicitation ....................................................................................... F.1

Appendix G - Phase II Extension Solicitation........................................................................ G.1 


\section{Figures}

4.1 Example of a Completed Open Bid Request Form ............................................................... 4.8

4.2 Input Screen for the Energy Savings Estimator ................................................................... 4.9

5.1 Sales of Highly Insulating Windows Reported by the WVP Program Vendors in Phase I ......... 5.2

7.1 Sales of Highly Insulating Windows Reported by the WVP Program Vendors in Phase II......... 7.2

8.1 Sales of Highly Insulating Windows Reported by the WVP Program Vendors in Phase II Extension

\section{Tables}

4.1 Sample Bid Submittal ......

4.2 Qualified Vendors in Phase I of the WVP Program

6.1 Qualified Vendors in Phase II of the WVP Program

9.1 Historic Incremental Cost Premium for a Highly Insulating Window over an ENERGY STAR Window

9.2 Ratio of Triple-Glazed Windows Installed in the Residential Sector as a Percentage of Housing Units Constructed.... 



\subsection{Introduction}

The U.S. Department of Energy (DOE) integrated approach to commercialize cost-effective highly insulating windows (triple-pane windows) was initiated in 2006. Previously, highly insulating windows had been on the market for over 30 years as a limited niche market segment and were not cost-effective for consumers. The integrated approach included the unveiling of an advanced prototype window that had technical features with the potential to reduce cost significantly. The core market-conditioning activity to increase consumer demand and reduce manufacturers' risk in investing in highly insulated windows included a comprehensive volume purchase program, which was also supported by a competitive funding opportunity to aid manufacturers' production-engineering efforts.

In Fiscal Year (FY) 2009, DOE began laying the groundwork for a market transformation effort to increase the penetration and reduce the cost of highly insulating windows and low emissivity (low-E) storm windows ${ }^{1}$ into the United States marketplace. The need for this effort was based on previous DOE research showing that windows directly impact 57 percent of the energy loads in a typical building, equating to $\$ 133$ Billion annually and almost 14 percent of the total energy use in the United States. ${ }^{2}$ Today, conventional windows remain the weak links in the building envelope, and result in the use of approximately 4.4 quadrillion Btus of energy annually in the United States in the form of building heating and air conditioning loads. Thus, DOE continues to establish goals in their multi-year program plan and support research and development $(\mathrm{R} \& \mathrm{D})$ to improve residential window performance by 70 percent by 2020 (see the U.S. Department of Energy Building Technology (DOE/BT) FY 2011-2015 Multi-Year Program Plan at http://apps1.eere.energy.gov/buildings/publications/pdfs/corporate/myp11.pdf).

Highly insulating windows and low-E storm windows were already commercially available in the United States in 2009, but annual surveys by the National Association of Home Builders (NAHB) showed that highly insulating windows accounted for less than 2 percent of the total volume of windows being sold in the United States. Although actual sales data were not available, the availability and penetration of highly insulating windows in Europe is much greater, probably due to a combination of building codes and the price of energy. Sales of low-E storm windows were not quantified in the NAHB survey, but they were determined by DOE to be a low-volume product given the very limited number of U.S. distributors of this product.

Highly insulating windows require additional and higher-performance materials to perform above the 2009 ENERGY STAR level (U-factor no greater than 0.30, commonly shown as U-0.3). These included, but were not limited to, low-E coating, a third pane of glass, an insulated frame, and advanced spacers. The incremental production cost above ENERGY STAR windows for a highly insulating window had been identified as the principal barrier to market penetration for highly insulating windows.

\footnotetext{
${ }^{1}$ Highly insulating windows were defined in this program as primary windows that were certified with performance characteristics at or above those of ENERGY STAR windows. This includes a U-factor no greater than $0.22 \mathrm{Btu} / \mathrm{h}-\mathrm{ft}^{2}-{ }^{\circ} \mathrm{F}(\mathrm{R}-$ value of $\sim 5$ ) and other performance characteristics such as air leakage no greater than $0.30 \mathrm{cfm} / \mathrm{ft}^{2}$. Low-E storm windows are secondary windows with a low emissivity coating (less than 0.22 ) and are applied to the inside or outside of a primary window. 2 http://www.eereblogs.energy.gov/buildingenvelope/file.axd?file=2012\%2f7\%2fwindows_roadmap_workshop_doe_lafrance_062812.pdf
} 
Therefore, the Highly Insulating Windows Volume Purchase (WVP) program ${ }^{1}$ was created to collaborate with other researchers and work with industry to develop a strategy to decrease the incremental cost of these windows and increase their market penetration through an education and awareness campaign. In a complementary but separate R\&D effort launched in 2009, DOE also funded the development of production-engineering and manufacturing process $\mathrm{R} \& \mathrm{D}$ to reduce the production cost of windows and window components, including the insulated glass units (IGUs). ${ }^{2}$

\footnotetext{
${ }^{1}$ At the launch of the program, the program was known as the "R-5 Windows" program. The R-5 term was adopted because R-values were more recognized by the building community and by the public, and because it was desirable to allow an easy comparison of the insulative property of windows to walls, floors, and ceilings. This was later changed to the Highly Insulating Windows Program based on industry/stakeholder feedback. In this report the terms "highly insulating" and "high performance" are used interchangeably.

2 http://energy.gov/articles/hit-road-jack-new-thermal-window-technology-lessens-menace-jack-frost
} 


\subsection{Program Goals and Approach}

The WVP program had two goals:

1. Reduce the average incremental cost of highly insulating windows for customers compared to ENERGY STAR windows with a target of $\sim \$ 4 / \mathrm{ft}^{2}$.

2. Raise consumer/purchaser/builder awareness of the value and availability of highly insulating windows and low-E storm windows.

Based on prior experience by DOE and others in developing and executing market transformation programs ${ }^{1}$ the incremental cost reduction was anticipated to be accomplished by a combination of increasing the products in the marketplace, competition among the window manufacturers, greater consumer/purchaser/builder demand for the products thus increasing the volume sold, and the cost savings through the DOE production-engineering R\&D program. The second goal supported the first goal by making consumers/purchasers/builders more aware of the window products, their availability and the benefits of using them.

The incremental cost goal DOE established for the WVP program was an incremental cost metric of $\sim \$ 4 / \mathrm{ft}^{2}$ (window area independent of window type) over an ENERGY STAR window. This goal was based on the long-term energy cost payback for a 40 percent heat-loss reduction with a U- 0.20 window compared to a U-0.3 (ENERGY STAR) window. One key metric for the second program goal was an increase in the penetration (sales as a percentage of overall window sales) of highly insulating windows and low-E storm windows.

\subsection{General Approach}

The approach for meeting these goals was to 1) develop industry- and stakeholder-vetted specifications for the highly insulating windows and low-E storm windows; 2) issue a solicitation using Pacific Northwest National Laboratory (PNNL) contracts requesting manufacturer bids for windows meeting the specifications; 3) execute agreements with manufacturers meeting the specifications; 4) create a WVP website to list the window products, from which buyers can view the products and contact the manufacturers to purchase the products; 4) track sales of window products; and 5) raise awareness and educate buyers about the WVP program and the value of the highly insulating windows.

The WVP program was conducted from May 2009 through December 2012. It was conducted in two phases. Phase I was from May 2009 through May 1, 2011. Phase II was launched on May 2, 2011 and ended on April 30, 2012. Phase II was extended on May 1, 2012 and ended December 31, 2012. The principal differences between Phase I and Phase II were minor modifications to the window specifications, addition of commercial-grade windows, window pricing strategy, and improvements to the functionality of the website. The details of each phase are provided below.

The program relied heavily on industry, stakeholders and program partners to raise awareness, educate buyers and promote the program. There was also extensive use of the trade media. A summary of the program outreach and education is given in Appendix A.

\footnotetext{
${ }^{1}$ MR Ledbetter et al. U.S Energy-Efficient Technology Procurement Projects: Evaluation and Lessons Learned. PNNL-12118. February 1999. Pacific Northwest National Laboratory, Richland, Washington.
} 



\subsection{Program Partners and Stakeholders}

Several partners and stakeholders played key roles in the WVP program. The partners and their roles are described below.

\subsection{Principal Partners: Windows Volume Purchase Core Team}

Principal partners are those that were funded by DOE to participate in the WVP project. This was the core WVP team, and included

- PNNL - PNNL led the development of the specifications for the solicitations, issued the solicitations, made awards and executed agreements, developed and maintained the WVP program windows vendors' website, collected sales data, led interactions with the trade media and participated in awareness and education activities.

- Energetics, Incorporated - Energetics led the education and public outreach for the program. This included solicitation of letters of support from stakeholders prior to Phase I of the program, development and publication of fact sheets, planning of educational webinars and workshops, interaction with buyers/stakeholders at industry trade shows, and maintenance of the DOE WVP program website. ${ }^{1}$

- Lawrence Berkeley National Laboratory $(\mathrm{LBNL})^{2}$ - LBNL provided technical review of the specifications, assistance with interface with industry, and development of technical analysis used in the consumer awareness materials.

- Efficient Windows Collaborative (EWC $)^{3}$ - The EWC was operated by the Alliance to Save Energy $(\mathrm{ASE})^{4}$. Two members of the EWC provided direct technical support to the program including development and review of the specifications, development of educational materials including workshop presentations and fact sheets, technical contributions, contribution to the WVP vendors' website including the development of an energy savings estimator, and liaison with the window industry. This collaboration was a key interface, particularly early in the program, with window manufacturers and suppliers, home performance contractors, research organizations, trade associations, utilities, and consultants. The EWC is dedicated to increasing the market penetration of high-efficiency windows in the residential and commercial sectors.

\subsection{Other Key Partners}

Other key partners are those partners that receive funding from DOE's Emerging Technologies Program for a broad range of support for DOE's buildings programs. These partners primarily provided advocacy and awareness for the WVP program among their constituents. These partners included:

\footnotetext{
1 http://www1.eere.energy.gov/buildings/windowsvolumepurchase/. All WVP Program technical information, educational materials, calendar of events and program metrics/successes are posted on this website.

2 http://windows.lbl.gov/

3 www.efficientwindows.org The focus of the EWC is to increase the market penetration of high-efficiency windows in the residential and commercial sectors.

4 www.ase.org
} 
- Consortium for Energy Efficiency $(\mathrm{CEE})^{1}$ - Shortly after the WVP program was launched, CEE initiated a whole house work group with the goal of advancing and promoting highly insulating windows to their members. The ultimate goal of the whole house initiative was for utilities and energy efficiency organizations to consider adopting the WVP specifications and offering incentive programs to their customers for windows meeting these specifications.

- National Fenestration Ratings Council (NFRC) $)^{2}$ - Almost all of the participating manufacturers in the program are members of the NFRC. The NFRC provided technical support in the development of the specifications, coverage of the program on their website and newsletter, and support for the meetings of the EWC during the NFRC meetings.

\subsection{Stakeholders}

There were a number of stakeholders providing support to the program. These stakeholders were not directly funded by DOE. Stakeholders included:

- American Architectural Manufacturers Association (AAMA) ${ }^{3}$ - Similar to the NFRC, the AAMA provided coverage of the program at their member meetings and technical assistance during the development of the specifications - primarily those where AAMA certification was required-for both Phase I and Phase II of the program.

- Window and Door Manufacturers Association (WDMA) ${ }^{4}$ - Similar to the AAMA, the WDMA was a liaison with their members and constituency and kept them informed of the program and program goals. WDMA was also supportive of the program in public venues.

- Northwest Energy Efficiency Alliance (NEEA) ${ }^{5}$ - NEEA provided information to the program on the nationwide highly insulating windows market as NEEA was considering developing an initiative in highly insulating windows in the Pacific Northwest.

- Midwest Energy Efficiency Alliance (MEEA) ${ }^{6}$ - MEEA allowed a link from their website for the WVP program. They also organized a conference call with efficiency program managers in their 12-state membership area to educate them about the volume purchase. MEEA also posted an article on the WVP program in their quarterly e-newsletter.

- National Association of Home Builders (NAHB) ${ }^{7}$ - NAHB provided the venue for the kickoff meeting for the launch of Phase I at NAHB Headquarters and provided outreach to the building industry, media coverage for the program on their website and newsletters, and support for the kickoff meeting for the launch of Phase II at their 2010 Green Building Conference.

\footnotetext{
${ }^{1}$ www.cee1.org CEE is a consortium of efficiency program administrators from across the United States and Canada who work together on approaches to advancing efficiency.

2 www.nfrc.org The NFRC administers the only uniform, independent rating and labeling system for the energy performance of windows, doors, and skylights.

3 www.aamanet.org AAMA brings together window, door, skylight, curtain wall and storefront window manufacturers, suppliers and test labs to promote codes and standards development and testing and certification for the industry.

${ }^{4}$ www.wdma.com WDMA provides proactive positions and education on national policies such as energy conservation, building codes and housing.

5 http://neea.org/ NEEA is a nonprofit organization using the market power of the Pacific Northwest region to accelerate the innovation and adoption of energy-efficient products, services and practices

${ }^{6} \mathrm{http}$ :/Www.mwalliance.org/ MEEA is a nonprofit organization that raises awareness, facilitates energy efficiency programs and strengthens policy across the Midwest region.

${ }^{7}$ www.nahb.org NAHB is a trade association that helps promote the policies that make housing a national priority.
} 
- U.S. Environmental Protection Agency (EPA) ENERGY STAR Windows Program ${ }^{1}$ - There were periodic discussions with the ENERGY STAR program to keep them informed and exchange information. In venues with the window industry and other buildings-related technology venues, ENERGY STAR was supportive of the WVP program as a strategy to raise the overall efficiency of homes and businesses.

\footnotetext{
${ }^{1}$ www.energystar.gov/index.cfm?fuseaction=find_a product.showProductGroup\&pgw_code=WI
} 



\subsection{Phase I}

In July 2009 the project team attended the NFRC Summer Membership Meeting to announce and discuss the launch of DOE's WVP program. The concept and timeline of Phase I of the program was described to interested window industry representatives and their input was sought at the meeting. An open invitation was extended to participants for their future formal input into the program design and specifications.

\subsection{Development of the Overall Approach}

The WVP team agreed on a general approach of drafting the technical specifications for highly insulating windows and low-E storm windows that included minimum thermal and structural performance, certifications, and warranty. In parallel, PNNL engaged their contracting organization to develop the framework for the solicitation including the pricing structure, sales reporting requirements and terms and conditions of the agreement that would be executed with the qualified vendors. PNNL also initiated the development of the WVP products website. The initial overarching strategy was to list the qualified vendors and the windows they were offering on the WVP products website with contact information for buyers to purchase the windows directly from the vendors.

A comprehensive list of candidate vendors and stakeholders was developed for soliciting comments on the specifications. Also, a program launch plan was discussed, and an awareness and education strategy was under development that included trade shows, media, workshops and technical presentations. The goal of the outreach, education and awareness strategy was to drive potential buyers to view the WVP products website and purchase windows.

\subsection{Specifications Development}

After significant discussion with the WVP team, a first draft of the specifications was released to industry on August 30, 2009, and comments were solicited until September 4, 2009. Comments were discussed with the team and incorporated into a second draft. The final draft specifications were once again sent to industry for comment. Comments were accepted until November 13, 2009. Comments were again discussed with the team and the final specifications were prepared for the solicitation (see Appendix B).

The Phase I specifications included the minimum thermal and structural performance, other critical window characteristics, the warranties, certification and testing requirements, window types, colors and size categories, bid template and sales reporting requirements. The development of the specifications was therefore evolutionary over the approximately three months of development. Important decisions were made on several of the specifications based on comments received from industry and WVP team

discussions. The key decisions on the Phase I specifications include air leakage, minimum order, pricing, certifications, and sales reporting. 


\subsubsection{Thermal Performance: U-Factor}

The whole-window thermal performance was initially focused on a thermal resistance (R) value of R-5 as windows with that performance were available from a few U.S. manufacturers at a premium price over ENERGY STAR (see Table ES.1). For Phase I, all of the windows meeting that performance were triple-pane windows. Windows with an R-value of 5 or higher were more common in Europe with some European manufacturers offering windows with R-values greater than $7 .{ }^{1}$ Given that windows in the United States are certified based on U-factor, the R-5 value was translated to a U-factor for the specifications. In discussions with the window industry, the specifications were slightly modified to specify a U-factor no greater than 0.20 for fixed (picture) windows and a U-factor no greater than 0.22 for operable windows and patio doors given the additional thermal leakage pathways for operable windows. There was also a concern that manufacturers would only offer fixed windows in the program if the specification was a U-factor of 0.20 and thus the allowance was made for a greater $U$-factor $(0.22)$ to encourage offering operable windows.

\subsubsection{Air Leakage}

Maximum air leakage (AL) was included as a performance criterion given that a minimum AL was a recommendation of the EWC and determined to be a necessary criterion for a highly insulating window with a premium cost. Air leakage was neither a requirement for ENERGY STAR nor a requirement by NFRC for rating a window, although there is an NFRC test procedure for AL. ${ }^{2}$

\subsubsection{Minimum Order (Purchase Quantity)}

Several manufacturers had requested the use of a minimum purchase order as a means of focusing on builders, contractors and agencies/institutions who commonly order large quantities $(25+)$ of windows and thereby eliminating individual consumers seeking to replace small numbers of windows. A lower bid price is a typical result of larger volumes. The team decided to strike a balance with a minimum bid quantity that would allow individual consumers to buy in modest volumes yet retain the concept of a 'volume' price. The bid request was also segmented into windows for 'retrofit' application and for new construction given that there are differences in the configuration (and manufacturer) of a retrofit window versus a new-construction window. Therefore the bids were requested for a minimum of 15 retrofit windows and 20 new-construction windows. The qualified vendors could still fulfill requests for windows in smaller volumes, but were not obligated to honor the prices bid into the program.

\subsubsection{Pricing}

Many window manufacturers price their product to include installation, and those prices can vary depending upon the location of the installation and the markup. In addition, many manufacturers sell the windows only through dealers, who establish the final price. The bidders were requested to provide a 'base' price that did not include installation, delivery (or taxes), and for many manufacturers, this pricing was different than their dealer-based business model. Ultimately, it was left to the bidders to determine

\footnotetext{
${ }^{1}$ The higher R-values of European windows are due to a combination of higher energy prices, aggressive building codes, carbon reduction goals, and significant populations living in cold climates.

${ }^{2}$ The lower a window's air leakage rating, the better its airtightness. A maximum AL requirement would reduce the potential that the building occupant would feel a noticeable draft around window seals. Windows with a high AL can also noticeably 'leak' (and even squeal) during high wind events.
} 
their price structure knowing that the price in the final bid under the solicitation was considered a 'base' price. Manufacturers were allowed to lower their initial bid prices at any time, but not raise them for a period of six months.

In prior experience with volume-purchase market transformation programs, ${ }^{1}$ the prices of the product offerings were generally revealed to the buyers for each participating vendor. Based on considerable comments from the window manufacturers regarding industry sensitivity to showing prices for a specific window product (including low-E storm windows), the WVP team determined that only a price range for a given window type and size bin $^{2}$ would be shown to the buyers on the WVP vendor website along with a list of the vendors that supplied that window type.

\subsubsection{Certifications}

One important element of the program was the requirement that all products be part of a certification program for both thermal and structural performance. Without these programs, a manufacturer could conceivably make a window and have it tested to a given standard, and then make the product differently in their factory. Certification programs have been developed which allow independent organizations to make random, unannounced audits of a participating manufacturers' factories and make sure that the products continue to be made according to their tested standards. Participating manufacturers in the WVP program were required to be part of a certification program to verify their thermal and structural performance claims and provide that certification before being allowed in the program. The WVP program team determined that certification was essential to make sure that all manufacturers, some of which may be new to the industry and/or have a relatively small market, would be certified to give buyers confidence in the products.

Structural performance certification was not a requirement of ENERGY STAR but was deemed important to include in the specifications as it deals with load-bearing performance - a feature that a buyer of a highly insulating window with a cost premium would consider important. Products undergo air/water/structural testing to determine the amount of pressure they can withstand, which then determines their Performance Grades. For example, a window with a Performance Grade of 25 can withstand at least $25 \mathrm{lbs} / \mathrm{ft}^{2}$ of air pressure, water pressure, and physical loads.

\subsubsection{Sales Reporting}

Given that one of the goals of the program is to increase the sales and penetration of highly insulating windows, it was important that the vendors in the program periodically report sales throughout the program period. The WVP team understood that sales of highly insulating windows meeting the program specifications may be sold by the participating vendors outside of the program - that is, not necessarily originating via the program website - and that the program probably could not require that these sales be reported as part of the program. In addition, given the sensitivity of industry to window pricing, the program could not publically report sales by vendor. Therefore, based on team discussions and industry comments, the WVP team set forth minimum requirements for sales reporting. Only those sales

\footnotetext{
${ }^{1}$ MR Ledbetter et.al. U.S Energy-Efficient Technology Procurement Projects: Evaluation and Lessons Learned. PNNL-12118. February 1999. Pacific Northwest National Laboratory, Richland, Washington.

${ }^{2}$ Bids were requested by industry-standard size bins of united inches (UI, window length + width) or area (length $\times$ height) for windows. Bids for patio doors were in industry standard sizes of length $\times$ height. All products bid by window area (except patio doors) were converted to UI for listing on the WVP vendor website for consistency among the vendors.
} 
originating via the program website would be required to be reported and the aggregate total sales (total number of windows and total number of low-E storm windows or square footage of low-E storm windows) and total sales dollars would be reported.

\subsection{Solicitation}

On December 17, 2009, PNNL released the solicitation for Phase I. It was mailed directly to vendors who had expressed interest in the program and also posted on the Federal Business Opportunities website, www.fbo.gov. The solicitation closed February 19, 2010. The solicitation consisted of three documents:

1. a cover letter: Request for Proposal (RFP) No: 121400, December 19, 2009 (Appendix C) ${ }^{1}$

2. the Phase I Specifications (Appendix B)

3. a 'sample' Agreement ${ }^{2}$ that would need to be signed by the vendor prior to being qualified for the program (Appendix D).

During the time period when the solicitation was open, several questions were submitted by potential vendors and these questions, with answers provided by PNNL, were posted for all potential respondents to view. In addition, clarifying information was included with the questions and answers. PNNL also provided clarifying information directly to the bidders and that information was then posted for all potential bidders on the fbo.gov website. An example of the questions, answers and clarifying information posted on February 12, 2010, on the fbo.gov website is given in Appendix E.

\subsection{Verification of Products and Prices}

As noted in Appendix B, prices were requested for eight primary window types which represented the most common windows available in the United States: single hung, double hung, casement, slider, fixed (or picture), tilt-n-turn, and patio door (or sliding glass door). The bid prices were for a minimum quantity of 20 for new construction and a minimum quantity of 15 for retrofit construction. Prices were also requested for low-E storm windows (there was no minimum quantity). Unlike most traditional competitive bid processes in which awards are given to one or more bidders based on pricing and other factors, all vendors who met the requirements of the solicitation were considered 'pre-certified' for participation in the program.

To help streamline the bidding process an Excel $^{\circledR}$-based form was provided to the initial distribution of potential bidders and posted on fbo.gov. In this file, a table was provided for entering products and prices (the bid), and an example completed bid sheet was shown. The sample bid sheet with explanatory notes from the Excel file is given in Table 4.1.

\footnotetext{
${ }^{1}$ The RFP was issued under Battelle Memorial Institute (BMI) Pacific Northwest Division as that is the contracting vehicle under the BMI operating agreement with DOE to manage PNNL.

${ }^{2}$ The Agreement is with Battelle Memorial Institute (BMI) Pacific Northwest Division as that is the contracting vehicle under the BMI operating agreement with DOE to manage PNNL that is used for this type of legal document.
} 
Table 4.1. Sample Bid Submittal

\begin{tabular}{|c|c|c|c|c|c|c|c|c|}
\hline Window type & U-factor* & Emissivity* & $\mathrm{AL}^{*}$ & Frame Material & Frame Color & Size $(\mathrm{h} x \mathrm{w}) / \mathrm{UI}$ & Base Price** & \\
\hline single hung & 0.21 & & 0.2 & Aluminum & White & $36 \times 48$ & 275.00 & \\
\hline single hung & 0.21 & & 0.2 & Aluminum & Black & $36 \times 48$ & 275.00 & \\
\hline single hung & 0.21 & & 0.2 & Wood & Dark Brown & $36 \times 36$ & 225.00 & \\
\hline single hung & 0.21 & & 0.2 & Wood & Dark Brown & $36 \times 42$ & 250.00 & \\
\hline double hung & 0.2 & & 0.19 & Vinyl & White & $48 \times 24$ & 400.00 & \\
\hline double hung & 0.2 & & 0.19 & Vinyl & White & $48 \times 36$ & 435.00 & \\
\hline storm & & 0.22 & & Aluminum & White & $48 \times 36$ & 260.00 & \\
\hline storm & & 0.22 & & Aluminum & Silver & $48 \times 42$ & 289.00 & \\
\hline storm & & 0.22 & & Vinyl & White & $48 \times 48$ & 309.00 & \\
\hline casement & 0.2 & & 0.19 & Wood & White & $30 \times 36$ & 206.00 & \\
\hline casement & 0.2 & & 0.19 & Wood & White & $36 \times 36$ & 224.00 & \\
\hline casement & 0.2 & & 0.19 & Wood & White & $36 \times 42$ & 240.00 & \\
\hline patio door & 0.22 & & 0.2 & Aluminum & Silver & $8^{\prime} \times 6^{\prime}-8^{\prime \prime}$ & 815.00 & \\
\hline \multicolumn{9}{|c|}{ *Must be certified value } \\
\hline \multicolumn{9}{|c|}{$\begin{array}{l}\text { ** Price is the base price of window with the identified frame material, color and size. Other window options available tc } \\
\text { purchaser (e.g., grids, custom color) as well as shipping, handling, and tax for the listed window are an additional cost to } \\
\text { and are not reported here. The volume purchase program web site will show a range of the maximum prices in each UI } \\
\text { qualified vendor along with the web site (URL) link for the vendors providing windows and/or low-e storm windows in th } \\
\text { Each window bid into the program will be assigned a unique model\# for reporting purposes. See "Reporting Form" tab. } \\
\text { All certified values must be verified from an independent, third-party tester. }\end{array}$} \\
\hline
\end{tabular}

Each vendor's products bid into the program were reviewed and verified in the NFRC and LBNL databases. Each vendor was then contacted by phone by PNNL to obtain additional clarifying information and required information/documentation before the vendor was considered 'qualified' to be listed on the WVP vendor website, and to communicate the expectations of the program. The bidders were also encouraged to ask questions about the program. The discussion with the vendors included:

- clarification of the products and prices where there were questions

- a request for a copy of the certification documentation per the specifications

- a request for the address of the website from which the window products would be sold and/or the vendor could be contacted

- a request for manufacturer points of contact for the program, including sales reporting

- a listing of the regions of North America where the vendors would not sell products

- the bidder's signature on the Agreement documenting the bidder as a qualified participant in the program.

The Agreement (Appendix D) outlined the terms for participation in the program. To ensure program compliance, Section K of the Agreement addressed what was expected with respect to Program Compliance (for example, pricing and sales reporting). Contractors not in compliance would be given clear corrective action instructions via written communication along with deadlines for response and correction. The Agreement would be terminated if the contractor did not meet program compliance within a reasonable time frame as communicated to the contractor in writing.

The Agreement was in effect until the end of Phase I, May 1, 2011. Participants were free to leave the program at any time and PNNL reserved the right to remove participants at their discretion at any time. 
A sample of the sales reporting document that is referenced in Section B of the Agreement was also provided to the vendors. Participants in the program were required to report monthly sales of all qualifying products sold when the sales originated from the program website. The only requirements in the monthly sales numbers were the total number of units sold and the total sales dollar volume, not including tax, shipping, installation, or additional features. ${ }^{1}$ Individual sales numbers and prices would not be publicly released, but aggregate sales numbers could be used publicly at the discretion of PNNL.

\subsection{Solicitation Response}

A total of 63 responses to the RFP were received before the February 19, 2010, deadline. Over the next several weeks the bidders were contacted as noted above and 40 met all of the RFP requirementsincluding a signed Agreement - to be qualified for participation in the program. Profiles of the qualified vendors varied greatly, with some companies generating over $\$ 1$ billion in annual revenues and other companies in start-up stages with only a few window products available in a small geographical region. Almost two-thirds of the manufacturers were identified as having regional (as opposed to national or North American) distribution. Nine of the top 12 companies in window sales in the United States were qualified participants in Phase I. A list of the 40 qualified manufacturers is given in Table 4.2.

Table 4.2. Qualified Vendors in Phase I of the WVP Program

\begin{tabular}{ll}
\hline Accuweld, a Haddon Windows LLC & LowEStormWindows.com \\
Advanced Window Corp. & Mercury Excelum, Inc. \\
Andersen Corp. & MGM Industries \\
Armaclad Windows \& Doors & MI Windows and Doors, Inc. \\
Associated Materials, Inc. & National Vinyl LLC \\
Atrium Windows \& Doors & Newtec Windows and Doors \\
B.F. Rich Windows \& Doors & NT Window, Inc. \\
Champion Window Manufacturing & Pella Corp. \\
Clear Concepts \& Windows & Ply Gem Windows \\
Crystal Window \& Door Systems, LTD & Serious Materials \\
Four Seasons Sunrooms & Shwinco \\
Gilkey Window Co. & Simonton Windows \\
Gorell Windows and Doors & Soft-Lite, LLC \\
Harvey Building Products & Sunrise Windows \\
Ideal Window & Thermal Industries, Inc. \\
Jeld-Wen, Inc. & Thermo-Tech Windows, Inc. \\
Kasson \& Keller, Inc. & THV Compozit Windows \& Doors \\
Kolbe \& Kolbe Millwork Co., Inc. & Valley Building Supply \\
Larson Manufacturing Co., Inc. & Vista Window Company \\
Lindsay Windows & Weathervane Windows \\
\hline
\end{tabular}

\footnotetext{
${ }^{1}$ Buyers could request windows with features (e.g., grids or custom frame colors) that were not included in the base bid price by the vendors, and vendors could charge extra for those features.
} 


\subsection{WVP Program Vendor Website}

On May 2, 2010, the WVP program vendor website was launched

(www.windowsvolumepurchase.org). The website was configured to primarily provide access for buyers to the window products and the qualified vendors selling those products. In addition, the website provided information on the goals of the program, a description of window types and window performance features and metrics, the benefits of high performance (highly insulating) windows, and links to window-related resources including the DOE high performance WVP website (http://www1.eere.energy.gov/buildings/windowsvolumepurchase/). The website also included periodically updated frequently asked questions based on input from user comments and questions that the vendors frequently received.

The WVP program vendor website did not display individual window prices for each vendor, as discussed above. Rather, the highest and lowest price for each window type and the united inches (UI) category (or bin) was displayed. This range of prices and vendors for any given window type were listed in a table with a link to the website of the vendor offering the window type and size of interest. These tables were accessed by clicking on an image of the window type of interest (including low-E storm windows) and whether or not the application was new construction or retrofit construction.

For example, a buyer using the website to search for a casement window of 96 UI for new construction would see a price range of $\$ 185$ to $\$ 362$ (for a minimum quantity of 20 ) followed by a list of all of the vendors who were selling new-construction casement windows of that size through the program. ${ }^{1}$ The buyer would know that every vendor on the list would offer the window of interest somewhere in that price range but would need to contact each vendor to determine their prices. The buyer could click on a link and be taken to an external website provided by that vendor specifically for the WVP program. At the external site, buyers could obtain more information about that vendor's qualified products and place an order.

There were also two tools available to help website users with the decision making process; the Open Bid Request Form and the Energy Savings Estimator for residential buildings.

\subsubsection{Open Bid Request Form}

The Open Bid Request Form was an Excel spreadsheet developed by the WVP team for any buyer to download and enter specific information about the windows in the WVP program they were considering purchasing. Figure 4.1 is an example of a form completed by a buyer.

The completed form was sent directly to PNNL by the buyer; PNNL redacted the buyer contact information and forwarded the form to all qualified vendors listing the windows products requested by the buyer. Vendors would - but were not required to - return the form to PNNL with a price quote which would then be forwarded to the buyer who was free to choose the manufacturers they wanted to contact. Vendors were given 14 calendar days to return the form with price quotes.

\footnotetext{
${ }^{1}$ Note that the minimum quantity was for any combination of types of primary windows for any size. Thus a buyer could order 14 double-hung windows, 5 fixed windows and 1 patio door to meet the minimum quantity order and pricing.
} 


\begin{tabular}{|c|c|c|c|c|c|}
\hline \multirow[b]{2}{*}{ Contact Information } & & \multicolumn{4}{|c|}{ Contact information will NOT be given to the vendors } \\
\hline & & & & & \\
\hline Name or Company Name* & Contact name & \multicolumn{4}{|l|}{ John Smith } \\
\hline E-mail* & Contact e-mail & \multicolumn{4}{|c|}{ xxx.xxxxxxx@xxx.com } \\
\hline Phone* & Contact phone number & \multicolumn{4}{|l|}{$(x x x)-x x x-x x x x$} \\
\hline Windows Bid Requested & & Group 1 & Group 2 & Group 3 & Group 4 \\
\hline Pickup or Delivery* & drop down box & pickup & pickup & delivery & \\
\hline Pickup/Delivery Zip Code* & enter & 99352 & 99352 & 99354 & \\
\hline Installation & drop down box & self & self & vendor & \\
\hline Type of Construction* & drop down box & retrofit & retrofit & new & \\
\hline Window Type* & drop down box & horizontal slider & fixed & casement & \\
\hline \# of Windows* & enter & 10 & 25 & 78 & \\
\hline Window Size* & width $x$ height (inches) & 68 & 84 & 96 & \\
\hline Window Frame Color* & drop down box & white & white & white & \\
\hline Other Window Features & see below & & & & \\
\hline Grids (grilles) & drop down box & yes & no & no & \\
\hline Jamb Depth (inches) & enter number, or not sure & $5-3 / 4^{\prime \prime}$ & $5-3 / 4^{\prime \prime}$ & not sure & \\
\hline Other & Describe any other & screens & high altitude & impact resistant & \\
\hline Other & features which you believe & tempered glass & & & \\
\hline Other & will help the vendors return & high altitude & & & \\
\hline Other & a more accurate price & & & & \\
\hline Other & estimate & & & & \\
\hline
\end{tabular}

Figure 4.1. Example of a Completed Open Bid Request Form

The price quote from each vendor was checked to make sure the base price was no more than the price bid by the vendors for the windows products in the WVP program. If the base price was greater, it was returned to the vendor for adjustment. This bid request form was an optional method for buyers who did not want to spend time contacting each qualified vendor to obtain pricing information on particular window products. This form was also considered useful to government and public agencies required to receive multiple bids for products.

\subsubsection{Energy Savings Estimator}

The Energy Savings Estimator was developed by the ASE as an Excel spreadsheet that could be downloaded from the website and used to determine savings estimates for various residential window retrofits. The user was required to enter information about a building's location, size, fenestration percentage (square footage of windows divided by square footage of floor space), and existing window configuration (single or double pane, metal or non-metal frame, etc.). They could then choose a replacement option of either highly insulating primary windows or low-E storm windows and receive an estimate of the savings. The savings was based on internally recorded prices for electricity and natural gas in the user's area and was displayed in terms of annual cost savings, lifetime cost savings (assuming 20 year window life) and lifetime $\mathrm{CO}_{2}$ savings. A user's manual was also provided for downloading. The input screen for the Energy Savings Estimator is shown in Figure 4.2. 


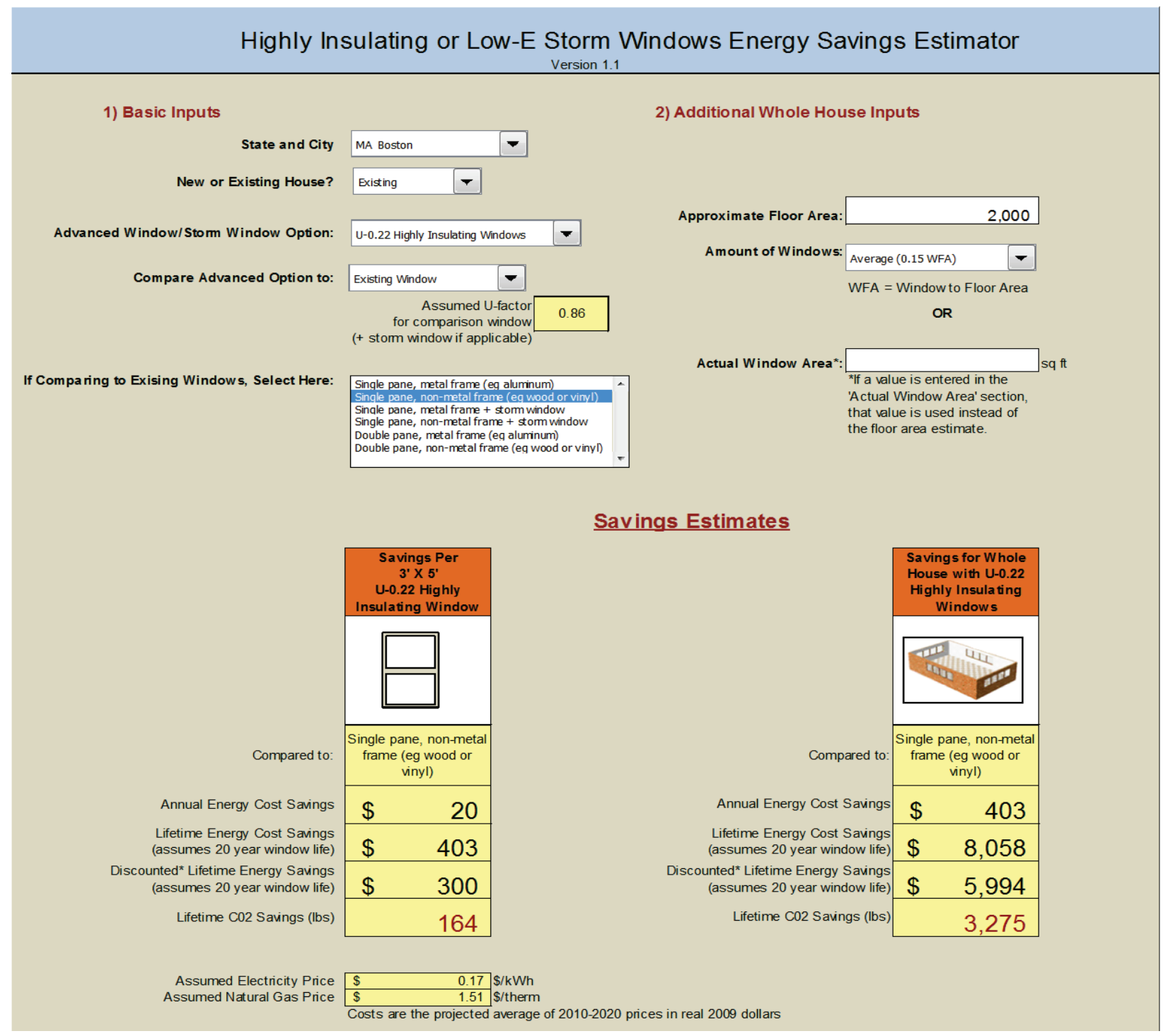

Figure 4.2. Input Screen for the Energy Savings Estimator

Six months after the website was launched PNNL added a list of the top three participating manufacturers based on the monthly sales reports being collected and recorded. The list named the top three sellers each quarter and the total window sales. 



\subsection{Outcome of Phase I}

The response to Phase I of the program exceeded initial WVP program team expectations. It was anticipated that 5 to 20 manufacturers would respond to the solicitation and 62 responses were received. During the several weeks between the end of the RFP and the target launch date of the website, 22 of the 62 manufacturers could not be qualified for the program given that their window product specifications could not be verified and/or they did not provide the required certifications. As noted above, the 40 qualified vendors represented a cross section of the industry and provided products to most of the United States. However, none of the vendors were based in Canada and as a result none were offering products delivered to Canada. The seven primary window types and low-E storm windows were well represented with at least three vendors' products appearing for each of the types and UI bins.

\subsection{WVP Program Promotion}

A strategy was developed by Energetics, Inc., to promote the WVP program by raising awareness and educating buyers about the benefits and availability of highly insulating windows through the volume purchase program. The strategy included posting materials on the DOE Windows Volume Purchase website, establishing an e-mail list of those interested in receiving information on the WVP program, holding workshops in cooperation with stakeholders, preparing and distributing fact sheets, holding webinars and attending and presenting at industry conferences and trade shows. A comprehensive listing of the program promotion activities and publications is given in Appendix A.

Of particular importance for education and promotion were the workshops organized in cooperation with stakeholders who provided the workshop venue and outreach to targeted invitees. The qualified vendors in the program were invited to bring their products to the workshops and each vendor was given an opportunity at the workshop to talk about their products. These workshops included:

\section{- Midwest Regional Workshop}

Chicago, Illinois - September 22, 2010

Key Partners: City of Chicago, State of Illinois, Cook County Community and Economic Development Association (CEDA), and MEEA

- Pacific Northwest Regional Workshop Portland, Oregon - October 11, 2010

Key Partners: Energy Trust of Oregon, Northwest Natural (gas utility)

- Mid-Atlantic Regional Workshop

Philadelphia, Pennsylvania - October 20, 2010

Key Partners: Energy Coordinating Agency

- Ohio Regional Workshop

Columbus, Ohio - April 26, 2011

Key Partners: State of Ohio (Ohio Energy Resources Division), The Ohio State University, The Ohio State University Extension, Ohio Home Builders Association, Mid-Ohio Regional Planning Commission, Green Energy Ohio, AEP Ohio, University Clean Energy Alliance of Ohio 


\subsection{Windows Sales}

Aggregate sales (\$) by month for the 40 vendors in Phase I (reporting from June 2010 through April 2011 ) are shown in Figure 5.1. Total sales were 3,565 windows valued at $\$ 897,352$. The spike in sales reported in January 2011 is likely a result of the expiration of the $\$ 1,500$ federal tax credit for energy efficient windows in December, 2010 (see below).

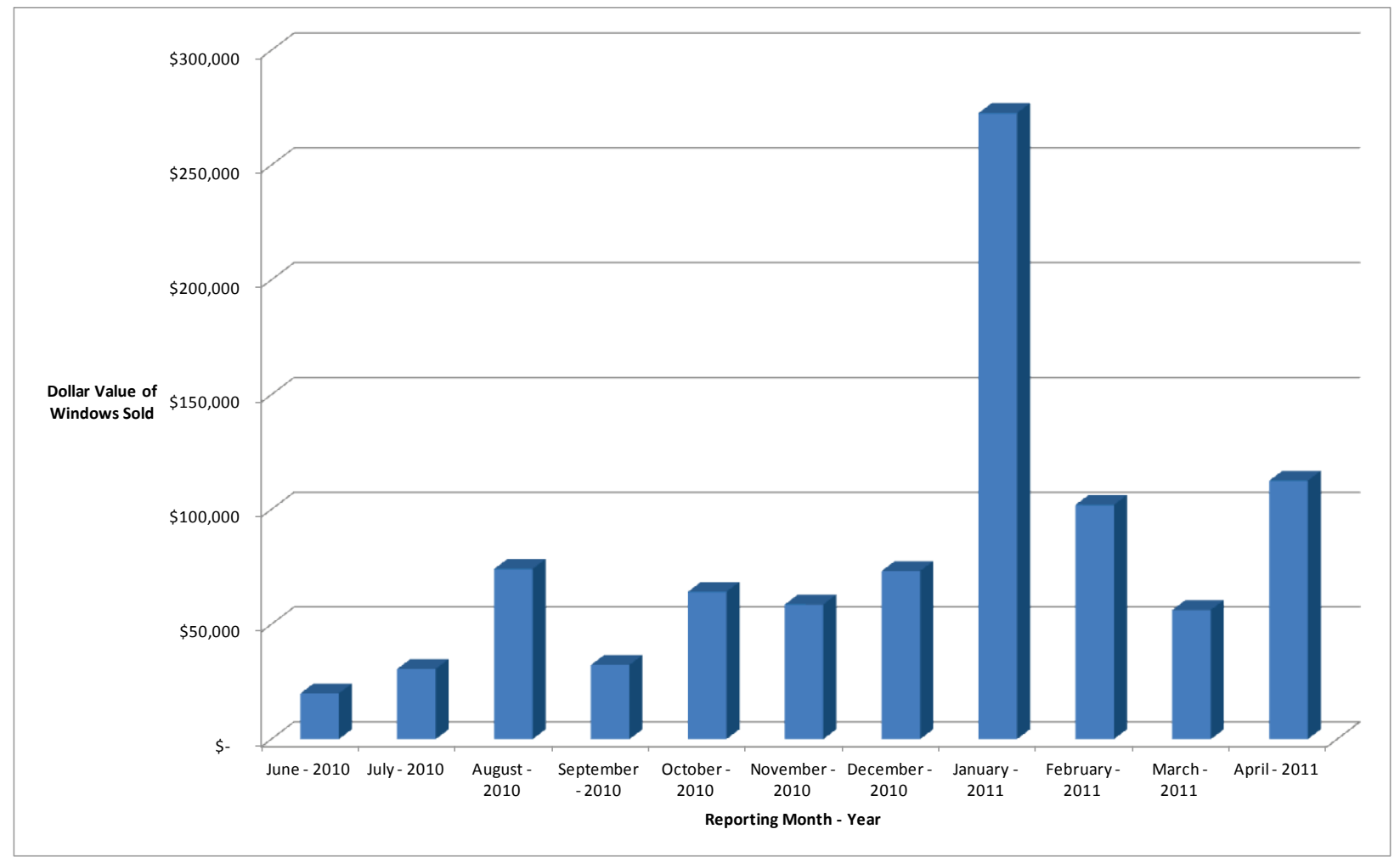

Figure 5.1. Sales of Highly Insulating Windows Reported by the WVP Program Vendors in Phase I

Sales were reported by $\sim 30$ percent of the qualified vendors with many vendors reporting no sales or not reporting sales. PNNL followed up with those vendors not reporting sales (a different group of vendors each month) to request sales data and determine whether the lack of a monthly sales report was an indication that there were no sales. The outcome was mixed as there were some vendors who continued to not report sales (even if there were no sales) on a monthly basis. These vendors who were inconsistent in reporting sales remained in the program through the entire time period of Phase I.

\subsection{Windows Products Pricing and Purchasing}

There were a significant number of comments received from buyers/potential buyers focused on the issue of prices displayed for the window products on the website and the purchasing process itself. Based on discussion with the vendors, only a range of the base prices for any given window type and size was shown on the website to buyers. In some cases the range of prices varied as much as ten to one for products of the same type and size. This seriously limited the effectiveness of displayed prices because the buyer could not know which manufacturers were near the low end of the range if the buyer was focused only on low cost. 
Under the business model used by most manufacturers in the window industry, only the smallest manufacturers will sell directly to the public and price their products accordingly. These small manufacturers do not have extensive dealer networks nor do they normally sell products through regional or nationwide hardware chains/big-box stores. Phase I included many of these smaller manufacturers and their 'base' price reflected this business model.

Many if not most of the larger manufacturers/vendors in Phase I chose to sell the windows in the program through their well-established dealer network and thus the base price reflected this business model. Some of the vendors selling windows in the volume purchase program through their dealers provided a 'base' window price that included installation given that was their business model, even though they were requested to submit bids for a 'base' price.

In addition to issues with the pricing structure, some buyers searching the website complained about linking to some of the vendors' websites. Most of the websites required leaving buyer contact information which did not yield a response or yielded a response from an uninformed dealer: either the vendor did not reply to the buyer or the contact was forwarded to a vendor's dealer who knew nothing about the program. Apparently the qualified vendor did not adequately inform their dealers/dealer staff of the nature and specifics of the program and particularly the window products and pricing. Attempts were made to address these issues with the Optional Bid Request Form ${ }^{1}$ (see discussion above), and with changes in the product pricing and purchasing in Phase II of the program (see below).

\subsection{Impact of the Nationwide Tax Credit for Windows}

As of June 1, 2009, windows, doors, and skylights with U-factor and SHGC ratings of less than or equal to $0.30^{2}$ were eligible for a federal tax credit of 30 percent of the product price, up to $\$ 1,500$. This tax credit was in place at the time of the launch of Phase I of the program. Many of the products bid into the program met both criteria and therefore the program very probably benefitted from the tax incentive. However, given the modest tax credit and premium price for the highly insulating windows in Phase I, buyers may have found the ENERGY STAR windows more cost-effective. In addition, for Northern climates, a higher SHGC is beneficial for taking advantage of winter solar gain. Many of the windows qualified in the program had an SHGC less than $\sim 0.25$ and therefore were not the optimal product for much of the Northern climate zone.

In future modifications to the windows tax credit in 2011 (extended through 2013), the windows criteria were modified to provide differentiation in U-factor and SHGC by climate zone. This allowed those buyers in the Northern climate zone to tailor their choice of windows to allow more solar insolation (higher SHGC) to take advantage of winter solar gain. However, the windows tax credit allowance was reduced to 10 percent of the product price up to $\$ 200$. Although no data are available, this relatively modest tax credit (compared to 2009-2010) may not have been sufficient for buyers to consider highly insulating windows given their premium price over ENERGY STAR windows.

\footnotetext{
${ }^{1}$ Bid request forms were received from $\sim 35$ buyers in Phase I. There was no follow-up to ascertain the number of windows sold through the bid request process.

${ }^{2}$ These criteria were the criteria for ENERGY STAR windows.
} 



\subsection{Phase II}

The launch date of Phase II was scheduled for May 2, 2011, and in anticipation, the WVP core team recommended modifications to the Phase I specifications and solicitation. These recommended modifications were vetted by industry (including the Phase I vendors) and stakeholders over a $\sim 3$ month period starting in early FY 2011. The recommended modifications to the specifications were designed to address issues raised by the buyers and vendors during Phase I and streamline the bidding process. This included making additional window types available, providing pricing for different bin volumesincluding pricing for a single window, and putting restrictions on dealers to bid into the program. Phase II was to terminate on April 30, 2012.

\subsection{Specifications Changes}

The Phase II solicitation was issued on January 24, 2011, and sent to an industry mailing list and posted on fbo.gov. The solicitation and enclosures are given in Appendix F. ${ }^{1}$ Also included in Appendix F are two addenda and two quality assurance documents that were posted on fbo.gov. Guidelines for reporting sales for Phase II are also given in Appendix F. As with Phase I, the solicitation included a Cover Letter, Specifications, Draft Agreement, Phase II Bid Template, and Sales Reporting Document. The due date for response was March 18, 2011. The vendors, after submitting a bid, were qualified for acceptance into the program in the same manner as in Phase I. The key changes and clarifications for the Phase II solicitation included condensation resistance (CR), adding window types, window dealers, prices and price increases, bid quantities, shipping regions, bid extension, and vendor websites.

\subsubsection{Condensation Resistance}

A change was made to the Specifications to include a requirement of CR no greater than 50 with the CR of the window bid into the program verified by the NFRC Certified Products Directory (CPD) number. In addition, any product bid into the program using the Component Modeling Approach (see below) were not required to meet this metric. Several manufacturers were beginning to offer double-pane windows that could reach the U-factor requirement of the program. However, unlike triple-pane windows, which had low-E coatings on two interior surfaces, these new double-pane windows required one of the coatings to be located on the exterior surface facing the inside of the building. This exterior coating increased the likelihood of condensation formation on the coated surface of the window, and the presence of condensation in a 'premium' highly insulating window was likely to be considered problematic for the buyers. Review of NFRC's CPD revealed that at least three companies in the program were capable of producing these double-pane windows with a $\mathrm{CR}$ in the range of 50-52 and therefore a CR requirement of 50 was added to the specifications.

\subsubsection{Adding Window Types}

One additional residential window type was added (awning) and commercial window products were included. Many smaller commercial buildings use punched openings in the façade which can be fitted with the same residential windows used in homes, usually with aluminum frames rather than vinyl. However, larger commercial buildings will often have the three primary parts of a window, (the glazing, the frame, and the spacer), shipped to the construction site and assembled 'on site.' This creates a

\footnotetext{
${ }^{1}$ Note that only the instructions page from the Excel-based bid template is included in Appendix 6.
} 
difficulty in accurately estimating how the assembled window will thermally perform after it is installed. In an effort to address this problem NFRC designed a Component Modeling Approach (CMA) which uses computer simulation software to make these estimates. The corresponding values would consequently appear in the Certified Products Database much in the same way as factory assembled windows. The CMA provided PNNL with the necessary resources to set performance criteria for commercial products in the WVP program that could be verified. With input from the industry, U-factor specifications were designed for commercial windows that were assembled on site, and the program was able to admit commercial products for the first time.

\subsubsection{Windows Dealers}

An addendum to the solicitation was issued on February 10, 2011, indicating that dealers and distributors were not allowed to directly enter the program in Phase II. The addendum specified that proposals for any window products must come from the manufacturer whose name appears in the NFRC Certified Products Directory for the CPD number associated with that window product. Manufacturers who use dealer networks will be responsible for entering proposal prices that reflect the maximum selling price they can expect from all participating dealers in their network. That maximum price will be posted on the WVP vendors website with information that the windows products are sold through the manufacturer's distributors and that potential buyers will be directed to the appropriate dealer or distributor. The team recognized that there was a variation in distributor prices for any given manufacturer's window product. Thus, in Phase II the solicitation was very clear in requesting that the maximum selling price be submitted for each window product by the manufacturer regardless of the channel through which the window was sold.

\subsubsection{Prices and Price Increases}

Section $\mathrm{F}$ of the Agreement was added to indicate to the vendors that the product prices would be posted on the WVP program vendor website and could not be increased for six calendar months starting from the time period of the signing of the Agreement. The posting of discrete prices for each individual vendor for each product bid rather than the relatively wide range of prices for a window type in Phase I was in response to the issues raised by the potential buyers. Buyers who routinely shop online have become accustomed to seeing and comparing prices for consumer products and were expecting the same kind of ability to comparison shop for windows.

\subsubsection{Bid Quantities}

To accommodate buyers who wanted to purchase smaller quantities of windows (primarily individual residents), the bid categories were modified to include bids for quantities from 1-19 windows. In addition, to accommodate larger purchasers and allow for discrete quantity pricing, additional bid bins of 20-49, 50-199 and 200+ windows were added. Also, there was no distinction required between new and retrofit construction pricing as price differences between new and retrofit windows in Phase I were observed to be minimal.

\subsubsection{Shipping Regions}

In the bids, the vendors were asked to identify those states where they would sell and/or ship window products. These regions included the provinces of Canada and would be identified on the website. This would allow buyers to know whether the desired window product would be available to their shipping destination. 


\subsubsection{Bid Extension}

Unlike in Phase I, in which no manufacturers were admitted after the solicitation deadline, the program would remain open to new applicants for six months after the launch date of Phase II (May 2, 2011). Those vendors who submitted bids by March 18 and were qualified were listed on the website for the program launch. Any vendors who submitted a bid after March 18 were vetted in order of the date the bid was received. Additionally, vendors were allowed to raise their prices one time after six months after signing the Agreement to allow for increases in the WVP program window manufacturing costs.

\subsubsection{Vendor Websites}

In an effort to eliminate vendor website links that resulted in "dead ends" for the buyers, the vendors were informed that their links needed to lead directly to a webpage with specific information about the DOE WVP program and the company's qualifying products. They were to be diligent in responding to all inquiries generated by their WVP website and communicating necessary program information to their dealers and make sure that the buyers inquiring about products were contacted in a timely manner by knowledgeable sales staff.

\subsection{Response to the Solicitation}

Eighteen of the 40 Phase I manufacturers and an additional 14 new vendors submitted bids by the close of the Phase II solicitation. At the launch of Phase II (May 2, 2011), 20 of the 32 vendors submitting bids for Phase II at the close of the solicitation had been qualified and were listed on the website. Over time, an additional eight vendors were qualified for Phase II, bringing the total to 28 vendors by midsummer 2011 (see Table 6.1).

Table 6.1. Qualified Vendors in Phase II of the WVP Program

\begin{tabular}{ll}
\hline Amerimax Windows and Doors & Mathews Brothers Company \\
Armaclad Windows \% Doors LLC & Monda Windows and Doors \\
Atrium Windows and Doors & MI Windows and Doors \\
B.F. Rich Windows and Doors & National Vinyl, LLC \\
Bonded Insulated Products & Okna Windows \& Doors \\
Cascade Windows & Ply Gem Windows \\
Champion Window Manufacturing Inc. & R5 Window and Door \\
Gilkey Window Company & Serious Materials \\
Gorell Windows and Doors & Shwinco \\
Great Lakes Window & Simonton Windows \\
Jantek Industries LLC & Soft-Lite, LLC \\
Jeld-Wen Windows and Doors & Sunrise Windows \\
Kasson and Keller Inc. & Thermal Industries Inc. \\
Larson Manufacturing Company & Vista Window Company \\
\hline
\end{tabular}




\subsection{Website Upgrades}

The vendor website was updated and reconfigured with additional links to information resources. The Optional Open Bid Request Form was retained from Phase I with slight modifications. The Energy Savings Estimator was also retained on the website. A file was created by the ASE listing all U.S. utility incentives for window products and posted to the website as a resource for buyers. Frequently asked questions were also posted on the website and updated periodically.

The most significant change to the website was the addition of a sorting feature that allowed buyers to enter criteria in drop-down boxes to yield a list of results that included all of their chosen criteria.

Window type, construction type, UI or sliding glass door size, structural class (residential or commercial), Performance Grade and shipping region could be entered (or left with no preference) as search criteria. After search results were shown, the list of products and vendors could be sorted according to any of the criteria or by vendor to facilitate the decision making process. Clicking on a vendor's name would take the buyer to an external website for that vendor. 


\subsection{Outcome of Phase II}

Phase II of the program did not create the same level of industry and stakeholder interest as Phase I, but the program was generally more recognized after its initial year. The Phase II launch event was modestly attended by industry and interested parties. This was anticipated given that the event was held in Salt Lake City at a trade show.

\subsection{Website Pricing Impact}

Changes to the pricing structure on the website did not totally resolve the issue with understanding and comparing the 'true' price structure of highly insulating windows given that the listed prices for some vendors included additional dealer costs such as 'handling' or even installation, whereas other vendors were truly selling the windows at a 'base' price. ${ }^{1}$

Some vendors were actively trying to promote highly insulating windows in creative ways through their dealer network. One vendor was able to approach their dealers with the idea that the WVP program was sending potential buyers from the WVP vendor website and therefore the dealers were not incurring one of the larger expenses in their operation, that of lead generation. As a result, many of the vendors' dealers agreed to provide substantial discounts to those people sent from the program. This was precisely the type of innovation which the program had been anticipating to accelerate the market adoption of highly insulating windows.

\subsection{WVP Program Promotion}

As with Phase I, a strategy was developed by Energetics, Inc., to promote the WVP program in Phase II by raising awareness and educating buyers about the benefits and availability of highly insulating windows through the volume purchase program and the added features of the WVP vendor website. Three workshops were held, eight webinars conducted and two feature articles were published in industry trade journals. The complete list of the program promotion activities and publications for Phase II is given in Appendix A.

\subsection{Sales}

In Section B of the Agreement for Phase II, manufacturers were required to provide sales information on high performance windows and low-E storm windows that were not attributed to sale through the WVP program in addition to those coming from the WVP website. This was a requirement given that DOE was interested in the market penetration of highly insulating windows that may be attributed indirectly to the program. As a result, reported sales were significantly greater in Phase II despite having fewer vendors with no nationwide incentive for efficient windows. Aggregate sales for Phase II by month are shown in Figure 7.1. Total sales were 18,454 windows with a value of $\$ 4,218,145$.

\footnotetext{
${ }^{1}$ This information was uncovered during periodic inquiries by anonymous buyers about purchasing the window products.
} 


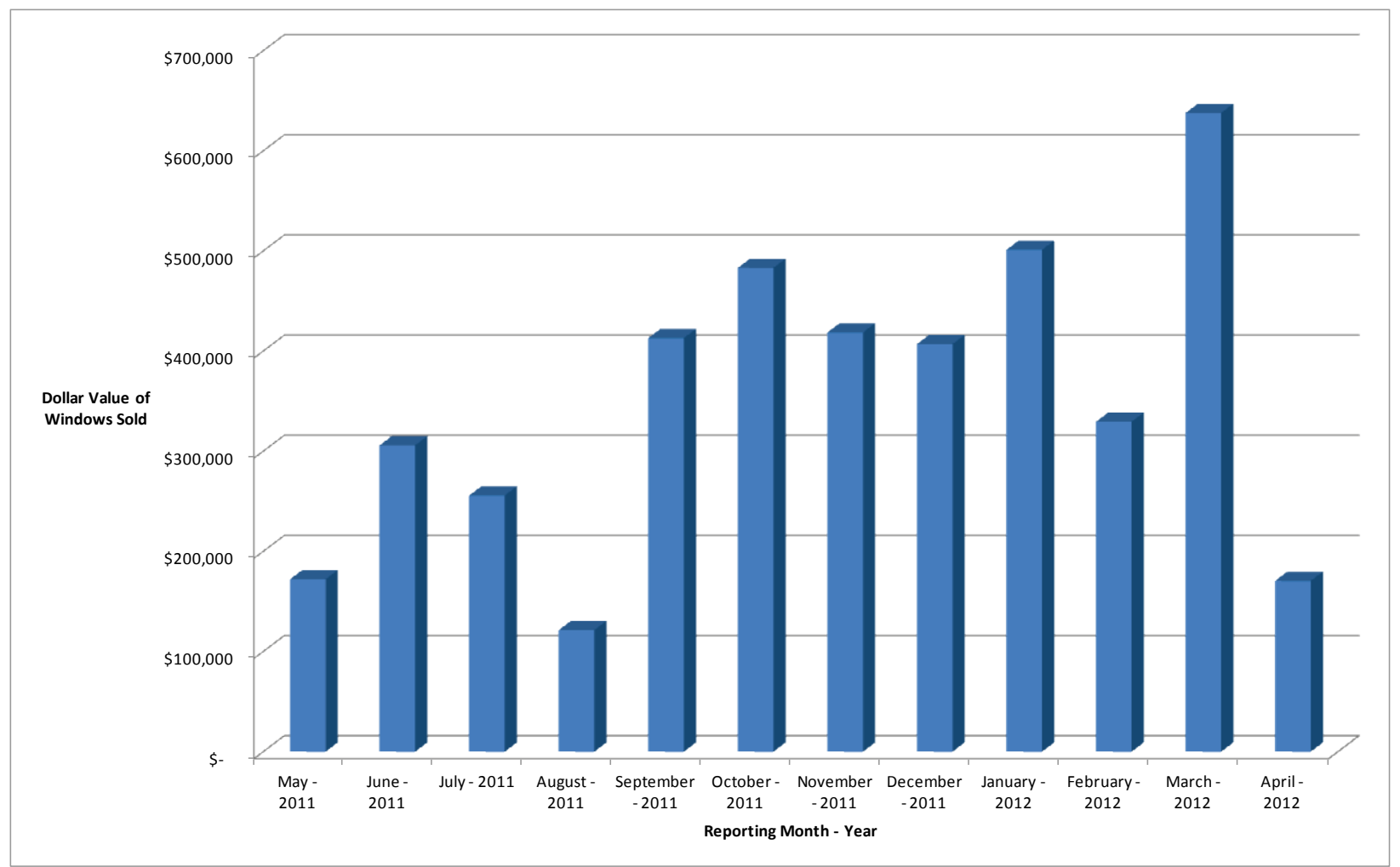

Figure 7.1. Sales of Highly Insulating Windows Reported by the WVP Program Vendors in Phase II 


\subsection{Phase II Extension}

In February 2012 DOE hosted a call-in for the window industry to discuss the program and what options they thought were best for future direction including the option of continuing the program beyond Phase II. Questions were posed to the participants and discussed, and an open forum for discussion was available at the end of the session. Much of the discussion focused on consumer education and promotion strategies that could increase sales of highly insulating windows.

Three distinct themes were recurring throughout the session; 1) several manufacturers commented that inquiries coming from the website were strong at the beginning of Phase I, but had declined steadily since; 2) almost all of the vendors on the call were interested in seeing new nationwide tax incentives for efficient windows similar to the $\$ 1,500$ federal credit which ended in December 2010; and 3) several manufacturers believed that the high brand recognition of EPA's ENERGY STAR windows program had successfully moved the market forward in the past and probably offered the best option for creating a higher-tier program in which the vendors would be eager to participate.

While no distinct resolutions resulted from the strategy session it seemed clear that momentum towards higher-performance products created by the program had slowed steadily and that a tax incentive combined with a higher-tier ENERGY STAR program was likely to be the most viable long-term strategy to significantly move the market for highly insulating windows.

Based on feedback from industry, the continued sluggish housing market and resulting stagnation in overall window sales, and no future planned national tax incentives, DOE made the decision to not launch a Phase III of the WVP program. It was decided that the WVP program would extend Phase II beyond April 30, 2012, and close it on December 31, 2012. The new focus of the WVP program became the sales reporting of the participating manufacturers in an effort to better quantify the impact the program was having on the market.

In early spring of 2012, PNNL announced to the industry that a Phase II Extension would be initiated in May and that two significant changes would be made. First, all prices shown on the website were removed and although buyers were still able to use the sorting tool to generate a list of participating vendors offering a particular product, those vendors would need to be contacted (via their website) to obtain any pricing information. Second, more emphasis would be placed on working with the vendors to obtain accurate and timely monthly sales and that these sales reports would include all sales of windows that met the program requirements even if those sales did not originate from the website. Appendix $G$ gives the Phase II Extension solicitation letter, Specifications, Agreement, and Sales Reporting Document.

Seven manufacturers from Phase II returned for the extension, one manufacturer from Phase I who had missed Phase II also returned, and one new manufacturer joined, giving a total of nine vendors in the Phase II Extension. New Agreement Letters were drafted which would expire on December 31, 2012, products were resubmitted and verified for their performance levels and certifications, and the extension began on May 1. 
During the extension period, the program focused primarily on sales reports from the program participants and overall program impact. There were no significant education and outreach activities during the Phase II Extension other than informal discussions with industry at trade association meetings (e.g., NAHB) and stakeholder meetings (e.g., CEE).

\subsection{Phase II Extension Sales \& Total Program Sales}

With only nine participating manufacturers, sales in the early part of the Phase II Extension were the highest during the entire program. Below are the monthly sales for the participating vendors in the Phase II Extension. Figure 8.1 shows the monthly sales. Sales for the Phase II Extension totaled 18,460 windows with a value of $\$ 4,628,005$. $^{1}$

The final total reported in the program was 40,479 windows with a value in excess of $\$ 9.6$ million.

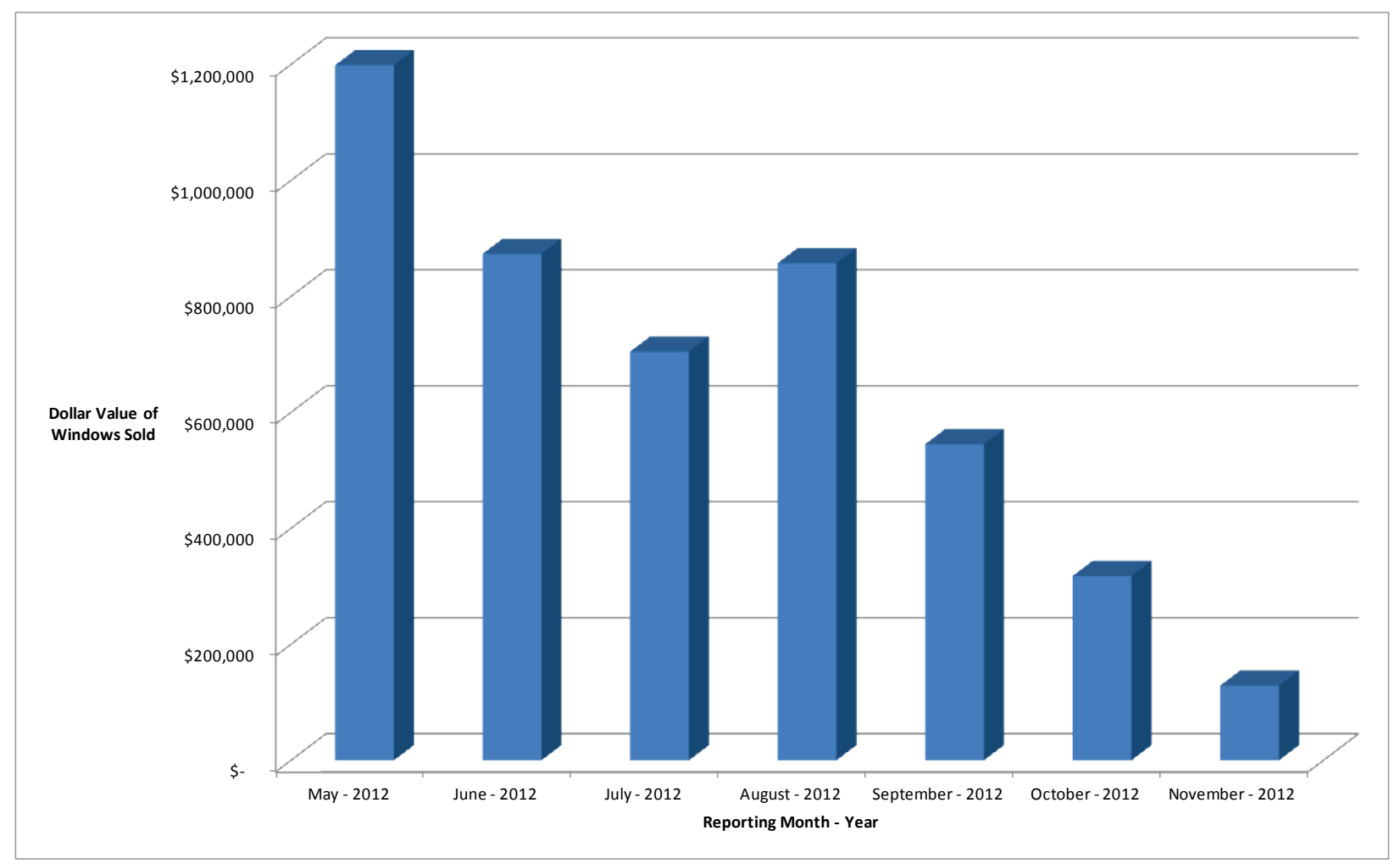

Figure 8.1. Sales of Highly Insulating Windows Reported by the WVP Program Vendors in Phase II Extension

\footnotetext{
${ }^{1}$ The program ended December 31, 2012; however no sales data were collected for the month of December.
} 


\subsection{Program Impact}

Several lasting impacts can be seen which have resulted directly from the WVP program during its three-and-a-half-year tenure.

\subsection{Incremental Cost Reduction}

The incremental cost of a U-0.20-0.22 uninstalled double-hung window compared to an ENERGY STAR window has been considerably reduced as shown in Table 9.1.

Table 9.1. Historic Incremental Cost Premium for a Highly Insulating Window over an ENERGY STAR Window

\begin{tabular}{ll} 
FY & U-0.20-0.22 Window Cost Premium over ENERGY STAR \\
$\mathbf{\$} /$ square foot & \multicolumn{1}{c}{$\begin{array}{c}\text { W } \\
2008\end{array}$} \\
2010 & $\$ 6.78-\$ 10.00$ (before WVP) \\
2012 & $\$ 5.83-\$ 7.23$ \\
2020 & $\$ 1.59-\$ 5.83$ \\
&
\end{tabular}

The 2012 average incremental cost premium of $\sim \$ 3.75$ is less than within the original WVP program target of $\$ 4 / \mathrm{ft}^{2}$.

\subsection{Increased Nationwide Market Penetration}

The overall penetration of highly insulating windows into the market can be one gauge of the program's impact. Such data were obtained from the NAHB, who conducts an annual survey of their member builders to obtain data about window units installed and whether those units were single pane, double pane, or triple pane.

Based on NAHB data acquired in 2012 (covering the period from 2008 through 2011), new privately owned housing units completed fell more than 50 percent from 2008 to 2011; however the ratio of triple-glazed units installed rose from 0.242 to 0.500 in the first two years of the WVP program. A summary of these data are shown in Table 9.2.

Table 9.2. Ratio of Triple-Glazed Windows Installed in the Residential Sector as a Percentage of Housing Units Constructed

\begin{tabular}{ccccc}
\hline & $\begin{array}{c}\text { New Privately Owned } \\
\text { Housing Units } \\
\text { Completed } \\
\text { (thousands) }\end{array}$ & $\begin{array}{c}\text { Triple-Glazed Units } \\
\text { Installed } \\
\text { (thousands) }\end{array}$ & $\begin{array}{c}\text { Ratio of Triple- } \\
\text { Glazed Units } \\
\text { Installed to New } \\
\text { Housing Units }\end{array}$ & Notes \\
\hline 2008 & 1119.7 & 357.5 & 0.319 & Before WVP Program \\
2009 & 794.4 & 192.2 & 0.242 & Phase I WVP Program \\
2010 & 651.7 & 295.9 & 0.454 & Phase II WVP Program \\
2011 & 584.9 & 292.7 & 0.500 & \\
\hline
\end{tabular}


While many factors contributed to the rise in triple-pane usage in 2010-2011, the relationship of increase in sales of triple-pane windows with the launch of the WVP program is strong. The program created an increased awareness among buyers of highly insulating windows and, as an outcome of the production-engineering funding from DOE, became a focal point for the industry to examine the emerging innovations (see below), production and cost of highly insulating windows to meet consumer demand.

\subsection{ENERGY STAR Most Efficient}

At the time the WVP program was underway the ENERGY STAR criteria for windows was a U-factor of no greater than 0.30 for the Northern climate zone of the United States (and including Canada, who adopted the ENERGY STAR criteria). And, as noted above, there were federal tax incentives in place with ENERGY STAR criteria eligibility to stimulate the purchase of ENERGY STAR windows for homeowner retrofits. Therefore, ENERGY STAR windows were a significant product in the market. Also, in many parts of the country, ENERGY STAR windows were included as a requirement in new residential construction building codes.

Therefore in mid-FY 2011, ENERGY STAR started a process to update the ENERGY STAR criteria for windows through a series of public meetings and public comments. The final criteria were established with a U-factor no greater than 0.27 in the Northern climate zone (and Canada). The updated ENERGY STAR windows criteria would take effect January 1, 2014.

During an EPA-hosted stakeholder meeting in late FY 2012, EPA announced that an EPA Most Efficient program for window technology would be launched in January 2013. ${ }^{1}$ The ENERGY STAR Most Efficient 2013 designation recognizes the most efficient products among those that qualify for the ENERGY STAR. The final criteria were established by ENERGY STAR in November 2012 for residential window products. The EPA criteria were in alignment with the WVP program specifications of a U-factor no greater than 0.20, with a Performance Grade of 15, certification to the North American Fenestration Standard (NAFS), and listing in the NFRC Certified Products Directory. ${ }^{2}$

In addition to ENERGY STAR Most Efficient, windows with a U-factor no greater than 0.22 are proposed for the update to the International Energy Conservation Code (IECC) for residential buildings. ${ }^{3}$

\subsection{Technical Innovations}

Two technologies were developed by industry during the program that will have considerable impact on the production of highly insulating windows in the future.

\subsubsection{Surface Four Technology}

At the start of Phase I it was necessary to use triple-pane IGUs to reach the program requirement of a $\mathrm{U}$-factor no greater than 0.22 . Two low-E coated surfaces were required to reach this level and these surfaces could not be applied within the same cavity of a double-pane window because the effect on

\footnotetext{
1 http://www.windowanddoor.com/news-item/government/industry-provides-feedback-new-energy-star-criteria

2 http://www.energystar.gov/ia/partners/downloads/EPA_Memo_ENERGY_STAR_Most_Efficient_2013.pdf?6ad0-a614

${ }^{3}$ IECC code development is supported by DOE. See http://www.energycodes.gov/residential-code-change-proposals-2015-iecc
} 
insulation was considerably diminished. Also, because the coats were sputtered, or soft coats, they could not be applied to either of the exposed surfaces of a double-pane window because they were too easily damaged and were very difficult to clean. A new type of coating was created by the glass industry which required tempering after it was applied and which gave the coat a harder consistency. As a result of this new coating, several companies began making products using double-pane IGUs with one coat applied to the surface exposed to the inside of the window (surface four).

By using two panes of glass, products can be made that are less expensive and have a lower overall weight than a triple-pane unit, and were therefore well suited to the WVP program's goal of reducing costs. However, these products have reduced CR and concerns have been raised about their durability compared to the triple-pane products. Safe methods for cleaning the surface have been researched and companies normally offer instructional literature to the dealers to distribute with the product.

\subsubsection{ATLAS Systems Development}

With DOE funding, GED Integrated Solutions created an Automated Tri-Lite Assembly System (ATLAS). This system is capable of producing triple-pane IGUs in 20-second cycle times. Previous window assembly lines could produce double-pane IGUs quickly, but a third pane would need to be added by hand, which is time consuming and prone to mistakes, or by a second piece of machinery which is also time consuming and requires a high investment cost. The ATLAS makes it possible to produce high volumes of triple-pane IGUs with unprecedented throughput, which leads to decreased cost of manufacturing triple-pane IGUs.

\subsubsection{TRACO R-5 Commercial Windows}

With DOE funding, TRACO ${ }^{1}$ developed more efficient production of R-5 aluminum-frame commercial windows. Before the improvements in engineering and production, there was no cost-effective process to manufacture an R-5 architectural grade commercial window. The outcome was an increase in the throughput (volume) as well as reduction in labor time required to manufacture the windows.

\subsection{Specifications, Certifications and Incentives}

The WVP was instrumental in assisting one agency in developing specifications for prioritizing low-E storm windows as a retrofit measure, and in AAMA updating a standard for certifying low-E storm windows. The program also provided technical assistance to utilities to align their incentives with the WVP specifications.

\subsubsection{State of Pennsylvania Weatherization Priority List}

In 2010, WVP program partners Energetics, Inc., and Quanta Technologies worked closely with the Pennsylvania Department of Community and Economic Development (DCED) to update their priority list which is used to direct weatherization subagencies. These subagencies are instructed to implement measures in order of the priority list according to the budget allotted for each home. After health and

\footnotetext{
${ }^{1}$ Traco was acquired by Kawneer North America in 2010. See

http://www.kawneer.com/kawneer/north_america/en/info_page/home.asp?traco=1\#
} 
safety measures are complete, energy efficiency measures are implemented with the remaining funds. DCED conducts cost-effectiveness analysis using the National Energy Audit Tool (NEAT) created by Oak Ridge National Laboratory, which estimates cost effectiveness in terms of savings-to-investment ratio (SIR). A SIR of greater than 1.0 indicates that a given measure will successfully return the investment cost within the lifetime of the product and is a requirement for any measure to be used in the Pennsylvania priority list.

Previous analysis of windows by DCED included primary windows, and the highly insulating window (designated R-5 by Pennsylvania) qualified with a SIR of greater than 1.0. For low-E storm windows, previous analysis did not estimate a qualifying SIR of 1.0 due to the high capital cost; however, WVP partners conducted an analysis of low-E storm windows using 37 home types in the four distinct climate zones in the state and produced SIR results of 1.5-2.0 in all cases. DCED successfully updated their priority list to include low-E storm windows with emissivity no greater than 0.22 . In the update, the "R-5" windows also remained on the DCED's priority list of weatherization retrofits with U-factor no greater than 0.20 for fixed windows and U-factor no greater than 0.22 for operable windows. ${ }^{1}$

\subsubsection{Updated Storm Window Certification}

During the research to determine specifications for low-E storm window products there was great difficulty in finding a suitable standard to use as a requirement for structural certification programs. AAMA had indicated to PNNL that no company had approached them about enrolling in such a program in more than a decade. As a result, the decision was made to use the AAMA 1002.10-93 standard for the WVP specifications although it had been written almost 18 years earlier and had not been revised. In 2011 AAMA created a task group assigned to revise the standard. PNNL invited industry partner Larson Manufacturing Company to work with the task group to create an updated version of the standard, which was completed by the end of the calendar year. This version was used in the industry-wide universal standard called the NAFS which is updated every three years. The NAFS-2011 includes the first appearance of a secondary storm product since its inception in 2002.

\subsubsection{Utility Incentives}

In 2011 the Energy Trust of Oregon (ETO) and their two member gas utilities (Northwest Natural and Cascade Natural Gas) adopted incentive programs specific to high performance windows. ETO approached the program staff about requirements for a new high performance window tier of their incentive program and aligned their specifications with those used in the WVP program.

Questar Gas of Utah created an incentive of $\$ 2.50 / \mathrm{ft}^{2}$ for highly insulating windows and used a link to the WVP website to indicate the products that were eligible for the incentive. PacifiCorp of Washington state created an incentive of up to $\$ 3.50 / \mathrm{ft}^{2}$ for their customers installing primary windows with a U-factor of 0.20 or less. Previous to the WVP program, there were no utility incentives in the country specific to high performance windows that performed above the ENERGY STAR requirements.

\footnotetext{
${ }^{1}$ http://www.paweatherization.org/vertical/sites/\%7BF27E296C-7668-49FF-9408DF453C70C62E\%7D/uploads/\%7B0E7110B4-256C-4024-9007-233C2EB81D6A\%7D.PDF
} 


\subsection{Lessons Learned}

As with any program designed to increase the market penetration of emerging technologies, lessons are learned that can and should be applied to future market transformation projects. For this program, the most important lessons learned include:

- Engage Manufacturers Early and Often - Early in the program, face-to-face meetings were held with the window industry to discuss the program, gauge their interest in the program and obtain their feedback. This engagement continued over the course of the program in multiple venues including technical meetings (e.g., NFRC, AAMA), conferences and trade shows (e.g., GlassBuild, Fenestration Week, International Builders Show), conference calls, webinars, stakeholder and partner meetings (e.g., CEE), at the program workshops, and in manufacturer-hosted venues. ${ }^{1}$ The manufacturers were kept involved in the development of the specifications with at least two formal reviews requested in each phase of the program.

Most importantly, the manufacturers saw evidence that their comments and concerns were being recognized and addressed in the specifications, and in the program design and execution. It is also important to understand that not all manufacturers will agree with the decisions and may make informal or even formal complaints to DOE about a program with which they disagree. Therefore it is also important to document the engagement with industry and the outcome as part of monthly project reporting.

- Develop Sustained Partnerships with Stakeholders - The program engaged a strong core team, with each team member bringing unique technical skills and experience in engaging with stakeholders. Early on, the team members reached out to stakeholders and industry to ascertain their interest and support for a highly insulating WVP program. Letters of support from a broad spectrum of agencies and organizations were obtained from over 20 interested parties, some of whom were potential buyers of the window products. Stakeholders were in turn instrumental in reaching out to their constituencies with program information and support. Also important was to regularly engage the stakeholders through multiple venues to keep them informed. For this program this included, but was not limited to, a regularly updated WVP program website, e-mailing list for program updates, development and distribution of press releases and fact sheets, contact through social media such as LinkedIn, and personal contact including face-to-face meetings, conferences and trade shows.

- Understand Industry Business Models - It is important early in a market transformation program to have a basic understanding of the business model for the industry providing the product. This includes the product distribution and pricing structure. This is particularly important for achieving price-point goals and to increase market share of the product. Early in the program there was considerable pushback from the manufacturers to showing prices for window products for each vendor given the industry pricing and distribution paradigm. Many window manufacturers, primarily the larger manufacturers, used extensive distribution networks (including big-box stores) and did not sell directly from the manufacturing plant to the public. The dealers and distributors set the final window price, which for many dealers and distributors included installation (a value-added service). A highly efficient window can pass through a distributer to a window contractor to a home builder and experience several markups in addition to the labor cost of installation. What was not clear at the

\footnotetext{
${ }^{1}$ For example, WVP core team members toured the manufacturing plants of several of the qualified vendors in the program including IGU manufacturing facilities.
} 
onset of the program was the minimal role which many manufacturers play in setting the final price to purchasers and the requirement of professional labor to have the windows installed correctly.

Therefore, in Phase I of the program there were windows of a given type and size which varied in price by more than ten to one.

One of the key elements of a volume purchase program is competition between participating vendors, and that could best be created by displaying discrete prices. It was anticipated that the demand created through the program combined with displaying prices would entice manufacturers to develop innovative methods to fabricate and distribute their products less expensively and that the entire industry would gain from these innovations. Therefore, when the decision was made based on purchaser feedback and the desire to spur competition to show discrete prices in Phase II, many of the vendors dropped out of the program because they were unable to accurately estimate the final prices that might be seen from their network of thousands of dealers. Attempts to change the existing business model of the industry for the good of the purchaser was met with resistance from many of the manufacturers and many saw interference with the pricing mechanisms as a form of intrusion. Therefore, the discrete pricing was removed for the extension of Phase II.

For this particular product, it may have been more efficient to work directly with the dealers. This would have required accepting bids from possibly hundreds of vendors depending upon how the manufacturers chose to work with their dealers. This approach would have given accurate pricing and resulted in vendors who were dealers having more knowledge of, and investment in, the program. Validation of the products' performance could still be done on the manufacturer level so that each dealer selling a given brand would not need to be validated again.

- Streamline Sales Reporting - A critical outcome of the program was window sales data. In Phase I the vendors were requested to report sales generated from the program on a monthly basis. A form was provided and the data requested were the aggregated total number of windows and the aggregated value of those windows. The agreement with the vendors was that the individual vendors' sales would not be made public. The sales reporting via electronic files was much more onerous than anticipated with many of the vendors not reporting (even if there were no sales). The core issue for almost all vendors, even those providing sales data, was the difficulty in separating out sales of highly insulating windows and low-E storm windows originating from this program (the WVP website) from the total sales of these window products by the vendor. This was particularly burdensome for the larger manufacturers with multiple distributors across the country. Posting the name of the quarterly 'sales leader' on the WVP vendor and DOE WVP website or the potential for removing the vendor from the WVP vendor website did not substantially change the reporting behavior of the vendors.

Reporting requirements were changed for Phase II to request that the vendors provide sales data for any highly insulating window product sold as a way to lessen the burden on the vendors. The reporting frequency improved somewhat, but was not consistent and contacting the vendors to request sales reports required significant staff time. Future technology procurement/purchase programs will be well-served by developing a sales reporting strategy very early on with the vendors and at the same time create an incentive structure for timely and accurate reporting. 


\section{Appendix A}

\section{Education and Outreach Summary for Windows Volume Purchase Program}





\section{Letters of Support}

Letters of support for the program were solicited and received prior to the launch of Phase I. These letters were posted on the DOE Windows Volume Purchase web site and included:

- Pierce and Associates

- Apartment and Office Building Association of Metropolitan Washington (AOBA)

- Building America Industrialized Housing Partnership (BAIHP)

- Clayton Homes

- Commonwealth of Massachusetts

- Community and Economic Development Association of Cook County, Illinois (CEDA)

- Consortium for Energy Efficiency (CEE)

- Curtain Wall Design \& Consulting (CDC)

- Davis Energy Group

- Energy Trust of Oregon

- Fenestar

- Habitat for Humanity
- IBACOS, Inc.

- Jordan, Knauff \& Company

- Midwest Energy Efficiency Alliance (MEEA)

- National Community Action Foundation (NCAF)

- Northwest Power and Conservation Council (NWPCC)

- NP Group, Inc

- Palm Harbor Homes

- Systems Building Research Alliance (SBRA)

- The Window Man

- Youthbuild USA

- ZETA

\section{Regional Workshops}

Educational workshops were held during both Phase I and Phase II of the program in several regions of the country to reach out to buyers and stakeholders with information on the WVP Program and the attributes of highly insulating windows. At each workshop, the qualified vendors in the program were invited to display their windows and speak to the attendees. These workshops and the key partners who helped organize, advertise and support the workshop included:

Phase I

- Midwest Regional Workshop Chicago, IL - September 22, 2010

Key Partners: City of Chicago, State of Illinois, CEDA, and MEEA

- Pacific Northwest Regional Workshop Portland, OR - October 11, 2010

Key Partners: Energy Trust of Oregon, Northwest Natural

- Mid-Atlantic Regional Workshop Philadelphia, PA - October 20, 2010

Key Partners: Energy Coordinating Agency, Philadelphia

- Ohio Regional Workshop Columbus, $\mathrm{OH}$ - April 26, 2011 
Key Partners: State of Ohio (Ohio Energy Resources Division), The Ohio State University, The Ohio State University Extension, Ohio Home Builders Association, Mid-Ohio Regional Planning Commission, Green Energy Ohio, AEP Ohio, University Clean Energy Alliance of Ohio

Phase II

- Utah Regional Workshop

Clearfield, Utah - May 4, 2011

Key Partners: Intermountain Weatherization Training Center, State of Utah's Weatherization Program, Governor's Office, Utah Division of Facilities Construction and Management, Utah Valley University Construction Technologies, Utah Home Performance with Energy Star, Questar Gas ThermWise Rebate Program, Utah Clean Energy, UBEES, Southwest Energy Efficiency Project, State Energy Program, Rocky Mountain Power

- Montana Regional Workshop Bozeman, MO - July 27, 2011

Key Partners: U.S. Department of Housing and Urban Development, Montana State University Extension Housing Program, and Montana Weatherization Training Center

- Colorado Regional Workshop Denver, CO - October 4, 2011

Key Partners: State of Colorado, City of Denver, NAHB of Colorado, National Renewable Energy Laboratory (NREL)

\section{Webinars}

Webinars were held during both Phases of the program to educate potential buyers and stakeholders similar to the Workshops. The webinars were generally organized by agencies interested in deploying and/or specifying and promoting the highly insulating windows.

Phase I

- Alliance Webinar: Window Energy Efficiency Beyond Business as Usual June 11, 2009

- "Cost-Effective Triple Pane (R-5) and Low-e Storm Windows - Available Now" $D O E / B T$

June 22, 2010

- Habitat for Humanity International

February 1, 2011

Phase II

- Youthbuild USA

April 12, 2011

- Apartment and Office Building Association of Metropolitan Washington June 7, 2011

- National Association of Realtors Webinar July 12, 2011

- Association of Energy Services Professionals (AESP) Brown Bag July 14, 2011

- MEEA Membership and Stakeholders

July 19, 2011 
- DOE/BT Commercial Buildings Energy Alliance (CBEA)

October 12, 2011

- Mountain West Region

November 16, 2011

- NAHB

December 14, 2011

\section{Presentations}

Technical presentations were made at industry events by the WVP core team to educate potential buyers about the program and the benefits of highly insulating windows.

Phase I

- Glass Expo Midwest Chicago, IL - Mar. 162009

- American Hotel \& Lodging Association Committee Meeting Washington, DC - April 29, 2009

- Ohio State Physical Plant Managers' Committee Meeting Columbus, OH - May 18, 2009

- National Fenestration Rating Council Meeting /Efficient Windows Collaborative Baltimore, MD - July 21, 2009

- National Weatherization Conference Indianapolis, IN - July 20-23, 2009

- GlassBuild Annual Conference Atlanta, GA - September 30, 2009

- Thermal Performance of the Exteriors Envelopes of Whole Buildings XI International Conference Clearwater Beach FL - December 5-9

- International Builders Show (IBS) Trade Show In cooperation with Building America/ORNL Las Vegas, NV - January 2010

- Northeast Sustainable Energy Association Conference Boston, MA - March 9, 2010

- DOE's Better Buildings Workshop Washington, DC - July 8, 2010

- American Hotel \& Lodging Association Committee Meeting Washington, DC - September 1, 2010

- GlassBuild Annual Conference/Quanax-Hosted Presentation Las Vegas, NV - September 15, 2010

- Consortium for Energy Efficiency Industry Partners Meeting Chicago, IL - September 16, 2010

- AAMA Fall National Conference Santa Ana Pueblo, NM - October 11, 2010

- Colorado Utility Efficiency Exchange Conference Aspen, CO - October 14, 2010

- NWDA Association Meeting York, PA - January 25, 2011 
- DOE/Federal Energy Management Program Staff

Washington, DC - March 10, 2011

- NCAF Conference

Washington, DC - March 12, 2011

- AAMA Western Region Meeting

Tempe, AZ - April 6, 2011

- Fenestration Day

Indianapolis, IN - April 7, 2011

- American Hotel \& Lodging Association Committee Meeting Washington, DC - September 1, 2011

- BF Rich R-5 Event

Newark, DE - April 2, 2011

- YKK AP America, Inc. 2011 National Sales Meeting

Stone Mountain, GA - April 20, 2011

Phase II

- NAHB Green Building Conference \& Expo (Phase II Kickoff Meeting)

Salt Lake City, UT - May 3, 2011

- AAMA Meeting

Minneapolis, MN - June 7, 2011

\section{Trade Shows}

WVP core team participated in targeted industry trades shows by sharing or staffing a booth with educational materials about the WVP Program. These included:

Phase I

- 2009 Greenbuild Conference Phoenix, AZ

- 2010 International Builders Show Las Vegas, NV

- 2010 Northwest Energy Efficiency Partnership (NEEP) Conference Boston, MA

- 2010 EEBA Conference Portland, OR

- 2010 Greenbuild Conference Chicago, IL

- 2011 Cincinnati Home and Garden Show Cincinnati, $\mathrm{OH}$

- 2011 Building Energy Conference Boston, MA

- 2011 CT Home \& Remodeling Show Hartford, CT
- 2011 Habitat for Humanity International Conference (Atlanta, GA)

Phase II

- 2011 NAHB Green Building Conference Salt Lake City, UT

- 2011 BF Rich R-5 Event Newark, DE

- 2011 Annual Utility Energy Forum Asilomar, CA

- 2011 PHADA Conference New Orleans, LA

- 2012 International Builder's Show Orlando, FL 


\section{Media Coverage}

Media coverage for the program was extensive and included articles developed by the WVP staff and also developed by the trade media from press releases (Phase I and Phase II) fact sheets and presentations at conferences and meetings.

Phase I

- DWM (Door \& Window Manufacturer) Magazine - July 20, 2010. “Will R5 become R future?” http://www.dwmmag.com/index.php/will-r5-become-r-future/

- DWM (Door \& Window Manufacturer) Magazine - June 22, 2010. “DOE officials say they plan to market R5 Volume Purchase Program aggressively."

http://www.dwmmag.com/index.php/doe-officials-say-they-plan-to-market-r5-volumepurchase-program-aggressively/

- Nation's Building News - June 14, 2010. “Highly efficient windows available at a reduced price." http://www.nbnnews.com/NBN/issues/2010-06-14/Green+Building/4.html

- BuildingGreen Online - June 10, 2010. "DOE Launches Website for Affordable, High Efficiency Windows." http://www.buildinggreen.com/auth/article.cfm/2010/6/10/DOE-LaunchesWebsite-for-Affordable-High-Efficiency-Windows/?redirsupercede $=0$

- Greening Schools - May 28, 2010. “DOE launches the High Efficiency Windows Volume Purchase Program." http://www.greeningschools.org/news/?start=11

- National Association of State Energy Officials - May 28, 2010. "DOE Launches the high efficiency windows volume purchase program." http://www.naseo.org/news/newsletter/2010-05-28.htm

- DWM (Doors and Windows Magazine) Online - May 28, 2010. "DOE Kicks Off Windows Volume Purchase Program with Event in Washington, D.C." http://www.dwmmag.com/index.php/doe-kicks-off-windows-volume-purchase-programwith-event-in-washington-d-c/

- Window \& Door Magazine - May 28, 2010. “R-5 Window Site Goes Live.” http://www.windowanddoor.com/news-item/government/r-5-window-site-goes-live

- Glass Magazine - May 28, 2010. "DOE launches high-efficiency windows volume purchase program." http://www.glassmagazine.com/news-item/commercial/doe-launches-highefficiency-windows-volume-purchase-program123

- NRDC Switchboard - May 27, 2010. "DOE paves the way for super efficient windows with new program." Lane Burt's blog. http://switchboard.nrdc.org/blogs/lburt/doe_paves_the_way_for_super_ef.html 
- Environmental Leader - May 28, 2010. “DOE connects high-efficiency window suppliers with buyers." http://www.environmentalleader.com/2010/05/28/doe-connects-high-efficiencywindow-suppliers-with-buyers/

- DOE's goal to make R-5 energy-saving windows more affordable ...

Feb 16, 2011 ... That's why the DOE's Building Technologies Program is boosting the development of R-5 value windows for widespread use. ... http://www.proudgreenhome.com/article/179400/DOE-s-goal-to-make-R-5-energy-savingwindows-more-affordable

- Commercial Windows Included in Phase II of Window Volume Purchase Feb 1, 2011 ... The Department of Energy announced last week that Phase Two of the Windows Volume Purchase Program, commonly referred to in the industry as ... www.usgnn.com/newsPhase20110201.htm

- Energy Star Replacement Windows : Dept of Energy : Marc LaFrance ... The R-5 Window Program only allows windows with the highest $\mathrm{R}$ ratings or better said the Lowest U Values. U.22 for operating windows and $.20 \mathrm{U}$ value for....http://www.windowandsiding.com/LearningCenter/EnergyStarList.htm

- DOE Aims to Make 'Low E' Windows a Must-Have for Home Construction ... Jun 2, 2010 ... The volume purchase program covers windows with an "R-value" of 5, signifying a high resistance to heat passing through....

www.nytimes.com/.../02greenwire-doe-aims-to-make-low-e-windows-a-must-have-for11276.html

- Charlotte, NC New and Replacement Windows, Sunrooms, Home Siding ...

Definition of the program. The Department of Energy (DOE) volume purchase project for $\mathbf{R}-\mathbf{5}$ highly insulating windows helps window buyers by developing a ... www.carolinabuildinggroup.com

- SiteMap - Modern View Window Systems, quality replacement windows DOE R5 Program Windows · 3200 Replacement Patio Door · 3200 Replacement Patio Door with Grids $\cdot 3200$ New Construction Patio Door 3200 New Construction ... www.modernviewwindows.com/Page/SiteMap

- R-5 PROGRAM MAY PROMOTE RE-THINKING OF TRIPLE GLAZING. - States. Nov 30, 2010 ... Insulating R-5 Window and Low-E Storm Window Volume Purchase Program." Series 200 vinyl windows by Crystal Window and Door . www.highbeam.com/doc/1G1-243132134.html

- U.S. DOE Offering Volume Discounts on R-5 Windows - Northwest ...

R-5 windows have a U-factor of around 0.2 and are at the top tier of ... To learn more about this program, visit www.windowsvolumepurchase.org ...

www.ecobuilding.org/guild-chapters/seattle/news-1/sheri-is-our-vp

- DOE Kicks Off R-5, Low-E Window Program May 26, 2010 ... The agency's Builder Technologies Program has readied a special web page ... Tags: DOE, low-e windows, national, R-5 windows, triple-glazed ... www.greenbuildingadvisor.com/book/export/html/17110 
- Window and Siding : Replacement Windows : NJ Window Contractors ...

The Department of Energy (DOE) on February 19, 2010 kicked off the New R-5 Window

Program. This program was developed for two reasons, one to help educate ...

www.windowandsiding.com

- R-5 Window Volume Purchase Program | DWM/Shelter Magazine

DWM provides of list of manufacturers participating in the R-5 Window Volume Purchase

Program.

www.dwmmag.com/index.php/r-5-windows/

- Home Energy Savings \& Information: R-5 Windows

Dec 14, 2010 ... R-5 windows are windows which meet the energy savings standard of .22u

value for operating windows and $.20 \mathrm{u}$ value for fixed windows. ...

http://johnkamor.blogspot.com/2010/12/r-5-windows.html

- View gallery of windows and doors from National Viny

The US DOE is working with window manufacturers, such as National Vinyl, to offer competitive

pricing on R-5 windows. Would you like to find out where to ...

www.nvpwindows.com/R-5

- High R-value windows the best energy-saving upgrade - macombdaily.com

Oct 14, 2010 ... In Edminster's single-pane (R-1) window replacement scenario, an upgrade to R-

5 windows produced a dramatic 38.4 percent energy-saving ...

www.macombdaily.com/articles/2010/10/.../srv0000009573387.txt

- Best energy efficient windows

Jump to New R-5 standard for windows: All R-5 windows must be - you guessed it - about R-5 or better. In fact the specification requires ...

www.green-energy-efficient-homes.com/best-energy-efficient-windows.html

- High R-Value Windows Are Best Choice to Improve Home Energy Savings

Aug 3, 2010 ... In the single pane (R-1) window replacement scenario, the $\mathbf{R}-\mathbf{5}$ window upgrade

yielded a dramatic 38.4 percent improvement (with a 1.05

www.globenewswire.com/newsroom/news.html?d=198260

- The WAP Effect: High-Efficiency Windows \& The Dilemma (Tyranny ...

The focus was on high-end R-5 window technologies, but lower-cost products, such as low-E storm windows, and the specific needs of low-income weatherization ...

www.slideshare.net/.../the-wap-effect-highefficiency-windows-the-dilemma-tyranny-of-

audit-algorithms

- Manufacturers | ebuild.com | Vinyl Windows--Single Units

This breakthrough enables window producers to meet the growing demand for $\mathbf{R}-\mathbf{5}$ windows

with less expense and less disruption to their manufacturing ..

www.ebuild.com/windows.../vinyl-windows--single-units.hwx

- NFRC News Now: DOE to Launch R-5 Program Tomorrow at NAHB

May 26, 2010 ... DOE to Launch R-5 Program Tomorrow at NAHB ... DOE reports that 50

companies submitted proposals to participate in the $\mathbf{R}-\mathbf{5}$ windows program. ...

http://nfrcnews.blogspot.com/2010/05/doe-to-launch-r-5-program-tomorrow-at.html

- R-5 Insulating Properties Possible from Windows and Doors Using ... 
Oct 19, 2010 ... Paul Bush, PPG manager technical services, performance glazings, said R-5 windows, which by definition have a U-value of 0.20 or less, www.azobuild.com/news.asp?newsID=12145

- DOE Program Expands Market for Highly Efficient Windows | Alliance ... Oct 24, 2010 ... Despite the amount of energy that R-5 Windows can save, ... The program's window products are triple pane, with a $\mathrm{U}$-factor of around 0.2 .... http://ase.org/efficiencynews/doe-program-expands-market-highly-efficient-windows

- B.F. Rich Windows \& Doors Recognized as Top Seller in DOE's R-5 ... Jan 11, 2011 ... B.F. Rich, based in Newark, Del., has been recognized as a "2010 Top Seller" in the U.S. Department of Energy's High-Performance R-5 Windows ... www.dwmmag.com/.../b-f-rich-windows-doors-recognized-as-top-seller-in-doe's-r-5-program

- The ENERGY STAR and R-5 Standards for Windows

Feb 4, 2011 ... All R-5 windows must be - you figured it out- around R-5 or more new windows and having them installed http://ezinearticles.com/?The-ENERGY-STAR-and-R-5-Standards-forWindows\&id $=5860648$

- Energy Efficient Windows Available through DOE Volume Purchase Program Aug 10, 2010 ... Through the U.S. Department of Energy's (DOE) Highly Insulating R-5 Windows and Low-e Storm Windows Volume Purchase Program, distributors, ... www.qualifiedremodeler.com/...Windows...Program/39\$2156

- $\quad$ R-5 Triple Glass : Replacement Windows : energy efficient windows ... Triple glass windows are the only window that qualify for the Department of Energy R-5 Volume Window Program. Triple glazed windows are the best. www.windowandsiding.com/triple_glass_windows.htm

- High Efficiency Windows Volume Purchase... - EcoRenovator Feb 3, 2010

The phase II RFP for the Windows Volume Purchase Program (WVP) has been ... Successful use of triple-pane R-5 windows in concert with an ... http://ecorenovator.org/forum/conservation/1423-high-efficiency-windows-volumepurchase.html

- Production Engineering and Commercialization of Residential R 5 ... Estimated Total Program Funding: Information not provided ... The $\mathbf{R}-\mathbf{5}$ windows are to achieve a whole window National Fenestration Rating Council (NFRC) ... www.federalgrants.com/Production-Engineering-and-Commercialization-of-Residential-R-5Highly-Insulating-Windows-12599.html

- $\quad$ FedCenter - Cost-Effective Triple Pane ( $\underline{\mathbf{R}}-\underline{\mathbf{5}})$ and Low-e Storm ... Jun 22, 2010 ... Cost-Effective Triple Pane (R-5) and Low-e Storm Windows ... Offered by the U.S. Department of Energy's (DOE) Building Technologies Program, ... http://www.fedcenter.gov/Events/index.cfm?id=15051\&date=06/22/2010\&pge_prg_id=0\&pg e_id $=0$

- Highly-Insulating (R-5*) Windows and Low-e Storm Windows Volume ... 
Description:The U.S. Department of Energy's Building Technologies Program (BTP) is coordinating a volume purchase of R-5 windows, and low-e storm windows, ... http://energyexperts.org/EnergySolutionsDatabase/ResourceDetail.aspx?id=5212

- Window Volume Purchase Program Working to Lower Cost, Improve ... Window Volume Purchase Program Working to Lower Cost, Improve Availability. May 18, 2010 1:28pm | By mlyles. R-5 windows can reduce average heat loss by ... www.newbuildings.org/window-volume-purchase-program-working-lower-cost-improveavailability

- A Market Transformation for Windows eere.energy.gov. 9. Technology Procurement. Highly Insulating (R5) Windows and. Low-e Storm Windows. Volume Purchase Program ... www.cee1.org/cee/mtg/09-10mtg/.../Thu_Windows2_Mapes

- Haddon Windows \& Doors Announces Promotional \$499 Installed Price ...

Aug 24, 2010 ... Haddon is a Certified Vendor in the Department of Energy's R-5 Highly Insulating Windows Volume Purchase Program. Visit www.haddonwindows. ... www.seopressreleases.com/haddon-windows...windows/11989

- About National Vinyl LLC, newsworthy items, articles, Chicopee MA ... On May 27th the U.S. Department of Energy (DOE) announced the launch of the HighlyInsulating R-5 Windows and Low-e Storm Windows Volume Purchase Program, ... www.nvpwindows.com/in_the_news.html

- R-5: A Window on the Future - Remodeling Magazine Jan 10, 2011 ... The DOE's R-5 Windows Volume Purchase Program is about more than saving ... R-5 windows are the focus of the program, offering a U-factor of ... www.remodeling.hw.net/windows/r-5-a-window-on-the-future.aspx

- Vinyl Windows--Bay/Bow | Truseal Introduces $\underline{\mathbf{R}}-\underline{\mathbf{5}}$ Double-Pane IG ... To achieve R-5 ratings (U-values of 0.22 for operable windows and 0.20 for ... aligns with the Department of Energy's R-5 Windows Volume Purchase Program. www.ebuild.com/articles/1492736.hwx

- Government raising bar on windows - chicagotribune.com Jan 15, 2010 ... The Department of Energy is trying to get window manufacturers to partner in a program to offer volume discounts on $\mathbf{R}-\mathbf{5}$ and low-e storm ... www.chicagotribune.com

- The R5 Windows Program: Efficiency Made Budget friendly | 4rticle ... Jan 31, 2011 ... Most of us value efficiency in our everyday lives, specifically as it relates to our budget. Even though cost effective windows can help to ... www.4rticle.com/the-r5-windows-program-efficiency-made-budget-friendly-75398.html

- Energy-efficient R-5 windows coming to market in 2011 ... Jan 17, 2011 ... Ply Gem, a large building-products manufacturer displayed its entry into the R-5 window program at the International Builders' Show. ... www.proudgreenhome.com/.../Energy-efficient-R-5-windows-coming-to-market-in-2011

- Will Triple Pane R-5 Windows Become the Norm? | Green Talk ${ }^{\mathrm{TM}}$ 
Nov 4, 2009 ... The volume purchasing program will help increase demand for these energy saving R-5 windows, just like the renewable energy tax incentives www.green-talk.com/.../will-triple-pane-r-5-windows-become-the-norm/

- DOE Officials Say They Plan to Market R5 Volume Purchase Program ... Jun 22, 2010 ... Most windows in program have a U- factor of .22 or lower (depending ... also pointed out to attendees that $\mathbf{R} 5$ windows will make the biggest http://www.dwmmag.com/index.php/doe-officials-say-they-plan-to-market-r5-volumepurchase-program-aggressively/

- R5 Windows Volume Purchase Program The U.S. Department of Energy (DOE) Building Technologies Program launched the R-5 Windows Volume Purchase Program that gives manufacturers an opportunity http://www.edgetechig.com/manufacturers/page .aspx?pid=195

- The R-5 Windows Program: Efficiency Made Affordable Jan 21, 2011 ... For years, cost has prevented consumers from embracing the most energy efficient windows. The Department of Energy has embarked on a program http://ezinearticles.com/?The-R-5-Windows-Program:-Efficiency-MadeAffordable\&id $=5768090$

- $\quad$ R5 vs. R3.33 Windows - Colorado Windows - Denver | SolarGlass Jun 22, 2009 ... The Department of Energy is pushing a volume purchase program to help drive the cost of R5 windows down to an acceptable premium. ... www.solarglass.com/2009/06/22/r5-vs-r333-windows/

- R5 windows | Glass Magazine Chelsea Building Products, Oakmont, Pa., will introduce its R5 thermal performing window products. Chelsea products that achieve $\mathbf{R} \mathbf{5}$ and better include: ... www.glassmagazine.com/product/commercial/r5-windows

- Highly Insulating Windows for Utility Energy Efficiency Programs Sep 16, 2010 ... Highly insulating (R5) windows are here now. DOE's Volume Purchase Program Available today from many suppliers ... www.cee1.org/cee/mtg/09-10mtg/Presentations/Thu_Windows2_Roy.pdf

- DOE Launches Website for Affordable, High-Efficiency Windows ... Jun 10, 2010 ... Windows in the 400 Series from Andersen are offered to meet the $\mathbf{R}-\mathbf{5}$ criteria of DOE's bulk purchase program. Hoping to make high-efficiency ... www.buildinggreen.com/.../DOE-Launches-Website-for-Affordable-High-Efficiency-Windows

- Windows and Low-e - Highly-Insulating (R-5) Windows and Low-e ...

The DOE Building Technologies. Program has embraced the strategic goal of developing netzero-energy buildings. Highly insulating R-5 windows are ... www.ecoshieldwindows.com/.../R5/windows_volume_purchase_program_summary.pdf

- About Maintenance Free Windows | Window Replacement in Atlanta On May 27, 2010, the U.S. Department of Energy today announced the launch of the HighlyInsulating R-5 Windows Volume Purchase Program. ... www.maintenancefree.com/about_us.html

- Efficiency: DOE aims to make 'low E' windows a must-have for home ... 
Jun 2, 2010 ... The volume purchase program covers windows with an "R-value" of 5, signifying a high resistance to heat passing through....

www.eenews.net/public/Greenwire/2010/06/02/14

- DOE Launches Website for High-Efficiency Windows - Building Ecology

The U.S. Department of Energy today announced the launch of the Highly-Insulating R-5

Windows and Low-e Storm Windows Volume Purchase Program, ...

www.buildingecology.com/.../doe-launches-website-for-high-efficiency-windows/

- WoW Summer 2009

is produced with funding from the Windows and. Glazings Program at the ... R-5 window price to spur market demand. This project, referred to as the www.efficientwindows.org/newsletter/WoWSummer2009.pdf

- High R-value windows the best energy-saving upgrade - macombdaily.com

Oct 14, 2010 ... In Edminster's single-pane (R-1) window replacement scenario, an upgrade to R-

5 windows produced a dramatic 38.4 percent energy-saving ...

www.macombdaily.com/articles/2010/10/.../srv0000009573387.txt

- Department of Energy's R5 Volume Purchase Program | SolarGlass Nov 13, 2009 ... Department of Energy's R5 Volume Purchase Program. Posted on the 13 November, 2009 at 4:22 pm Written by Gwenael Hagan in Energy \& Window ...

www.solarglass.com/.../department-of-energys-r5-volume-purchase-program

- Emerging Technologies: R-5 Windows | Clean and Efficient Energy ...

Promotion of R-5 windows through utility programs could include customer education about window selection criteria as well as incentives for installing R-5 ... http://cleanefficientenergy.org/resource/emerging-technologies-r-5-windows

- Windows (R5) - Vinyl Replacement Windows Discussion Board Jan 22, 2009

They have mentioned a Windows Company in Maine (starts with a P) they manufacture R5 windows at $1 / 2$ the cost. ( $\$ 35$ per sq ft) We are window ...

www.vinyl-replacement-windows.com

- High Energy-Efficient R-5 Windows Available for Homebuilders and ...

Aug 11, 2010 ... Through the U.S. Department of Energy's (DOE) Highly Insulating R-5 Windows and Low-e Storm Windows Volume Purchase Program, distributors, ...

www.azobuild.com/news.asp? newsID=11352

- Composite Windows--Single Units | Truseal Envirosealed Windows ...

Duralite enables manufacturers to produce Envirosealed Windows with R-5 ratings in both ... Truseal has developed a comprehensive marketing program for ...

www.ebuild.com/articles/1492734.hwx

- DOE Launches Program to Boost Use of Energy-Efficient Windows ...

May 27, 2010 ... The program is meant to pair "manufacturers with buyers looking to ...

According to DOE, "R-5 Windows can reduce heat loss through the ...

http://planetgreen.discovery.com/home-garden/doe-launches-program-to-boost-use-ofenergy-efficient-windows.html

- Choosing Triple-Glazed Windows | GreenBuildingAdvisor.com 
Mar 26, 2010 ... The U.S. Department of Energy's Building Technologies Program (BTP) is coordinating a volume purchase of R-5 windows, and low-e storm ... www.greenbuildingadvisor.com/.../choosing-triple-glazed-windows

- Pacific Northwest - Low E storm windows.com home page Department of Energy's Highly Insulating (R-5) Windows and Low-e Storm Windows Volume Purchase Program http://lowestormwindows.com/LowEStorm\%20Program\%20Letters.pdf

- Haddon Launches Dual Pane R-5 Windows | Window \& Door Aug 24, 2010 ... Haddon Windows \& Doors reports it is the first to offer an R-5 window ... R-5 window volume purchase program, according to the company. ... www.windowanddoor.com/.../haddon-launches-dual-pane-r-5-windows

- U.S. DOE Free Webinar: Cost-Effective Triple Pane (R-5) and Low-e ... Jun 7, 2010 ... Through the launch of a new DOE-sponsored volume purchase program, builders and distributors can buy these windows at a competitive price. ... http://www.buildinggreen.com/auth/article.cfm/2011/1/27/Choosing-Windows-LookingThrough-the-Options/

- Windows Volume Purchase Midwest Regional Workshop | Alliance to ...

Sep 22, 2010 ... Please join the Windows Volume Purchase Team and our partners at the Chicago Center for Green Technology, September 22-23, ... http://ase.org/event/windows-volume-purchase-midwest-regional-workshop

- DOE Windows Volume Purchase Program Phase II Comment - American Jan 13, 2011 ... The comment period for the Phase II specifications of the Windows Volume Purchase Program (WVP) has closed (specifications that were ...

www.aamanet.org/.../doe-windows-volume-purchase-program-phase-ii-comment-periodclosed-rfp-to-be-released-late-january

- The Efficient Windows Collaborative: Guidance DOE Highly-insulating Windows and Low-E Storm Windows Volume Purchase Program ... To qualify for the volume purchase program, windows must meet these ...

www.efficientwindows.org

- Highly-Insulating (R-5) Windows and Low-e Storm Windows Volume ... Jul 20, 2010 ... The windows volume purchase web page allows the user to browse through different window types... http://delafleur.com/blog/?p=1707

- DOE Gains Feedback in Volume Purchase Strategy Session February 3, 2012...The Department of Energy (DOE) hosted a strategy session yesterday which attracted many door and window manufacturers, as well as other interested parties, and served as a candid sharing of input regarding the DOE's Volume Purchase Program (VPP) for Windows. http://www.dwmmag.com/index.php/doe-gains-feedback-in-volume-purchase-strategysession/ 
Phase II

O Door and Window Manufacturer magazine, or DWM - May 2011. "Are you ready for phase two?" (by Terry Mapes, page 44) http://www.dwmmag.com/digital/2011/May2011.pdf

- Window and Door magazine - May 2011. "Phase II Begins for DOE Volume Purchase Program." (by Graham Parker) http://www.windowanddoor.com/article/may-2011/phase11-beginsdoe\%E2\%80\%99s-volume-purchase-program

- Nation's Building News - April 18, 2011. “DOE Expanding High Performance Windows Volume Purchase Program." http://www.nbnnews.com/NBN/issues/2011-04-18/Green+Building/index.html

- R\&D Magazine - May 2, 2011. "Making it easier to buy highly insulating windows." http://www.rdmag.com/News/Feeds/2011/05/energy-making-it-easier-to-buy-highlyinsulating-windows/

- Energy Efficiency in the Home - May 2, 2011. "Making it easier to buy highly insulating windows." http://www.energyefficiencyinthehome.co.uk/making-it-easier-to-buy-highlyinsulating-windows/

- Today's Facility Manager - May 2, 2011. "Commercial Fms Can Access DOE Window Purchase Program." http://www.todaysfacilitymanager.com/facilityblog/2011/05/commercial-fms-canaccess-doe-window-purchase-program.html

- IB Times' Green Economy - May 3, 2011. "Next phase of DOE's High Performance Windows Volume Purchase Program offers expanded website, product selection for residential and commercial buyers." http://uk.ibtimes.com/articles/20110503/next-phase-doe-039highperformance-windows-volume-purchase-program-offers-expanded-website-product-s.htm

- The Green Living Guy - May 2, 2011. "Next phase of DOE's High Performance Windows Volume Purchase Program offers expanded website, product selection for residential and commercial buyers." http://www.greenlivingguy.com/greenliving/next-phase-of-does-high-performancewindows-volume-purchase.html

- Green Environment News - May 2, 2011. "Making it easier to buy highly insulating windows." http://www.greenenvironmentnews.com/Environment/Energy/Making+it+easier+to+buy+hig hly+insulating+windows 



\section{Appendix B}

\section{Phase I Specifications}





\section{High Performance (R-5) Windows Specifications}

High Performance Windows Performance Specifications

\begin{tabular}{|c|c|}
\hline & Mandatory \\
\hline Thermal Performance & $\begin{array}{l}U \leq 0.20 \mathrm{Btu} / \mathrm{h}-\mathrm{ft}^{2}-\mathrm{F} \\
\mathrm{U} \leq 0.22 \mathrm{Btu} / \mathrm{h}-\mathrm{ft}^{2}-\mathrm{F}\end{array}$ \\
\hline Air Leakage & $\leq 0.30 \mathrm{cfm} / \mathrm{ft}^{2}$ (See Certification Requirements) \\
\hline $\begin{array}{l}\text { Warranty } \\
\text { Warranty }\end{array}$ & $\begin{array}{l}20 \text { years } \\
10 \text { years }\end{array}$ \\
\hline Warranty Details & $\begin{array}{l}\text { (glass) Warranted against visible obstruction through the glass } \\
\text { caused by defect or failure of the air seal around the glass. } \\
\text { Provider has option to repair, replace, or refund the glass. } \\
\text { (non-glass) Product is warranted to be free from defects in } \\
\text { manufacturing, materials, and workmanship. Provider has the } \\
\text { option to repair, replace, or refund the defective materials } \\
\text { and/or entire product. }\end{array}$ \\
\hline Frame Color & $\begin{array}{l}\text { All available frame colors are to be identified in the vendors' } \\
\text { bid. White is a preferred option. }\end{array}$ \\
\hline Size Categories & See Windows and Sliding Doors Matrices \\
\hline Minimum Order & See Windows and Sliding Doors Matrices \\
\hline Sales Reporting Requirements & $\begin{array}{l}\text { Volume Purchase Program vendors will be required to report } \\
\text { window sales monthly to PNNL. The purpose of reporting } \\
\text { sales is to assure PNNL that the products are sold to the } \\
\text { buyers at no greater than the base bid price*. The sales data } \\
\text { will not be shared with any other participant/vendor in the } \\
\text { volume purchase program nor outside of PNNL or the U.S. } \\
\text { Department of Energy. An example of a monthly sales report } \\
\text { spreadsheet is attached. The monthly sales report will be e- } \\
\text { mailed or faxed to Terry Mapes, PNNL Engineer. } \\
\text { Terry.Mapes@pnl.gov; Fax: } 509-372-4370 \text { by the 10th working } \\
\text { day of the following month. } \\
\text { *The base bid price is the price of the product bid into the } \\
\text { volume purchase program without customer-specified options } \\
\text { and less sales tax and delivery at the time of the specified date } \\
\text { of sale. }\end{array}$ \\
\hline
\end{tabular}

December 18, 2009 


\section{High Performance Windows Testing and Certification Requirements}

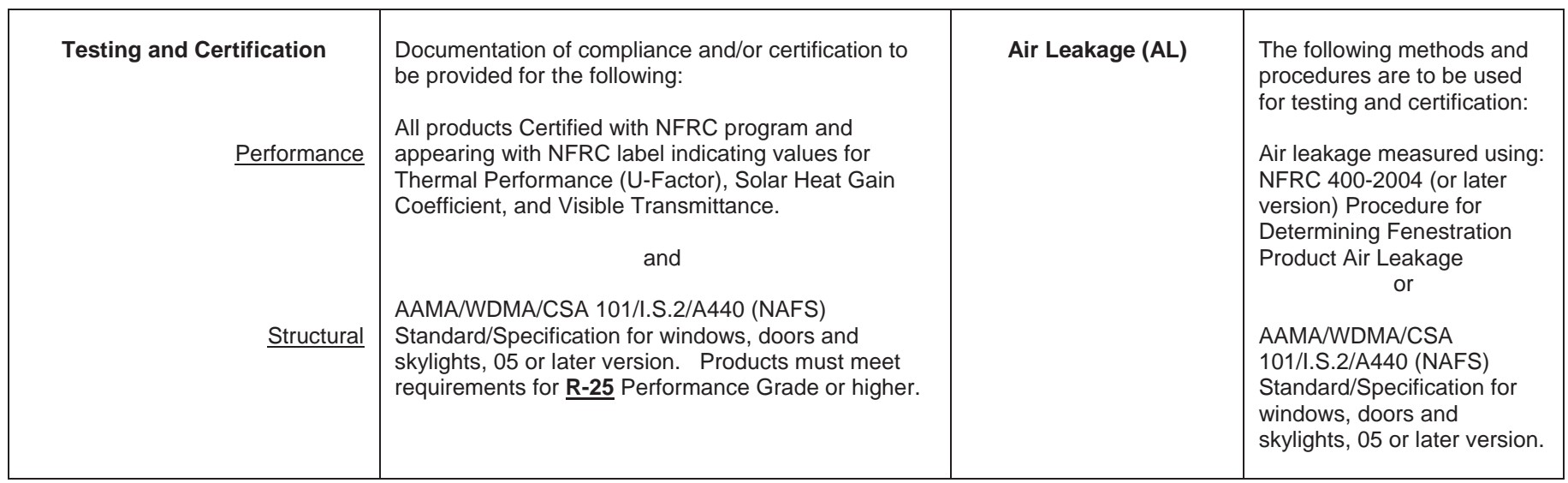

High Performance Windows and Sliding Doors Matrices

\begin{tabular}{|c|c|c|}
\hline $\begin{array}{c}\text { Single } \\
\text { Hung }\end{array}$ & $\begin{array}{c}\text { New } \\
(\$)\end{array}$ & $\begin{array}{c}\text { Retrofit } \\
(\$)\end{array}$ \\
\hline up to 50 UI & & \\
\hline $51-60$ UI & & \\
\hline $61-70$ UI & & \\
\hline $71-80$ UI & & \\
\hline $81-90$ UI & & \\
\hline $91-100$ UI & & \\
\hline $\begin{array}{c}\text { per UI over } \\
100\end{array}$ & & \\
\hline
\end{tabular}

\begin{tabular}{|c|c|c|}
\hline $\begin{array}{c}\text { Double } \\
\text { Hung }\end{array}$ & $\begin{array}{c}\text { New } \\
(\$)\end{array}$ & $\begin{array}{c}\text { Retrofit } \\
(\$)\end{array}$ \\
\hline up to 50 UI & & \\
\hline $51-60$ UI & & \\
\hline $61-70$ UI & & \\
\hline $71-80$ UI & & \\
\hline $81-90$ UI & & \\
\hline $91-100$ UI & & \\
\hline $\begin{array}{c}\text { per UI over } \\
100\end{array}$ & & \\
\hline
\end{tabular}

\begin{tabular}{|c|c|c|}
\hline Slider & $\begin{array}{c}\text { New } \\
(\$)\end{array}$ & $\begin{array}{c}\text { Retrofit } \\
\text { (\$) }\end{array}$ \\
\hline up to 50 UI & & \\
\hline $51-60$ UI & & \\
\hline $61-70$ UI & & \\
\hline $71-80$ UI & & \\
\hline $81-90$ UI & & \\
\hline $91-100$ UI & & \\
\hline $\begin{array}{c}\text { per UI over } \\
100\end{array}$ & & \\
\hline
\end{tabular}

\begin{tabular}{|c|c|c|}
\hline $\begin{array}{c}\text { Tilt and } \\
\text { Turn }\end{array}$ & $\begin{array}{c}\text { New } \\
(\$)\end{array}$ & $\begin{array}{c}\text { Retrofit } \\
(\$)\end{array}$ \\
\hline up to 50 UI & & \\
\hline $51-60$ UI & & \\
\hline $61-70$ UI & & \\
\hline $71-80$ UI & & \\
\hline $81-90$ UI & & \\
\hline $91-100$ UI & & \\
\hline $\begin{array}{c}\text { per UI over } \\
100\end{array}$ & & \\
\hline
\end{tabular}

\begin{tabular}{|c|c|c|}
\hline Casement & $\begin{array}{c}\text { New } \\
(\$)\end{array}$ & $\begin{array}{c}\text { Retrofit } \\
(\$)\end{array}$ \\
\hline up to 50 UI & & \\
\hline $51-60$ UI & & \\
\hline $61-70$ UI & & \\
\hline $71-80$ UI & & \\
\hline $81-90$ UI & & \\
\hline $91-100$ UI & & \\
\hline $\begin{array}{c}\text { per UI over } \\
100\end{array}$ & & \\
\hline
\end{tabular}

\begin{tabular}{|c|c|c|}
\hline Picture & $\begin{array}{c}\text { New } \\
(\$)\end{array}$ & $\begin{array}{c}\text { Retrofit } \\
(\$)\end{array}$ \\
\hline up to 50 UI & & \\
\hline $51-60$ UI & & \\
\hline $61-70$ UI & & \\
\hline $71-80$ UI & & \\
\hline $81-90$ UI & & \\
\hline $91-100$ UI & & \\
\hline $\begin{array}{c}\text { per UI over } \\
100\end{array}$ & & \\
\hline
\end{tabular}

\begin{tabular}{|c|c|c|}
\hline $\begin{array}{c}\text { Patio } \\
\text { Doors }\end{array}$ & $\begin{array}{c}\text { New } \\
(\$)\end{array}$ & $\begin{array}{c}\text { Retrofit } \\
(\$)\end{array}$ \\
\hline $\mathrm{L} \times \mathrm{H}$ & & \\
\hline $6^{\prime} \times 6^{\prime}-8^{\prime \prime}$ & & \\
\hline $8^{\prime} \times 6^{\prime}-8^{\prime \prime}$ & & \\
\hline $9^{\prime} \times 6^{\prime}-8^{\prime \prime}$ & & \\
\hline
\end{tabular}

\section{United Inches $(\mathrm{UI})=$ Length + Width}

Minimum orders $=15$ for retrofit windows, 20 for new windows. Purchasers may meet this minimum through any combination of window types and sizes found on the program website. Vendors may choose to honor orders for less than the required minimums at their discretion. The contents of the bins in the above matrices may change during the course of the program at the discretion of PNNL.

December 18, 2009 


\section{Energy Efficiency}

\section{and Renewable Energy}

\section{Internal and External Low-e Storm Windows Specifications}

\section{Low-e Storm Windows Performance Specifications}

\begin{tabular}{|c|c|}
\hline & Mandatory \\
\hline Emissivity & $<0.22$ \\
\hline $\begin{array}{ll}\text { Warranty } & \text { (glass) } \\
\text { Warranty } & \text { (non-glass) }\end{array}$ & $\begin{array}{l}10 \text { years } \\
10 \text { years }\end{array}$ \\
\hline Minimum Glass Thickness & $3 \mathrm{~mm}$ \\
\hline Warranty Details & $\begin{array}{l}\text { If a defect appears during the term of the warranty, the } \\
\text { provider can elect to: (1) repair the defective product, }(2) \\
\text { replace the defective materials or (3) refund the purchase } \\
\text { price. If replacement is elected, provider will not be responsible } \\
\text { for installation or refinishing of replacement parts. }\end{array}$ \\
\hline Frame Color & $\begin{array}{l}\text { All available frame colors are to be identified in the vendors' } \\
\text { bid. White is a preferred option. }\end{array}$ \\
\hline Size Categories & See Storm Windows Matrices \\
\hline Minimum Order & See Storm Windows Matrices \\
\hline Sales Reporting Requirements & $\begin{array}{l}\text { Volume Purchase Program vendors will be required to report } \\
\text { window sales monthly to PNNL. The purpose of reporting } \\
\text { sales is to assure PNNL that the products are sold to the } \\
\text { buyers at no greater than the base bid price*. The sales data } \\
\text { will not be shared with any other participant/vendor in the } \\
\text { volume purchase program nor outside of PNNL or the U.S. } \\
\text { Department of Energy. An example of a monthly sales report } \\
\text { spreadsheet is attached. The monthly sales report will be e- } \\
\text { mailed or faxed to Terry Mapes, PNNL Engineer. } \\
\text { Terry.Mapes@pnl.gov; Fax: } 509-372-4370 \text { by the 10th working } \\
\text { day of the following month. } \\
\text { *The base bid price is the price of the product bid into the } \\
\text { volume purchase program without customer-specified options } \\
\text { and less sales tax and delivery at the time of the specified date } \\
\text { of sale. }\end{array}$ \\
\hline
\end{tabular}

December 18, 2009 


\section{Energy Efficiency \\ and Renewable Energy}

Bringing you a prosperous future where energy

\section{Low-e Storm Windows Testing and Certification Requirements}

\begin{tabular}{|l|l|}
\hline \hline Testing and Certification & \multicolumn{1}{c|}{ Mandatory } \\
\hline \hline Performance & $\begin{array}{l}\text { Test in accordance with the following standards: } \\
\text { All glass materials must be registered in the International Glazing Database with } \\
\text { Lawrence Berkeley National Laboratory and measured in accordance with NFRC } \\
300-09,301-09, \text { and 302-09. }\end{array}$ \\
$\qquad \underline{\text { Structural }}$ & $\begin{array}{l}\text { ANSI/AAMA 1002.10-93 (or later version). Documentation of testing from } \\
\text { independent party is required, certification is not. Products must meet requirements } \\
\text { for } \underline{\mathbf{1 5}} \text { Performance Grade or higher. }\end{array}$ \\
\hline \hline
\end{tabular}

\section{Storm Windows Matrices}

\begin{tabular}{|c|c|}
\hline Storm & $\begin{array}{c}\text { New } \\
(\$)\end{array}$ \\
\hline up to $40 \mathrm{UI}$ & \\
\hline $41-65 \mathrm{UI}$ & \\
\hline $66-90 \mathrm{UI}$ & \\
\hline $90-115 \mathrm{UI}$ & \\
\hline $116-140 \mathrm{UI}$ & \\
\hline $\begin{array}{c}\text { per UI over } \\
140\end{array}$ & \\
\hline
\end{tabular}

United Inches (UI) = Length + Width

December 18, 2009 


\section{Appendix C}

Cover Letter: Request for Proposal (RFP) NO: 121400, December 19, 2009 



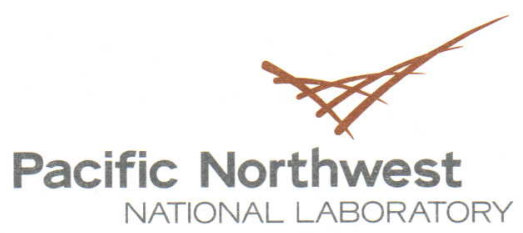

December 16, 2009

Dear Offeror,

REQUEST FOR Proposal (RFP) NO: 121400

Battelle Memorial Institute, Pacific Northwest Division operating the Pacific Northwest National Laboratory (PNNL) for the U.S. Department of Energy (DOE) is interested in receiving proposals for vendors to participate in a program to generate a market for high performance (R-5) windows and low-e storm windows. The specification outlines detailed services and is contained within Attachment No. 1.

Attached is a copy of Battelle's Request for Proposal. It consists of one set of enclosures:

Enclosure set No. 1 Request for Proposal. This attachment contains the Specifications, Sample Memorandum of Understanding, Questions and Answers document, Bid Sheet, Reporting Forms, Universal Inches (UI) definition, Sample Bid Sheet, and a Sample Report Form

Battelle plans to list all qualified vendors on the DOE Energy Efficiency and Renewable Energy website to stimulate a market for high performance (R-5) and low-e storm windows.

Proposals should be prepared simply and economically, providing a straight-forward, concise delineation of the specific information required to be furnished relative to the specifications. Emphasis in the RFP should be on completeness and clarity of content. Elaborate brochures or other representations are neither required nor desired.

All proposals submitted are to be broken into two parts, technical and financial. The technical section shall consist of a statement of acceptance of the requirements in the specification in Enclosure Set No. 1. Please provide a brief approach and details necessary to meet the requirements listed in the specifications.

The Financial proposal shall include a proposed rate table with a fixed price for each window category as outlined in the Bid Sheet Excel form.

Battelle must receive one original proposal marked in response to RFP No. 121400 electronically no later than 4 p.m. Pacific Time, February 19,2010 and should be signed by a representative of the Offeror authorized to enter into legally binding commitments. The proposal delivery shall be by email to eric.garcia@.pnl.gov or fax number 509-372-4801 by the due date and time above. 


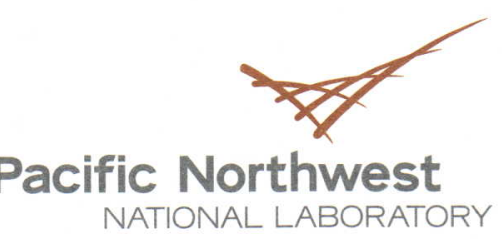

Battelle reserves the right to make award based on technically responsive proposals received without discussions; accept the proposal as offered; reject the proposal received; negotiate with the Offeror; issue an invitation for new proposals; or cancel the requirement without award. This RFP does not obligate Battelle to pay costs incurred in the preparation and submission of proposals nor to enter into a contract or other arrangement with the Offeror. Additionally, this RFP will not result in any direct contracts with Battelle or DOE. All vendors meeting the requirements of the specification will be listed on the volume purchase program website (http://www.r5windowsvolumepurchase.com) as an approved vendor and considered as such.

Vendors are encouraged to review the Questions and Answers document if they have questions regarding all aspects of this RFP. If a response is not included in the Questions and Answers document, please contact me via email at eric.garcia@pnl.gov. You can also reach me via phone at (509) 375-2632.

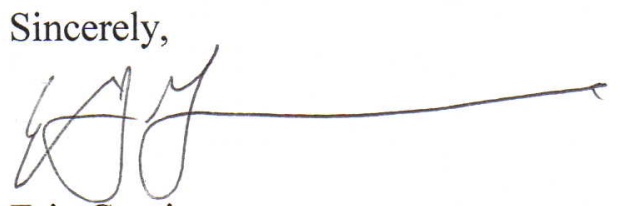

Eric Garcia

Contracts Specialist

Enclosures:

Specifications

Sample Memorandum of Understanding

Questions and Answers document

Excel Document, including the following:

Bid Sheet

Reporting Forms

Universal Inches (UI) definition

Sample Bid Sheet

Sample Report Form 
Appendix D

Sample Agreement 



\section{AGREEMENT \\ Between \\ Battelle Memorial Institute \\ Pacific Northwest Division \\ and}

(Contractor)

\section{A. PURPOSE}

The purpose of this Volume Purchase Agreement (hereinafter "AGREEMENT") is to establish a collaborative relationship between the Pacific Northwest Division of Battelle Memorial Institute (hereinafter "Battelle") in support of its management and operation of Pacific Northwest National Laboratory for the U.S. Department of Energy (hereinafter "DOE"), and (hereinafter "Contractor"), and hereinafter collectively referred to as the "Parties."

The purpose of this AGREEMENT is to document this contractor as a qualified participant in the High Performance (R-5) and Low-E Storm Windows program per the High Performance (R-5) and Low-E Storm Windows specifications dated 12/18/09.

\section{B. OBJECTIVES}

It is envisioned that the Parties will work together to develop the mechanisms that will promote and sustain a market for High Performance (R-5) and Low-E Storm Windows. This objective will be accomplished by listing qualified vendors on the volume purchase program web site (http://www.windowsvolumepurchase.org).

The contractor agrees to sell their listed products at their quoted maximum price or a lesser price; agrees to meet the requirements outlined in specification; and agrees to report their sales generated from the program website directly to Battelle for the duration of the program. DOE in turn agrees to market the program and products from the qualified contractors participating in the volume purchase program to potential buyers and ensure all contractors adhere to the program requirements throughout the program.

This agreement also consists of

- Program specification, dated December 18, 2009

- Sales reporting instructions, dated March 29, 2010

\section{INTELLECTUAL PROPERTY}

No rights of any kind whatsoever in any invention, copyright, trade secret, or any other form of intellectual property (collectively defined as "IP") are granted or transferred under this AGREEMENT. Any IP exchanged pursuant to this AGREEMENT shall be governed by the terms of a separate written sales or licensing agreement. 


\section{FUNDING}

This AGREEMENT shall not be used to obligate or commit funds. As the need may arise, specific work statements and details of support to be furnished by each of the Parties to this AGREEMENT will be developed separately from this AGREEMENT in specific agreements or contracts, subject to the availability of funds. No proposal or contract purporting to commit either Party to perform any work shall be binding upon that Party without the express written approval of Parties who are duly authorized to issue such agreements and contracts.

\section{E. PROPRIETARY INFORMATION}

Recognizing that no IP shall be granted or transferred under this AGREEMENT, neither Party shall be obligated to disclose information deemed proprietary, confidential, and/or a trade secret (proprietary information) to the other Party outside of the reporting sales generated from the program to Battelle. Reported sales will be kept strictly confidential and will not be shared with any other organization outside of Battelle and DOE.

\section{F. NO ADDITIONAL COMMITMENTS}

This AGREEMENT is not intended to limit or restrict activities of any sector, business unit, division, subsidiary, or affiliate of the Parties. Other organizations may be invited to participate through a subcontract or other arrangement with either of the Parties in pursuing the objectives and scope described in this AGREEMENT.

Nothing contained in this AGREEMENT is intended to preclude either Party from quoting and offering for sale, or from selling to others, any item or service that it may otherwise offer for sale now and in the future.

\section{G. NO AGENCY}

This AGREEMENT is not intended to directly or indirectly constitute, create, or give effect to or to otherwise imply a joint venture, corporation, partnership, contract, or any form of formal business entity, other than the collaborative relationship set forth herein. Each entity signing this AGREEMENT is acting as an independent contractor. Neither Party to this AGREEMENT is intended to have, or is granted by the other Party, any authority or control over the other Party nor shall either Party have the power to bind the other Party. Nothing contained in this AGREEMENT is intended to be construed as providing for the sharing of profits or losses arising from the efforts of either of the Parties, and each Party will be responsible for bearing the costs incurred by it in performing any activity contemplated hereunder.

\section{H. LIMITATION OF LIABILITY}

No rights or limitation of rights will arise from the terms of this AGREEMENT. In the event that a Party is damaged through the actions or inaction of the other Party, the injured Party may pursue any and all rights available to it by law. 


\section{POINTS OF CONTACT}

Technical Lead: All technical questions and sales reports should be directed to Terry Mapes, at 509-371-6745 or at terry.mapes@pnl.gov.

Contract Administrator: All contractual questions should be directed to the Contract Administrator, Eric Garcia, at 509-375-2632 or at eric.garcia@pnl.gov.

\section{J. TERM OF AGREEMENT}

The term of this Agreement starts the date of the last signature below to May 1, 2011. This AGREEMENT may be terminated at any time by either Party for any reason upon written notice to the non-terminating Party.

\section{K. PROGRAM COMPLIANCE}

Battelle reserves the right to ensure contractors' program compliance at its discretion. Battelle will address incidents of non-compliance directly with the contractor. Contractors in noncompliance will be given clear corrective action instructions via written communication along with deadlines for response and correction. If contractor does not meet program compliance within a reasonable time frame as communicated to the contractor in writing, Battelle will exercise its right to terminate this AGREEMENT.

\section{ENTIRE UNDERSTANDING}

This AGREEMENT constitutes the entire understanding of the Parties pertaining to matters contemplated hereunder at this time. The Parties signing this AGREEMENT intend that any implementing contract, license, or other agreement entered between the Parties subsequent hereto shall supersede and preempt any conflicting provision in this AGREEMENT.

\section{DISCLAIMER AND USE OF NAMES}

Each party agrees not to use the name(s) or identifying characteristics of the other party for any advertising, sales promotion, raising of investment capital or similar purpose without the prior, written permission of the other party.

By

Eric Garcia

Battelle Memorial Institute

Pacific Northwest Division

Title

Date
Date

By

Title 

Appendix E

Sample Sales Reporting Document 



\section{Sales Reporting Requirements}

It is the intention of Battelle to gather data regarding all window products sales originating from the volume purchase program website (www.windowsvolumepurchase.org) for the DOE High Performance (R-5) Windows and Low-e Storm Windows Volume Purchase Program. This will include all future sales between the Contractor and any buyer originating from the volume purchase program website for the duration of the program. The Contractor will assume all responsibility for reporting those sales to Battelle.

These sales should be reported to Battelle using the contact information given below at no later than the $10^{\text {th }}$ business day of each month. These reports will be used to convey information to the Department of Energy in order to assess the overall effectiveness of the Volume Purchase Program. Reports shall include, at a minimum, the following:

1. Total aggregate number of windows including number of sliding glass doors.

2. Total aggregate number of low-e storm windows OR total square footage of low-e storm windows.

3. Total sales amount of windows sold.

4. Total sales amount of low-e storm windows sold.

In an effort to verify these sales reports Battelle may request supplemental information and the Contractor is encouraged to keep additional records for this reason. The Contractor may choose the form of this information as long as it meets the satisfaction of Battelle. Examples of supplemental information include but may not be limited to the following:

- Sales by window types - e.g. Double Hung, Slider, etc.

- Sales by state (or Canadian province)

- Sales by new and retrofit projects

- Breakdown of sales by base price vs. final price

PNNL will work together with the Contractor to determine what requested supplemental information, if any, would be deemed appropriate. Specific sales information from any individual Contractor will not shared with anyone outside of DOE, although aggregate sales (i.e., total number of windows and total number or square footage of low-e storm windows) resulting from the volume purchase program may be made public on the volume purchase web site.

\section{CONTACT INFORMATION}

Terry Mapes

E-mail: terry.mapes@pnl.gov

Phone: 509-371-6745

Fax: $\quad 509-372-4730$ 



\section{Appendix F}

\section{Phase II Solicitation}



January 24, 2011

Dear Offeror,

REQUEST FOR Proposal (RFP) NO: 163369

Battelle Memorial Institute, Pacific Northwest Division operating the Pacific Northwest National Laboratory (PNNL) for the U.S. Department of Energy (DOE) is interested in receiving proposals for vendors to participate in a program to generate a market for high performance windows and low-e storm windows. The specification outlines detailed services and is contained within Attachment No. 1.

Attached is a copy of Battelle's Request for Proposal. It consists of one set of enclosures:

Enclosure set No. 1 Request for Proposal. This attachment contains the Phase II Specifications Document, Draft Agreement, Phase II Bid Templates, and Sales Reporting Document

Battelle plans to list all qualified vendors on the PNNL Windows Volume Purchase Program website to stimulate a market for high performance and low-e storm windows. Prices will be posted on the PNNL Windows Volume Purchase Program website and will be locked in until September 18, 2011.

There is no restriction in the program which prohibits windows dealers and distributors from entering the program with their own bid price structure. However, if any dealer would like to bid products which will also be bid in to the program from the manufacturer or another dealer, a previous arrangement must be made from all involved vendors which allows only one vendor to sell the product in each state. There can be no overlap in any state for any product from more than one vendor in the program.

Proposals should be prepared simply and economically, providing a straight-forward, concise delineation of the specific information required to be furnished relative to the specifications. Emphasis in the RFP should be on completeness and clarity of content. Elaborate brochures or other representations are neither required nor desired.

All proposals submitted shall consist of a statement of acceptance of the requirements in the specifications in Enclosure Set No. 1 and a completed Phase II Bid Template. Any qualified vendor participating in Phase I must resubmit a bid to participate in Phase II. The listing of all current qualified vendors will be terminated at the time the products for Phase II are displayed on the PNNL Windows Volume Purchase Program website. 


\section{re \\ Pacific Northwest}

NATIONAL LABORATORY

Battelle must receive one original proposal marked in response to RFP No.163369 electronically no later than 4 p.m. Pacific Time, March 18, 2011 to be in the first round of proposals. Proposals will be accepted after March 18, 2011 but will be processed in the order they are received once the proposals received on or before March 18, 2011 are processed. All proposals should be signed by a representative of the Offeror authorized to enter into legally binding commitments. The proposal delivery shall be by email to christine.kelly@pnl.gov or fax number 509-372-6266.

Battelle reserves the right to allow participation in the program based on technically responsive proposals received without discussions; accept the proposal as offered; reject the proposal received; negotiate with the Offeror; issue an invitation for new proposals; or cancel the requirement without award. This RFP does not obligate Battelle to pay costs incurred in the preparation and submission of proposals nor to enter into a contract or other arrangement with the Offeror. Additionally, this RFP will not result in any direct contracts with Battelle or DOE. All vendors meeting the requirements of the specification will be listed on the PNNL Windows Volume Purchase Program website (http://www.windowsvolumepurchase.org) as an approved vendor and considered as such.

If vendors have questions regarding this RFP, please contact me via email at christine.kelly@pnl.gov. You can also reach me via phone at (509) 375-2622.

Sincerely,

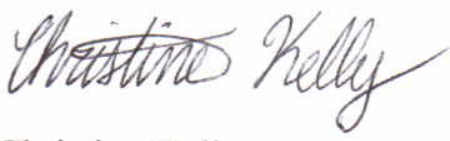

Christine Kelly

Contracts Specialist

Enclosures:

Phase II Specifications

Draft Agreement

Phase II Bid Templates, including the following:

Instructions

Shipping

Performance Data

Pricing for Primary and Storm

Pricing for Patio Door

Performance Example

Pricing Example

Sales Reporting Document

902 Battelle Boulevard | P.O. Box 999 | Richland, WA 99352 | 1-888-375-PNNL (7665) | inquiry@pnl.gov | www.pnl.gov 


\section{Phase II Solicitation High Performance Windows and Low-E Storm Windows}

The following are the specifications and requirements for vendors submitting proposals for high performance windows and low-E storm windows into the volume purchase program

\section{High Performance Windows Specifications and Requirements}

\begin{tabular}{|c|c|}
\hline Specification & Mandatory Requirement \\
\hline $\begin{array}{l}\text { Thermal Performance: Fixed window } \\
\text { Thermal Performance: Operable window }\end{array}$ & $\begin{array}{l}U \leq 0.20 \mathrm{Btu} / \mathrm{h}-\mathrm{ft}^{2}-^{\circ} \mathrm{F} \\
\mathrm{U} \leq 0.22 \mathrm{Btu} / \mathrm{h}-\mathrm{ft}^{2}-{ }^{\circ} \mathrm{F}\end{array}$ \\
\hline Air Leakage & $\begin{array}{l}\leq 0.30 \mathrm{cfm} / \mathrm{ft}^{2} \text {. } \\
\text { See High Performance Windows Testing and Certification } \\
\text { Requirements (below). }\end{array}$ \\
\hline Solar Heat Gain Coefficient (SHGC) & $\begin{array}{l}\text { Must report NFRC-certified SHGC with windows bid into the } \\
\text { program. Performance will be verified by NFRC Certified } \\
\text { Product Directory number (CPD\#). }\end{array}$ \\
\hline Condensation Resistance (CR) & $\begin{array}{l}\mathrm{CR} \geq 50 \text { and reported with bid into the program. } \\
\text { Performance will be verified by NFRC Certified Product } \\
\text { Directory number (CPD\#). Products using the Component } \\
\text { Modeling Approach (CMA) are not required to meet this } \\
\text { metric. }\end{array}$ \\
\hline $\begin{array}{l}\text { Warranty Period-Glass } \\
\text { Warranty Period-Non-glass } \\
\text { Warranty Documentation }\end{array}$ & $\begin{array}{l}\text { Minimum of } 20 \text { years } \\
\text { Minimum of } 10 \text { years } \\
\text { Copy of warranty for all products must be entered with the } \\
\text { products bid into the program. }\end{array}$ \\
\hline Frame Color & $\begin{array}{l}\text { All window frame colors are to be identified in the vendors' } \\
\text { bid for each product. }\end{array}$ \\
\hline Structural & $\begin{array}{l}\text { See High Performance Windows Testing and Certification } \\
\text { Requirements (below). }\end{array}$ \\
\hline Size and Pricing Categories & $\begin{array}{l}\text { See Windows and Low-E Storm Windows Size and Pricing } \\
\text { Matrices (below). }\end{array}$ \\
\hline Minimum Bid Quantities & $\begin{array}{l}20 \text { for new or retrofit construction windows } \\
1 \text { for new or retrofit construction patio doors }\end{array}$ \\
\hline Optional Bid Quantities & $\begin{array}{l}\text { Bids are accepted for optional quantities. See Windows } \\
\text { and Low-E Storm Windows Size and Pricing Matrices } \\
\text { (below). }\end{array}$ \\
\hline
\end{tabular}




\section{High Performance Windows Testing and Certification Requirements}

Testing and Certification

Structural Performance

Air Leakage (AL)
Thermal - All products must be certified with NFRC. Products must appear with the required performance metrics in the NFRC certified product directory (CPD), or in the NFRC Component Modeling Approach (CMA) CPD.

Structural - All products must be tested and certified according to the AAMAMDMA/CSA 101/I.S.2/A440 North American Fenestration Standard/Specification (NAFS) for windows, doors and unit skylights (2005 or more recent version) by one of the following four certifying organizations; AAMA, WDMA, NAMI, Keystone Certifications, Inc.

Certification numbers must be provided for all products in the Bidding Templates included with the solicitation package.

All windows products to be certified with NFRC for listing on the Volume Purchase Program web site. All products sold through the Volume Purchase Program will have an NFRC label affixed to window indicating values for Thermal Performance (U-factor), Solar Heat Gain Coefficient (SHGC), and Visible Transmittance (VT).

The Structural Performance of the windows shall be tested according to AAMA/WDMA/CSA 101/I.S.2/A440 North American Fenestration Standard/Specification (NAFS) for windows, doors and unit skylights. (2005 or more recent version.) The highest performance grade that can be achieved at the gateway size for each performance class shall be included in the product bid. Class types of windows will follow the NAFS 2008 convention (R,LC,CW,AW) with products tested according to the 2005 version being converted as follows:

\begin{tabular}{cc}
\hline 2005 & 2008 \\
\hline R & R \\
LC & LC \\
C & LC* $^{\star}$ \\
C & $C^{\star \star}$ \\
HC & CW \\
AW & AW \\
\hline
\end{tabular}

*Default conversion when the window does not meet the L/175 deflection test or when deflection test results are not provided

${ }^{* *}$ Conversion applies when manufacturer provides documentation that the window would meet the L/175 deflection test required by the $2008 \mathrm{CW}$ class.

If a window could be rated under more than one category in the 2005 standard and the above methodology results in two possible performance grades for a window, the higher performance grade will be displayed. For purposes of this program R and LC will be considered residential products while HC and AW will be considered commercial products.

The minimum performance grade for all products regardless of class type is 25 .

Air leakage of the windows shall be measured using: NFRC 400-2010 ${ }_{[E O A 1]}-$ Procedure for Determining Fenestration Product Air Leakage.

or

AAMA/WDMA/CSA 101/I.S.2/A440 North American Fenestration Standard/Specification (NAFS) for windows, doors and unit skylights. (2005 or most recent version.)

\section{U-factor Requirements for Higher Structural Performance}

\begin{tabular}{|c|c|}
\hline Commercial Window (CW) & $\begin{array}{l}\text { For windows tested to } \mathrm{CW} \text {, the u-factor requirement is: } \\
\qquad \begin{array}{ll}\text { Fixed: } & \mathrm{U} \leq 0.24 \mathrm{Btu} / \mathrm{h}-\mathrm{ft}^{2}-\mathrm{F} \\
\text { Operable: } & \mathrm{U} \leq 0.27 \mathrm{Btu} / \mathrm{h}-\mathrm{ft}^{2}-\mathrm{F}\end{array}\end{array}$ \\
\hline Architectural Window (AW) & $\begin{array}{l}\text { For windows tested to } \mathrm{AW} \text {, the } \mathrm{u} \text {-factor requirement is: } \\
\qquad \begin{array}{l}\text { Fixed: } \quad U \leq 0.27 \mathrm{Btu} / \mathrm{h}-\mathrm{ft}^{2}-\mathrm{F} \\
\text { Operable: } \quad U \leq 0.32 \mathrm{Btu} / \mathrm{h}-\mathrm{ft}^{2}-\mathrm{F}\end{array}\end{array}$ \\
\hline
\end{tabular}




\section{Low-E Storm Windows Specifications and Requirements}

\begin{tabular}{|l|l|}
\hline \multicolumn{1}{|c|}{ Specification } & \multicolumn{1}{c|}{ Mandatory Requirement } \\
\hline \hline Emissivity & $<0.22$ \\
\hline \hline $\begin{array}{l}\text { Warranty Period-Glass } \\
\text { Warranty Period-Non-glass }\end{array}$ & $\begin{array}{l}\text { Minimum of 10 years } \\
\text { Minimum of 10 years }\end{array}$ \\
\hline \hline Frame Color & $\begin{array}{l}\text { All available frame colors are to be identified in the vendors' } \\
\text { bid. }\end{array}$ \\
\hline \hline Size Categories & $\begin{array}{l}\text { See Windows and Low-E Storm Windows Size and Pricing } \\
\text { Matrices (below). }\end{array}$ \\
\hline \hline $\begin{array}{l}\text { Minimum Bid Quantity } \\
\text { Optional Bid Quantities }\end{array}$ & $\begin{array}{l}20 \text { for Low-E storm windows. } \\
\text { Bids are accepted for optional quantities } \\
\text { See Windows and Low-E Storm Windows Size and Pricing } \\
\text { Matrices (below). }\end{array}$ \\
\hline \hline
\end{tabular}

\section{Low-E Storm Windows Testing and Registration Requirements}

\begin{tabular}{|c|l|}
\hline $\begin{array}{c}\text { Product Testing and } \\
\text { Registration }\end{array}$ & \multicolumn{1}{c|}{ Mandatory Requirement } \\
\hline \hline Performance & $\begin{array}{l}\text { Test product in accordance with the following standards: } \\
\text { All glass materials must be registered in the International Glazing Database } \\
\text { (IGDB) with Lawrence Berkeley National Laboratory and measured in } \\
\text { accordance with NFRC 300-09, 301-09, and 302-09. The glass manufacturer, } \\
\text { the glass name, and the ID\# as listed in the IGDB must be entered with every } \\
\text { storm window bid. }\end{array}$ \\
Product Certification & $\begin{array}{l}\text { ansI/AAMA 1002.10-93 (or later version). Product must meet requirements for } \\
\text { an performance grade or higher. }\end{array}$ \\
& $\begin{array}{l}\text { ASTM E1886-05 (or later version). Product must meet requirements for } \\
\text { performance grade or higher. } \\
\text { the following four certifying organizations; AAMA, WDMA, NAMI, Keystone. }\end{array}$ \\
\hline \hline
\end{tabular}


Windows and Low-E Storm Windows Size and Pricing Matrices

\begin{tabular}{|c|c|}
\hline \multicolumn{2}{|c|}{ 1-19 Windows* } \\
\hline up to 50 UI & \\
\hline $51-60$ UI & \\
\hline $61-70$ UI & \\
\hline $71-80$ UI & \\
\hline $81-90$ UI & \\
\hline $91-100$ UI & \\
\hline $101-110$ UI & \\
\hline $111-120$ UI & \\
\hline Each UI above 120 & \\
\hline
\end{tabular}

\begin{tabular}{|c|c|}
\hline \multicolumn{2}{|c|}{ 20-49 Windows* } \\
\hline up to 50 UI & \\
\hline $51-60$ UI & \\
\hline $61-70 ~ U I$ & \\
\hline $71-80$ UI & \\
\hline $81-90$ UI & \\
\hline $91-100$ UI & \\
\hline $101-110$ UI & \\
\hline $111-120$ UI & \\
\hline Each UI above 120 & \\
\hline
\end{tabular}

\begin{tabular}{|c|c|}
\hline \multicolumn{2}{|c|}{ 50-199 Windows* } \\
\hline up to 50 UI & \\
\hline $51-60$ UI & \\
\hline $61-70$ UI & \\
\hline $71-80$ UI & \\
\hline $81-90$ UI & \\
\hline $91-100$ UI & \\
\hline $101-110$ UI & \\
\hline $111-120$ UI & \\
\hline Each UI above 120 & \\
\hline
\end{tabular}

\begin{tabular}{|c|c|}
\hline \multicolumn{2}{|c|}{ 200+ Windows* } \\
\hline up to 50 UI & \\
\hline $51-60$ UI & \\
\hline $61-70$ UI & \\
\hline $71-80$ UI & \\
\hline $81-90$ UI & \\
\hline $91-100$ UI & \\
\hline $101-110$ UI & \\
\hline $111-120$ UI & \\
\hline Each UI above 120 & \\
\hline
\end{tabular}

*Windows or Low-E Storm Windows. Prices are to be entered into Bidding Templates included with solicitation package. Please do not enter the bids here.

\section{Patio Doors Size and Pricing Matrices}

\begin{tabular}{|c|c|}
\hline \multicolumn{2}{|c|}{ 1-9 Patio Doors } \\
\hline $\mathrm{L} \times \mathrm{H}$ & \\
\hline $6^{\prime} \times 6^{\prime}-8^{\prime \prime}$ & \\
\hline $8^{\prime} \times 6^{\prime}-8^{\prime \prime}$ & \\
\hline $9^{\prime} \times 6^{\prime}-8^{\prime \prime}$ & \\
\hline
\end{tabular}

\begin{tabular}{|c|c|}
\hline 10-49 Patio Doors \\
\hline $\mathrm{L} \times \mathrm{H}$ & \\
\hline $6^{\prime} \times 6^{\prime}-8^{\prime \prime}$ & \\
\hline $8^{\prime} \times 6^{\prime}-8^{\prime \prime}$ & \\
\hline $9^{\prime} \times 6^{\prime}-8^{\prime \prime}$ & \\
\hline
\end{tabular}

\begin{tabular}{|c|c|}
\hline \multicolumn{2}{|c|}{ 50+ Patio Doors } \\
\hline LxH & \\
\hline $6^{\prime} \times 6^{\prime}-8^{\prime \prime}$ & \\
\hline $8^{\prime} \times 6^{\prime}-8^{\prime \prime}$ & \\
\hline $9^{\prime} \times 6^{\prime}-8^{\prime \prime}$ & \\
\hline
\end{tabular}

The tables above represent the sizing and pricing structure for all products in the program and are based on united inches ( $\mathrm{UI}=$ height plus width). All qualified bids must contain at least one price in any $\mathrm{UI}$ category from one of the two shaded boxes above (either windows or low-E storm windows or patio doors). Once a vendor is qualified, any individual order of 20 to 49 windows or 20-49 low-E storm windows or 1 to 9 patio doors (including any combination of types and sizes) must be honored by the vendor and must be sold at or below the bid prices.

If a bidder would like to sell windows or low-E storm windows in quantities of less than 20 they may also complete the table labeled '1-19 Windows' for any UI category. If a bidder would like to price windows or low-E storm windows in quantities of greater than 49, they may choose to complete the optional tables for' 50-199 Windows' and/or '200+ Windows. If a bidder would like to price patio doors in quantities of greater than 9, they may choose to complete the optional tables for '10-49 Patio Doors' and/or '50+ Patio Doors'.

\section{Sales Reporting}

The vendors in this program will be required to report window and patio door sales resulting from the program monthly to PNNL. The required template for reporting monthly sales is attached. The monthly sales report will be emailed to pnnlwindowsvp@pnl.gov by the 10th working day of the following month. Reporting of sales of a vendor's high performance windows and patio doors meeting the program specifications and not sold through the program is requested but not required. 


\section{AGREEMENT \\ Between \\ Battelle Memorial Institute \\ Pacific Northwest Division \\ and}

(Contractor)

\section{A. PURPOSE}

The purpose of this Volume Purchase Program Agreement (hereinafter "AGREEMENT") is to establish a collaborative relationship between the Pacific Northwest Division of Battelle Memorial Institute (hereinafter "Battelle") in support of its management and operation of Pacific Northwest National Laboratory (hereinafter "PNNL") for the U.S. Department of Energy (hereinafter "DOE"), and collectively referred to as the "Parties." (hereinafter "Contractor"), and hereinafter

The purpose of this AGREEMENT is to document this contractor as a qualified participant in the High Performance Windows and Low-E Storm Windows Volume Purchase Program per the Specifications Document.

\section{B. OBJECTIVES}

It is envisioned that the Parties will work together to develop the mechanisms that will promote and sustain a market for high performance and low-E storm windows. This objective will be accomplished by listing qualified vendors on the Volume Purchase Program web site (http://www.windowsvolumepurchase.org).

The contractor agrees to sell their listed products at their quoted maximum price or a lesser price; agrees to meet the requirements outlined in specification; and agrees to report their sales of high performance windows and low-E storm windows that are part of the program directly to PNNL for the duration of the program. The contractor also agrees to provide sales information on high performance windows and low-E storm windows that are not attributed to sale through this program. To the extent provided by law all sales information provided to PNNL under this AGREEMENT will be kept confidential by DOE. Any sales information made available to the public through the program will not be identified by contractor. However DOE may identify the top selling contractor for any given sales period. DOE in turn agrees to market the program and products from the qualified contractors participating in the Volume Purchase Program to potential buyers and endeavor to ensure all contractors adhere to the program requirements throughout the program.

This agreement also consists of

- Phase II Specifications Document, dated January 21, 2011

- Sales Reporting Document, dated April 1, 2011 


\section{INTELLECTUAL PROPERTY}

No rights of any kind whatsoever in any invention, copyright, trade secret, or any other form of intellectual property (collectively defined as "IP") are granted or transferred under this AGREEMENT. Any IP exchanged pursuant to this AGREEMENT shall be governed by the terms of a separate written sales or licensing agreement.

\section{FUNDING}

This AGREEMENT shall not be used to obligate or commit funds. As the need may arise, specific work statements and details of support to be furnished by each of the Parties to this AGREEMENT will be developed separately from this AGREEMENT in specific agreements or contracts, subject to the availability of funds. No proposal or contract purporting to commit either Party to perform any work shall be binding upon that Party without the express written approval of Parties who are duly authorized to issue such agreements and contracts.

\section{E. PROPRIETARY INFORMATION}

Recognizing that no IP shall be granted or transferred under this AGREEMENT, neither Party shall be obligated to disclose information deemed proprietary, confidential, and/or a trade secret (proprietary information) to the other Party outside of the reporting sales to PNNL.

\section{F. PRICING}

Prices reported to PNNL will be posted on the PNNL Volume Purchase Program website and cannot be increased for six calendar months starting from the time period of the signing of this Agreement.

\section{G. NO ADDITIONAL COMMITMENTS}

This AGREEMENT is not intended to limit or restrict activities of any sector, business unit, division, subsidiary, or affiliate of the Parties. Other organizations may be invited to participate through a subcontract or other arrangement with either of the Parties in pursuing the objectives and scope described in this AGREEMENT.

Nothing contained in this AGREEMENT is intended to preclude either Party from quoting and offering for sale, or from selling to others, any item or service that it may otherwise offer for sale now and in the future.

\section{H. NO AGENCY}

This AGREEMENT is not intended to directly or indirectly constitute, create, or give effect to or to otherwise imply a joint venture, corporation, partnership, contract, or any form of formal business entity, other than the collaborative relationship set forth herein. Each entity signing this AGREEMENT is acting as an independent contractor. Neither Party to this AGREEMENT is intended to have, or is granted by the other Party, any authority or control over the other Party nor shall either Party have the power to bind the other Party. Nothing contained in this AGREEMENT is intended to be construed as providing for the sharing of profits or losses 
arising from the efforts of either of the Parties, and each Party will be responsible for bearing the costs incurred by it in performing any activity contemplated hereunder.

\section{LIMITATION OF LIABILITY}

No rights or limitation of rights will arise from the terms of this AGREEMENT. In the event that a Party is damaged through the actions or inaction of the other Party, the injured Party may pursue any and all rights available to it by law.

\section{J. POINTS OF CONTACT}

Technical Lead: All technical questions and sales reports should be directed to Terry Mapes, at 509-371-6745 or at terry.mapes@pnl.gov.

Contract Administrator: All contractual questions should be directed to the Contract Administrator, Christine Kelly, at 509-375-2622 or at christine.kelly@pnl.gov.

\section{K. TERM OF AGREEMENT}

The term of this Agreement starts the date of the last signature below to April 30, 2012. This AGREEMENT may be terminated at any time by either Party for any reason upon written notice to the non-terminating Party.

\section{PROGRAM COMPLIANCE}

PNNL reserves the right to ensure contractors' program compliance at its discretion. PNNL will address incidents of non-compliance directly with the contractor. Contractors in non-compliance will be given clear corrective action instructions via written communication along with deadlines for response and correction. If contractor does not meet program compliance within a reasonable time frame as communicated to the contractor in writing, PNNL will exercise its right to terminate this AGREEMENT.

\section{CHANGES}

The PNNL Contracts Representative may at any time, by written order, and without notice to the sureties, if any, make changes within this AGREEMENT.

\section{N. ENTIRE UNDERSTANDING}

This AGREEMENT constitutes the entire understanding of the Parties pertaining to matters contemplated hereunder at this time. The Parties signing this AGREEMENT intend that any implementing contract, license, or other agreement entered between the Parties subsequent hereto shall supersede and preempt any conflicting provision in this AGREEMENT. 


\section{O. DISCLAIMER AND USE OF NAMES}

Each party agrees not to use the name(s) or identifying characteristics of the other party for any advertising, sales promotion, raising of investment capital or similar purpose without the prior, written permission of the other party.

By

Christine Kelly

Battelle Memorial Institute

Pacific Northwest Division

Title

Date
By

Title

Date 


\section{RFP 163369 Addendum 1 \\ 02/10/11}

\section{The following shall hereby modify Request for Proposal 163369:}

\section{Replace:}

There is no restriction in the program which prohibits windows dealers and distributors from entering the program with their own bid price structure. However, if any dealer would like to bid products which will also be bid in to the program from the manufacturer or another dealer, a previous arrangement must be made from all involved vendors which allows only one vendor to sell the product in each state. There can be no overlap in any state for any product from more than one vendor in the program.

\section{With the following:}

Dealers and distributors will not be allowed to directly enter the program. The proposals for any window products must come from the manufacturer whose name appears on the NFRC certified product directory for the CPD \# associated with that window product. Manufacturers who use dealer networks will be responsible for entering proposal prices which reflect the maximum selling price they can expect from all participating dealers in their network. That maximum price will be posted on the volume purchase web site with information that the windows products are sold through the manufacturer's distributors and that potential buyers will be directed to the appropriate distributor.

PNNL understands that there is a variation in distributor prices for any given manufacturer's window product and that is why we are requesting the maximum selling price be submitted for each window product accepted into the program. A distributor may thus sell a window product in the program for less than that base maximum price.

Please contact Terry Mapes at PNNL if you have any questions. He can be reached at Terry.Mapes@pnl.gov. Thank you. 


\section{RFP 163369 Addendum 2 \\ $02 / 17 / 11$}

The following shall hereby modify Request for Proposal 163369:

\section{Addition:}

Even though all certified vendors in Phase I will be asked to re-bid for Phase II, we will allow any dealer who was certified in Phase I to re-bid Phase II as a dealer given they have already invested in the infrastructure to accommodate the selling requirements (e.g., a windows volume purchase URL) in Phase I. 


\title{
High Performance Windows and Low-E Storm Windows Program
}

\author{
$\underline{\text { Questions (Q) and Answers (A) }}$
}

$02 / 03 / 11$

1. Q. Do the vendors who are currently certified in Phase I need to resubmit bids for Phase II?

A. Yes. The original agreement letters signed in Phase I were intended to be used for one year and some of the specifications and requirements for products and vendors to be qualified and certified in Phase II have changed. For example, we are requiring bidders to complete templates for Phase II designed to convey information about performance metrics and prices in a more convenient format.

2. Q. Is it true that the products bid into the program cannot exceed a $\$ 4.00 / \mathrm{ft}^{2}$ premium for the incremental price difference between ENERGY STAR windows and R5 windows?

A. No. Vendors are allowed to bid any price for their products which they believe is appropriate. The $\$ 4.00 / \mathrm{ft}^{2}$ premium is just a goal that DOE believes would justify the added cost of choosing an R5 product over an ENERGY STAR product. There is nothing in the Specifications Document regarding required pricing.

3. Q. I have more R5 products being tested which will not be ready before the March $18^{\text {th }}$ priority deadline. Can I enter my existing products and then add additional products later?

A. Yes. This is one of the key features of the program. Once you have any product accepted and become a certified vendor in the program, you may add and/or remove any products at any time during Phase II.

4. Q. Am I allowed to change my bid prices during the program?

A. We will permit one price change on September $18^{\text {th }}, 2011$ to allow for changes in costs during the program. This is the only time you will be able to raise your bid prices, but you can always lower any bid price at any time.

5. Q. Is it true that you are going to display prices for individual vendors in Phase II?

A. Yes. In Phase I there was an agreement with the vendors in which we would only display a range of prices for each product in a size category without showing the individual vendor's prices. In Phase II the website will display a single price for each vendor's product in each size category.

6. Q. We sell all our products through a network of dealers. How can we account for dealer markups? 
A. We understand the challenges with using a dealer network and in Phase I we saw several vendors who overcame these challenges in different ways. We would be happy to discuss possibilities with anyone who contacts us and would encourage you to do so if you seeking solutions which will allow your products to be a part of the program. 


\title{
High Performance Windows and Low-E Storm Windows Program
}

\author{
Questions (Q) and Answers (A)
}

$03 / 08 / 11$

1. Q. How are shipping and handling charges handled?

A. Your base bid prices for your windows products should not include shipping and handling charges. They should also not include taxes, installation, and additional features (grids, tempered glass, etc.).

2. Q. Does this program put builders/contractors in a position to purchase windows and patio doors direct from manufacturers?

A. The vendors on the windows volume purchase web site (www.windowsvolumepurchase.org) have provided a URL for buyers seeking windows products that meet the specifications and requirements of the program. The vendors have the latitude to sell through any distribution channel they choose as long as the base price of the window is the same as the base price bid into the program. This could be direct sales from the manufacturer to a buyer or indirectly through a dealer/distributor.

3. Q. Paragraph E. of the Draft Agreement states that no information deemed proprietary need to be disclosed "outside of the reporting sales generated from the program to Battelle." Are we correct in assuming then that the total sales from all sources aggregate information request in paragraphs numbered 3 and 4 in the Sales Reporting Requirements document are not a requirement under the program?

A. Ideally we would like to know your aggregate sales of the qualified windows products. This includes your sales through the volume purchase program and from all other sources. However, we understand the sensitivity of reporting sales from sources that are not a part of the program and are therefore only requesting sales resulting from the program as a minimum. If sales of qualified windows products from the program cannot be easily separated from total sales, we will accept the total aggregate sales from all sources. We will not share sales information from any qualified vendor and would appreciate whatever information which will help us understand the impact of our program on the industry's sales.

4. Q. We need clarification on what the language in the solicitation means. Does glass mean IGU seal durability or the glass? What does 'non-glass' include?

A. It is difficult to define "glass" and non-glass" in exact terms and these were used mainly as guidelines for the vendors when comparing to the warranties they were already using. For our purposes we define "glass" as the entire IGU (glass, spacer, seal, etc.) and "nonglass" as all other materials that make up the window such as the hardware and frame material (but not paint). We cannot give exact definitions because there are too many 
variables involved, but we will use our own judgment when reading manufacturer warranties to determine if they are reasonably close to the program specifications.

5. Q. The prices submitted in Phase II cannot be raised for a period of one year just as in Phase I?

A. Unlike Phase I we will allow one opportunity to raise your prices six months after your bid proposal is received. E.g. those in the March $18^{\text {th }}$ priority group will have their one opportunity on Sept. $18^{\text {th }}$. A company whose proposal is received on July $11^{\text {th }}$ would have its one opportunity on January $11^{\text {th }}$.

6. Q. Is it true that only one company can sell our product per selected geography through this program.

A. There has been an addendum to the original solicitation which has been posted at http://www1.eere.energy.gov/buildings/windowsvolumepurchase/rfp_phase2.html, https://ebs.pnl.gov/ViewSolicitation.aspx?SolID =183, and https://www.fbo.gov/index?s=opportunity\&mode=form\&id=2814d6229a36f909fe5014 2b00b2894e\&tab=core\& cview $=1$. Pursuant to this addendum we will not allow any dealers to bid into the program. Only the company whose name is registered with NFRC for each product is allowed to bid. However, there is no limit to how many dealers you can use to sell your windows products. The manufacturer is responsible for bidding a price which will be matched or lowered by everyone in their dealer network, but they may certainly use as many dealers as they desire.

7. Q. The bid package that we submit need only consist of the properly filled out bid template and the Statement of Acceptance?

A. Correct. Other requirements will be submitted later, but these are the only two things initially required to begin processing of the submitted bid package. 


\section{Sales Reporting Requirements}

It is the intention of PNNL to gather data regarding all window products sales originating from the volume purchase program website (www.windowsvolumepurchase.org) for the DOE High Performance Windows and Low-e Storm Windows Volume Purchase Program. This will include all future sales between the Contractor and any buyer originating from the volume purchase program website for the duration of the program. The Contractor will assume all responsibility for reporting those sales to PNNL.

These sales should be reported to PNNL using the contact information given below at no later than the $10^{\text {th }}$ business day of each month. These reports will be used to convey information to the Department of Energy in order to assess the overall effectiveness of the Volume Purchase Program. Reports shall include, at a minimum, the following:

1. Total aggregate number of windows, low-E storm windows, and patio doors sold by the contractor through the Volume Purchase Program (i.e the program website).

2. Total sales amount of windows, low-E storm windows, and patio doors sold by the contractor through the Volume Purchase Program.

In addition to the above required information PNNL will request the following information:

3. Total aggregate number of windows, low-E storm windows, and patio doors sold by the contractor from all sources including the Volume Purchase Program.

4. Total sales amount of windows, low-E storm windows, and patio doors by the contractor from all sources including the Volume Purchase Program.

PNNL will work together with the Contractor to determine what requested information, if any, would be deemed appropriate. Specific sales information from any individual Contractor will not shared with anyone outside of DOE, although aggregate sales (i.e., total number of windows and total number or square footage of low-e storm windows) resulting from the volume purchase program may be made public on the volume purchase website.

\section{CONTACT INFORMATION}

Terry Mapes

E-mail: terry.mapes@pnl.gov

Phone: 509-371-6745

Fax: $\quad 509-372-4730$ 

Appendix G

\section{Phase II Extension Solicitation}





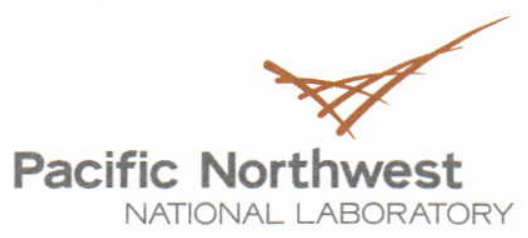

April 09, 2012

Dear Offeror,

REQUEST FOR Proposal (RFP) NO: 206262

Battelle Memorial Institute, Pacific Northwest Division operating the Pacific Northwest National Laboratory (PNNL) for the U.S. Department of Energy (DOE) is interested in receiving proposals for vendors to participate in a program to generate a market for high performance windows and low-E storm windows. The specification outlines detailed services and is contained within Attachment No. 1.

Attached is a copy of Battelle's Request for Proposal. It consists of one set of enclosures:

Enclosure set No. 1 Request for Proposal. This attachment contains the Phase II Extension SpecificationsD ocument, Draft Agreement, and Phase II Extension Sales Reporting Document

Battelle plans to list all qualified vendors on the PNNL Windows Volume Purchase Program website to stimulate a market for high performance and low-E storm windows.

Dealers and distributors will not be allowed to directly enter the program. The proposals for any window products must come from the manufacturer whose name appears on the NFRC certified product directory for the CPD \# associated with that window product.

Proposals should be prepared simply and economically, providing a straight-forward, concise delineation of the specific information required to be furnished relative to the specifications. Emphasis in the RFP should be on completeness and clarity of content. Elaborate brochures or other representations are neither required nor desired.

All proposals submitted shall consist of a statement of acceptance of the requirements in the specifications in Enclosure Set No. 1 and the CPD numbers. Any qualified vendor participating in Phase II must resubmit a bid to participate in the Phase II extension. The listing of all current qualified vendors will be terminated at the time the products for the Phase II extension are displayed on the PNNL Windows Volume Purchase Program website.

Battelle must receive one original proposal marked in response to RFP No.206262 electronically no later than 4 p.m. Pacific Time, April 30,2012 to be in the first round of proposals. Proposals will be accepted after April 30, 2012 but will be processed in the order they are received once the proposals received on or before April 30, 2012 are processed. All proposals should be signed by a representative of the Offeror authorized to enter into legally binding commitments. The proposal delivery shall be by email to christine.kelly@pnl.gov or fax number 509-372-6444. 


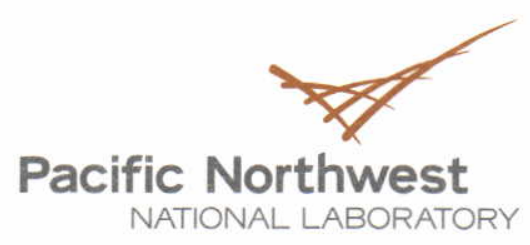

Battelle reserves the right to allow participation in the program based on technically responsive proposals received without discussions; accept the proposal as offered; reject the proposal received; negotiate with the Offeror; issue an invitation for new proposals; or cancel the requirement without award. This RFP does not obligate Battelle to pay costs incurred in the preparation and submission of proposals nor to enter into a contract or other arrangement with the Offeror. Additionally, this RFP will not result in any direct contracts with Battelle or DOE. All vendors meeting the requirements of the specification will be listed on the PNNL Windows Volume Purchase Program website (http://www.windowsvolumepurchase.org) as an approved vendor and considered as such.

If vendors have questions regarding this RFP, please contact me via email at christine.kelly@pnl.gov. You can also reach me via phone at (509) 375-2622.

Sincerely,

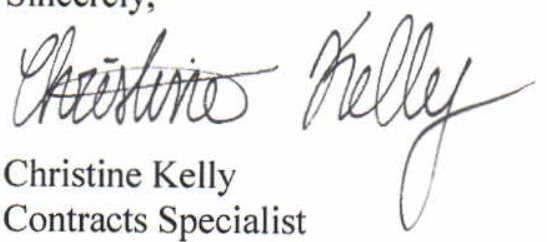

Enclosures:

Phase II Extension Specifications

Phase II Extension Draft Agreement

Phase II Extension Sales Reporting Document 


\section{Phase II Extension Solicitation High Performance Windows and Low-E Storm Windows}

The following are the specifications and requirements for vendors submitting proposals for high performance windows and low-E storm windows into the volume purchase program

\section{High Performance Windows Specifications and Requirements}

\begin{tabular}{|c|c|}
\hline Specification & Mandatory Requirement \\
\hline $\begin{array}{l}\text { Thermal Performance: Fixed window } \\
\text { Thermal Performance: Operable window }\end{array}$ & $\begin{array}{l}\mathrm{U} \leq 0.20 \mathrm{Btu} / \mathrm{h}-\mathrm{ft}^{2}-{ }^{\circ} \mathrm{F} \\
\mathrm{U} \leq 0.22 \mathrm{Btu} / \mathrm{h}-\mathrm{ft}^{2}-{ }^{\circ} \mathrm{F}\end{array}$ \\
\hline Air Leakage & $\begin{array}{l}\leq 0.30 \mathrm{cfm} / \mathrm{ft}^{2} . \\
\text { See High Performance Windows Testing and Certification } \\
\text { Requirements (below). }\end{array}$ \\
\hline Solar Heat Gain Coefficient (SHGC) & $\begin{array}{l}\text { Must report NFRC-certified SHGC with windows bid into the } \\
\text { program. Performance will be verified by NFRC Certified } \\
\text { Product Directory number (CPD\#). }\end{array}$ \\
\hline Condensation Resistance (CR) & $\begin{array}{l}C R \geq \_50 \text { and reported with bid into the program. } \\
\text { Performance will be verified by NFRC Certified Product } \\
\text { Directory number (CPD\#). Products using the Component } \\
\text { Modeling Approach (CMA) are not required to meet this } \\
\text { metric. }\end{array}$ \\
\hline $\begin{array}{l}\text { Warranty Period-Glass } \\
\text { Warranty Period-Non-glass }\end{array}$ & $\begin{array}{l}\text { Minimum of } 20 \text { years } \\
\text { Minimum of } 10 \text { years }\end{array}$ \\
\hline Warranty Documentation & $\begin{array}{l}\text { Copy of warranty for all products must be entered with the } \\
\text { products bid into the program. }\end{array}$ \\
\hline Frame Color & $\begin{array}{l}\text { All window frame colors are to be identified in the vendors' } \\
\text { bid for each product. }\end{array}$ \\
\hline Structural & $\begin{array}{l}\text { See High Performance Windows Testing and Certification } \\
\text { Requirements (below). }\end{array}$ \\
\hline Size and Pricing Categories & $\begin{array}{l}\text { See Windows and Low-E Storm Windows Size and Pricing } \\
\text { Matrices (below). }\end{array}$ \\
\hline
\end{tabular}




\section{High Performance Windows Testing and Certification Requirements}

Testing and Certification

Structural Performance

Air Leakage (AL)
Thermal - All products must be certified with NFRC. Products must appear with the required performance metrics in the NFRC certified product directory (CPD), or in the NFRC Component Modeling Approach (CMA) CPD.

Structural - All products must be tested and certified according to the AAMA/WDMA/CSA 101/I.S.2/A440 North American Fenestration Standard/Specification (NAFS) for windows, doors and unit skylights (2005 or more recent version) by one of the following four certifying organizations; AAMA, WDMA, NAMI, Keystone Certifications, Inc.

Certification numbers must be provided for all products in the Bidding Templates included with the solicitation package.

All windows products to be certified with NFRC for listing on the Volume Purchase Program web site. All products sold through the Volume Purchase Program will have an NFRC label affixed to window indicating values for Thermal Performance (U-factor), Solar Heat Gain Coefficient (SHGC), and Visible Transmittance (VT).

The Structural Performance of the windows shall be tested according to AAMA/WDMA/CSA 101/I.S.2/A440 North American Fenestration Standard/Specification (NAFS) for windows, doors and unit skylights. (2005 or more recent version.) The highest performance grade that can be achieved at the gateway size for each performance class shall be included in the product bid. Class types of windows will follow the NAFS 2008 convention (R,LC,CW,AW) with products tested according to the 2005 version being converted as follows:

\begin{tabular}{ccc}
\hline 2005 & 2008 \\
\hline R & R \\
LC & LC \\
C & LC* \\
C & CW $^{* *}$ \\
HC & CW \\
AW & AW \\
\hline
\end{tabular}

*Default conversion when the window does not meet the L/175 deflection test or when deflection test results are not provided

**Conversion applies when manufacturer provides documentation that the window would meet the L/175 deflection test required by the $2008 \mathrm{CW}$ class.

If a window could be rated under more than one category in the 2005 standard and the above methodology results in two possible performance grades for a window, the higher performance grade will be displayed. For purposes of this program R and LC will be considered residential products while HC and AW will be considered commercial products.

The minimum performance grade for all products regardless of class type is 25 .

Air leakage of the windows shall be measured using: NFRC 400-2010 ${ }_{[E O A 1]}-$ Procedure for Determining Fenestration Product Air Leakage.

or

AAMA/WDMA/CSA 101/I.S.2/A440 North American Fenestration Standard/Specification (NAFS) for windows, doors and unit skylights. (2005 or most recent version.)

\section{U-factor Requirements for Higher Structural Performance}

\begin{tabular}{l|r} 
Commercial Window (CW) & For windows tested to CW, the u-factor requirement is: \\
& Fixed: $\quad U \leq 0.24 \mathrm{Btu} / \mathrm{h}-\mathrm{ft}^{2}-\mathrm{F}$ \\
Operable: $U \leq 0.27 \mathrm{Btu} / \mathrm{h}-\mathrm{ft}^{2}-\mathrm{F}$
\end{tabular}

Architectural Window (AW) For windows tested to AW, the u-factor requirement is:
Fixed: $\quad U \leq 0.27 \mathrm{Btu} / \mathrm{h}-\mathrm{ft}^{2}-\mathrm{F}$
Operable: $\quad \mathrm{U} \leq 0.32 \mathrm{Btu} / \mathrm{h}-\mathrm{ft}^{2}-\mathrm{F}$ 


\section{Low-E Storm Windows Specifications and Requirements}

\begin{tabular}{|l|l|}
\hline \multicolumn{1}{|c|}{ Specification } & \multicolumn{1}{c|}{ Mandatory Requirement } \\
\hline \hline Emissivity & $<0.22$ \\
\hline \hline $\begin{array}{l}\text { Warranty Period-Glass } \\
\text { Warranty Period-Non-glass }\end{array}$ & $\begin{array}{l}\text { Minimum of } 10 \text { years } \\
\text { Minimum of } 10 \text { years }\end{array}$ \\
\hline \hline Frame Color & $\begin{array}{l}\text { All available frame colors are to be identified in the vendors' } \\
\text { bid. }\end{array}$ \\
\hline \hline Size Categories & $\begin{array}{l}\text { See Windows and Low-E Storm Windows Size and Pricing } \\
\text { Matrices (below). }\end{array}$ \\
\hline \hline
\end{tabular}

\section{Low-E Storm Windows Testing and Registration Requirements}

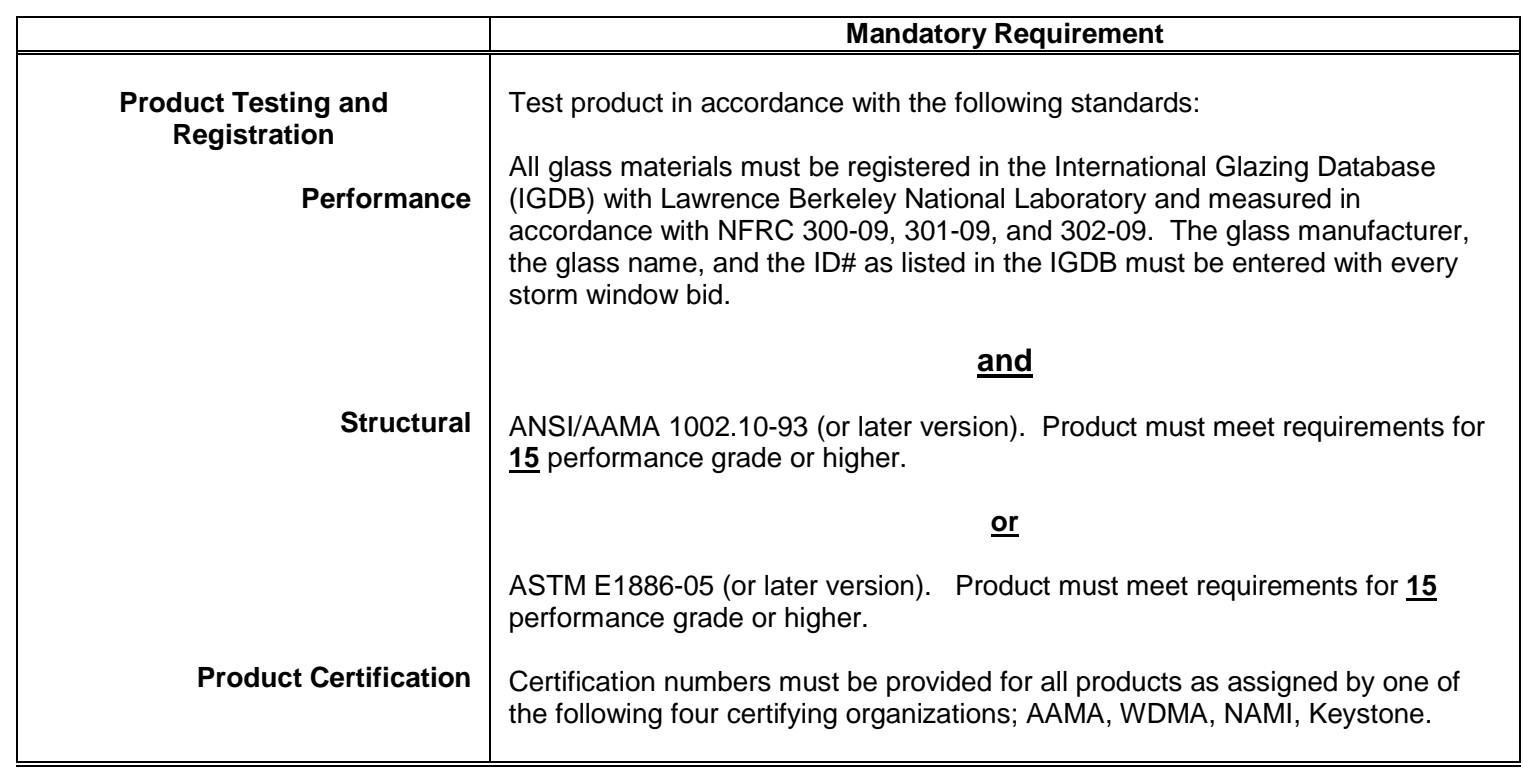

\section{Sales Reporting}

The vendors in this program will be required to report all window and patio door sales which meet the specifications of in this document on a monthly basis to PNNL. The monthly sales report will be emailed to pnnlwindowsvp@pnl.gov by the last working day of the month following the sales. For example, sales made in the month of June would be due by the last working day in July. 


\begin{tabular}{l|l} 
u.s. DEPARTMENT OF & Energy Efficiency \&
\end{tabular} 슬 Renewable Energy

Emerging Technologies Program

http://www1.eere.energy.gov/buildings/windowsvolumepurchase

PNNL-22183 • DOE/EE-0884 • February 2013 